\title{
Global Modeling of $\mathbf{N}_{2} \mathrm{O}$ Discharges: Rate Coefficients and Comparison with ICP and Glow Discharges Results
}

\author{
Konstantinos Katsonis and Chloe Berenguer \\ DEDALOS Ltd., Vassilissis Olgas 128, 54645 Thessaloniki, Greece \\ Correspondence should be addressed to Konstantinos Katsonis; katsonis.dedalos@gmail.com
}

Received 21 May 2013; Revised 13 June 2013; Accepted 14 June 2013

Academic Editor: Linda L. Vahala

Copyright ( $) 2013$ K. Katsonis and C. Berenguer. This is an open access article distributed under the Creative Commons Attribution License, which permits unrestricted use, distribution, and reproduction in any medium, provided the original work is properly cited.

\begin{abstract}
We developed a Global Model for $\mathrm{N}_{2} \mathrm{O}$ plasmas valid for applications in various power, gas flow rate, and pressure regimes. Besides energy losses from electron collisions with $\mathrm{N}_{2} \mathrm{O}$, it takes into consideration those due to molecular $\mathrm{N}_{2}$ and $\mathrm{O}_{2}$ and to atomic $\mathrm{N}$ and $\mathrm{O}$ species. Positive atomic $\mathrm{N}^{+}$and $\mathrm{O}^{+}$and molecular $\mathrm{N}_{2} \mathrm{O}^{+}, \mathrm{N}_{2}{ }^{+}$, and $\mathrm{O}_{2}{ }^{+}$have been treated as separate species and also negative $\mathrm{O}^{-}$ions. The latter confer an electronegative character to the discharge, calling for modified plasma sheath and plasma potential formulas. Electron density and temperature and all species densities have been evaluated, hence the ionization and dissociation percentages of $\mathrm{N}_{2} \mathrm{O}, \mathrm{N}_{2}$, and $\mathrm{O}_{2}$ molecules and the plasma electronegativity. The model is extended to deal with $\mathrm{N}_{2} / \mathrm{O}_{2}$ mixtures feedings, notably with air. Rate coefficients and model results are discussed and compared with those from available theoretical and experimental work on ICP and glow discharge devices.
\end{abstract}

\section{Introduction}

The present work aims to characterize $\mathrm{N}_{2} \mathrm{O}$ fed plasma devices working in various configurations, as plasma reactors, hollow cathodes, and plasma thrusters, by means of a Global (volume averaged) Model (GM). The well-known GM describes a plasma device in its entirety, taking into consideration the atomic and molecular properties of the used gas or mixtures, together with the device geometry and the prevailing physical conditions. Examples and general properties of such models can be found in standard handbooks [1].

Obviously, the problem of $\mathrm{N}_{2} \mathrm{O}$ plasmas description becomes more complex than in the case of a monoatomic inert gas as the argon, studied previously for inductively coupled plasmas (ICP) including plasma reactor (PR) and for helicon plasma thruster (HPT) applications, by means of an adequate GM (see [2] and references therein). In [2] the HPT plasma was separated in two regions, an external, cooler region encompassing about $90 \%$ of the plasma cross section area with low ionization percentage named the "mantle" region and an internal hotter one, the "core" region, where the plasma is mostly ionized. Conditions in the "mantle" region are rather similar to those of the PR, both for Ar and for $\mathrm{N}_{2} \mathrm{O}$ and $\mathrm{N}_{2} / \mathrm{O}_{2}$ mixtures feedings. In the present paper only ICP and glow discharge (GD) results are given, which are also useful in modeling the "mantle" region of HPT.

The molecular structure of the $\mathrm{N}_{2} \mathrm{O}$ and that of the molecular products examined here reveal vibrationally excited states that have to be taken into account in addition to the electronic ones. Because of the presence of molecular species, the dissociation processes have been taken into account as they play a very important role, leading to species which have to be considered both in the energy loss power balance equation $(\mathrm{PoBE})$ and in the particle balance equations $(\mathrm{PaBE})$ of the GM. Note that the $\mathrm{N}_{2} \mathrm{O}$ dissociation by electron impact is already important at intermediate pressures, for the absorbed power and $\mathrm{N}_{2} \mathrm{O}$ flow rates considered here. Also, the negative $\mathrm{O}^{-}$species introduce an electronegativity in the discharge, which was not always present in previous discharge studies of molecular species as $\mathrm{H}_{2}$. However, in [3] the electronegativity from $\mathrm{H}_{2}$ was duly taken into account. The GM which we obtained for $\mathrm{N}_{2} \mathrm{O}$ plasma discharges is successfully applied to experimental studies of $\mathrm{N}_{2} \mathrm{O}$ discharges and its results compare favorably with existing theoretical ones. Moreover, the present model can be used to design and study discharges in $\mathrm{N}_{2} / \mathrm{O}_{2}$ mixtures, often leading to products similar to those encountered in $\mathrm{N}_{2} \mathrm{O}$ discharges. It is very important to note 
that the $\mathrm{N}_{2} \mathrm{O}$ dissociation considered primarily here may become so important that the $\mathrm{N}_{2} \mathrm{O}$ feeding leads practically to an atmosphere of $\mathrm{N}_{2}$ and $\mathrm{O}_{2}$ mixture. GMs are also of interest to some atmospheric studies cases. GMs of $\mathrm{He}$ and $\mathrm{H}_{2}$ were also addressed lately, partly because these gases are also important in space entry studies (cf. [4-6]), although inclusion of additional equations as those of Navier Stokes becomes necessary when high pressure conditions prevail.

In the following, the main equations used and the model description are given in Section 2. A review of the main processes encountered in the plasma follows in Section 3, where processes which have been included when writing down the PaBEs are described. In Section 4, we shortly describe the $\mathrm{N}_{2} \mathrm{O}$ structure and also additional processes concerning electron collisions with $\mathrm{N}_{2} \mathrm{O}$. Then, we present briefly the $\mathrm{N}_{2}$ structure and $\mathrm{N}_{2}$ related processes. A similar analysis follows for the $\mathrm{O}_{2}, \mathrm{O}$, and $\mathrm{NO}$ species and their ions, necessary for the $\varepsilon_{C}$ evaluation. Calculations of $\varepsilon_{C}$ for $\mathrm{N}_{2} \mathrm{O}$, $\mathrm{N}_{2}, \mathrm{O}_{2}, \mathrm{~N}$, and $\mathrm{O}$ are presented and discussed in this section. Then, we give in Section 5 a short overview of three main $\mathrm{N}_{2} \mathrm{O}$ discharges regimes. Section 6 describes results obtained by our GM for a typical plasma reactor when fed with $\mathrm{N}_{2} \mathrm{O}$. Results are compared to those existing in the literature, mainly to the recent calculations and measurements of Shutov et al. [7] for a plasma reactor fed with $\mathrm{N}_{2} \mathrm{O}$, working in a pressure of about 4 mTorr. In Section 7, our GM results are compared with the $n_{e}$ and $T_{e}$ measurements of Yousif and Mondragon [8] made in a hollow cathode (HC) plasma discharge in pure $\mathrm{N}_{2} \mathrm{O}$, with pressure varying from 200 mTorr to 1.1 Torr. This comparison is mainly oriented towards lower pressures, reactions not included in our model becoming possibly important in atmospheric pressure. Therefore, no comparison is made with results obtained for air in [9], which concern the quite higher atmospheric pressure. We also compare our results to those obtained by de los Arcos et al. [10] for a hollow cathode fed with $\mathrm{N}_{2} \mathrm{O}$, with a flow rate varying from $3 \mathrm{sccm}$ to $265 \mathrm{sccm}$. In Section 8 we present results obtained for $\mathrm{N}_{2} / \mathrm{O}_{2}$ mixtures, which are compared to results obtained by Gordiets et al. [11]. A comparison is made of our $n_{e}$ and of vibrationally excited $\mathrm{N}_{2}$ densities with experimental and theoretical results of [11]. Finally, in Section 9, we give the conclusions of this work.

\section{Description of the Model and Governing Equations}

We first briefly remind that GMs are based on an equation system (see, e.g., [12]) essentially composed by the following.

(a) A power balance equation (PoBE), which relates the absorbed power to the electron density by means of the collisional energy loss $\left(\varepsilon_{C}\right)$ term, taking into account the main species. $\varepsilon_{C}$ quantifies the amount of energy loss by electron collisions with a "heavy" particle, due typically to elastic scattering, excitation, ionization, and dissociation processes. The main heavy particles considered here are $\mathrm{N}_{2} \mathrm{O}, \mathrm{N}_{2}$ and $\mathrm{O}_{2}$ molecules and $\mathrm{N}$ and $\mathrm{O}$ atoms. To obtain an account of the bulk of the energy spent in collisions involving electrons, a number of electronic (and vibrational in case of a molecule) excited states have been considered.

(b) A system of particle balance equations (PaBE) containing the densities of species for a set of electron density $n_{e}$ and electron temperature $T_{e}$. This is similar to the well-known statistical equations set constituting the basis of the Collisional-Radiative (C-R) models [13]. In order to reveal the properties of the main plasma parameters, a rather simplified scheme including only eighteen species and the eighteen corresponding kinetic equations was introduced in the present model. It includes seven ground level species $\left(\mathrm{N}_{2} \mathrm{O}, \mathrm{N}_{2}, \mathrm{O}_{2}, \mathrm{~N}, \mathrm{O}\left({ }^{3} \mathrm{P}\right), \mathrm{O}\left({ }^{1} \mathrm{D}\right)\right.$, and $\left.\mathrm{NO}\right)$ plus the most abundant excited species and the main ions. Less important species have been taken only indirectly into account, when calculating the corresponding $\varepsilon_{C}$ included in the PoBE. As $\mathrm{N}_{2}$ population is often considerable in the conditions considered here, its five lower vibrational states were included in the kinetic system.

Concerning oxygen species, the GL of the molecule $\left(\mathrm{O}_{2} X^{3} \Sigma_{g}{ }^{-}\right)$is included in the PaBE and the lower electronically excited state of the molecule $\left(\mathrm{O}_{2} a^{1} \Delta_{q}\right)$ in the PoBE. The first $\left(\mathrm{O}\left({ }^{3} \mathrm{P}\right)\right)$ and the second $\left(\mathrm{O}\left({ }^{1} \mathrm{D}\right)\right)$ ground levels of the atomic oxygen were also included in our calculations, as was also the case in previous studies [14, 15]. In describing the ionization-recombination equilibrium, the $\mathrm{N}_{2} \mathrm{O}^{+}$species are included in our PaBE system. This allows for correctly evaluating not only the density of neutral species but also the electron density and temperature. The single ions $\mathrm{N}_{2}{ }^{+}$, $\mathrm{O}_{2}{ }^{+}, \mathrm{N}^{+}$, and $\mathrm{O}^{+}$of the main products $\mathrm{N}_{2}, \mathrm{O}_{2}, \mathrm{~N}$, and $\mathrm{O}$ were also included in the PaBEs set; their densities become considerable in presence of important $\mathrm{N}_{2} \mathrm{O}$ dissociation. Moreover, $\mathrm{O}^{-}$ions are accounted in a dedicated equation of the PaBEs set because they are usually formed in an important amount and they confer the electronegative character to the discharge. Consequently, we are left with a simplified set of only seven equations for ground level species, of five for the excited states, and of six for the ions, a total of eighteen.

Charged particles (consisting here of six ionic species plus the electrons) are related through the quasi-neutrality equation, taking in the $\mathrm{N}_{2} \mathrm{O}$ plasma case the form

$$
n_{e}+n_{\mathrm{O}^{-}}=n_{\mathrm{N}_{2} \mathrm{O}^{+}}+n_{\mathrm{N}_{2}}+n_{\mathrm{N}^{+}}+n_{\mathrm{O}_{2}}+n_{\mathrm{O}^{+}} .
$$

Modeling of $\mathrm{N}_{2} \mathrm{O}$ plasmas is based primarily on $\mathrm{N}_{2} \mathrm{O}$ data. However, $\mathrm{N}_{2}, \mathrm{~N}, \mathrm{O}_{2}$, and $\mathrm{O}$ data are also very important, because dissociation of $\mathrm{N}_{2} \mathrm{O}$ generates nitrogen and oxygen species in various percentages. Because nitrogen species are present in an important amount in various gas discharges encountered in laboratory and nature plasmas including $\mathrm{N}_{2} \mathrm{O}$ ones, we proceeded to a separate study of pure $\mathrm{N}_{2}$ plasmas. Results of this study (see [16]) contributed to evaluate nitrogen data and to validate the corresponding part of the present GM. Results of our GM for pure $\mathrm{N}_{2}$ discharges not presented here compare favorably with those obtained by Kang et al. [17] and also with those from Thorsteinsson and 
Gudmundsson [12]. Both of these studies compare theoretical GM results with experiments.

Support of the part of the present GM which concerns oxygen species was obtained on the basis of our recent studies on discharges in plasmas containing $\mathrm{O}_{2}$ species, [18]. These address particularly evaluation of electronegativity in $\mathrm{O}_{2}$ discharges. Our results for pure $\mathrm{O}_{2}$ discharges compare favorably with those obtained by Gudmundsson et al. [14], Gudmundsson and Thorsteinsson [15], and Corr et al. [19]. Data and results from [18] as well as from [16] guided our choices on the selection of the oxygen and nitrogen species and on the processes to be retained in order to get a correct description of $\mathrm{O}_{2} / \mathrm{N}_{2}$ mixtures and of $\mathrm{N}_{2} \mathrm{O}$ plasmas.

Following standard procedures (see, e.g., our argon model described in [2] and references therein), the present $\mathrm{N}_{2} \mathrm{O}$ GM is composed of a power balance equation ( $\mathrm{PoBE}$ ) and of a particle kinetic equations set $(\mathrm{PaBE})$. The PoBE is written as

$$
\begin{aligned}
\frac{P_{\mathrm{abs}}}{V}= & e \varepsilon_{C, \mathrm{~N}_{2} \mathrm{O}} k_{I, \mathrm{~N}_{2} \mathrm{O}} n_{\mathrm{N}_{2} \mathrm{O}} n_{e}+e \varepsilon_{C, \mathrm{~N}_{2}} k_{I, \mathrm{~N}_{2}} n_{\mathrm{N}_{2}} n_{e} \\
& +e \varepsilon_{C, \mathrm{~N}} k_{I, \mathrm{~N}} n_{\mathrm{N}} n_{e}+e \varepsilon_{C, \mathrm{O}_{2}} k_{I, \mathrm{O}_{2}} n_{\mathrm{O}_{2}} n_{e} \\
& +e \varepsilon_{C, \mathrm{O}} k_{I, \mathrm{O}} n_{\mathrm{O}} n_{e}+e\left(\varepsilon_{e}+\varepsilon_{i}\right) k_{\mathrm{RW}, \mathrm{N}_{2} \mathrm{O}} n_{\mathrm{N}_{2} \mathrm{O}^{+}} \\
& +e\left(\varepsilon_{e}+\varepsilon_{i}\right) k_{\mathrm{RW}, \mathrm{N}_{2}} n_{\mathrm{N}_{2}}+e\left(\varepsilon_{e}+\varepsilon_{i}\right) k_{\mathrm{RW}, \mathrm{N}} n_{\mathrm{N}^{+}} \\
& +e\left(\varepsilon_{e}+\varepsilon_{i}\right) k_{\mathrm{RW}, \mathrm{O}_{2}} n_{\mathrm{O}_{2}}+e\left(\varepsilon_{e}+\varepsilon_{i}\right) k_{\mathrm{RW}, \mathrm{O}} n_{\mathrm{O}^{+}},
\end{aligned}
$$

where $e$ is the elementary charge and $\varepsilon_{C, X}$ the collisional energy loss of species $X$. Also, $k_{I, X}$ is the ionization rate coefficient for the species $X$ and $k_{\mathrm{RW}, X}$ is its recombination on the wall. The wall recombination rate is given by $k_{\mathrm{RW}, X}=u_{B, X} A_{\mathrm{eff}} / V$ with $u_{B}$ the Bohm velocity given by $u_{B}=\left(e T_{e} / M\right)^{1 / 2}$. For $\varepsilon_{e}$, the mean kinetic energy lost per electron, the value $\varepsilon_{e}=2 T_{e}$ proposed in [1] for electrons having a Maxwellian energy distribution was used. The mean kinetic energy lost per ion, noted by $\varepsilon_{i}$, is given in an electronegative gas by the sum of the sheath and presheath (plasma) potentials; that is, $\varepsilon_{i}=V_{s}+V_{p}$. The sheath potential $V_{s}$ is the potential of the sheath with respect to the wall, which is obtained by equating the positive ion fluxes $\Gamma_{X^{+}}=$ $u_{B, X^{+}} n_{X^{+}}\left(A_{\text {eff }} / A\right)$ with the electron flux $\Gamma_{e}=0.25 \cdot n_{e} v_{e}$ $\exp \left(-\phi / T_{e}\right)$, where the thermal velocity of electrons is $v_{e}=$ $\left(8 e T_{e} / \pi m_{e}\right)^{1 / 2}$; the potential $\phi$ becomes the plasma potential when $\Gamma_{+}$and $\Gamma_{e}$ are equal. $A$ is the cylindrical surface area of the device and $V_{p}$ is the potential of the plasma with respect to the sheath. For this potential we use the expression

$$
V_{p}=0.5 \cdot T_{e}\left(\frac{1+\alpha_{s}}{1+\alpha_{s} \gamma_{-}}\right)
$$

coming from [3] (see also [1, page 180]), where $\alpha_{s}$ is the plasma electronegativity at the sheath edge, with an approximate value of $\alpha_{s} \approx 0.5 \alpha$ conformal to [20]. In (3), the plasma electronegativity $\alpha$ is defined as $\alpha=n_{-} / n_{e}$, where $n_{-}$is the density of $\mathrm{O}^{-}$species and $\gamma_{-}=T_{e} / T_{-}$, with $T_{-}$being the negative ion temperature. We assume $T_{-}$to be equal to the positive ion temperature.

The area for effective loss $A_{\text {eff }}$ appearing in (2) under $k_{\mathrm{RW}, X}$ is given by $A_{\text {eff }}=2 \pi\left(h_{L} R^{2}+h_{R} R L\right)$ with $R$ and $L$ being the radius and length of the device and $h_{L}$ and $h_{R}$ the axial and radial edge to center ratios of positive ion density. A convenient formula joining the three plasma regimes of low, intermediate, and high pressure was proposed previously by Lee and Lieberman [21]. For cylindrical geometry it is given by $[1,21]$

$$
\begin{gathered}
h_{R}=0.80\left[4+\left(\frac{R}{\lambda_{i}}\right)+\left(\frac{0.8 R u_{B}}{\chi_{01} J_{1}\left(\chi_{01}\right) D_{a}}\right)^{2}\right]^{-1 / 2}, \\
h_{L}=0.86\left[3+\left(\frac{L}{2 \lambda_{i}}\right)+\left(\frac{0.86 L u_{B}}{\pi D_{a}}\right)^{2}\right]^{-1 / 2},
\end{gathered}
$$

where $J_{1}(\chi)$ is the first order Bessel function and $\chi_{01}=$ 2.405 the first zero of the $J_{0}$ Bessel function. The ambipolar diffusion coefficient $D_{a}$ is given by $D_{a}=D_{i}\left(1+T_{e} / T_{i}\right)$, with $D_{i}$ being the diffusion coefficient for positive ions (see [1]). A modification of $D_{a}$ due to the presence of a magnetic field in the "core" region of the HPT is also possible for instance by using adequate formulas contained in Chapter 5 of [1]. At the present stage, we introduced only a simple factor in the plasma wall reaction rates, taking into account both the ionic and the neutral species losses from the "core" to the "mantle" region (typically 5\% for the ions and 30\% for the neutrals). The mean free path of ions $\lambda_{i}$ is calculated by $\lambda_{i}=1 / \sum_{k} n_{k} \sigma_{i k}$, where $n_{k}$ is the density of a neutral species $k$ and $\sigma_{i k}$ is the ion-neutral scattering cross section for the collision of the $k$ th neutral with the $i$ th ion. Ionic momentum transfer for atomic and molecular oxygen is assumed to be $7.5 \cdot 10^{-19} \mathrm{~m}^{2}$ following [15]. Moreover, ionic momentum transfers for $\mathrm{N}_{2}{ }^{+}$with $\mathrm{N}$ and $\mathrm{N}_{2}$ correspondingly about 1.5 . $10^{-18} \mathrm{~m}^{2}$ and $3.0 \cdot 10^{-18} \mathrm{~m}^{2}$, following [22]. We assume a combined momentum transfer of $1.7 \cdot 10^{-18} \mathrm{~m}^{2}$ for the $\mathrm{N}_{2} \mathrm{O}$ plasma as well as for the $\mathrm{N}_{2} / \mathrm{O}_{2}$ mixtures. A term taking into account the electronegativity is to be added to the density ratios; therefore, in the $\mathrm{N}_{2} \mathrm{O}$ case, we write

$$
\begin{aligned}
& h_{R}^{\prime}=h_{R}\left[\frac{(1+3 \alpha / \gamma)}{1+\alpha}\right], \\
& h_{L}^{\prime}=h_{L}\left[\frac{(1+3 \alpha / \gamma)}{(1+\alpha)}\right]
\end{aligned}
$$

in which $\gamma$ encompasses $\gamma_{-}$.

In addition to the PoBE (2) we need the PaBE set, of which each equation, say of species $j$, is constituted by the sum of all the creation and destruction terms for the given species $j$ and can be written as

$$
\frac{d n_{j}}{d t}=\sum R_{\text {Production }}^{j}-\sum R_{\text {Loss }}^{j},
$$

where $\sum$ denotes the sum of all terms $R_{\text {Production }}^{j}$ and $R_{\text {Loss }}^{j}$ including the production and the loss rates involving the species $j$. Each reaction rate is given by the product of the reactant densities $n_{i}$ and the corresponding rate coefficient $k_{j}$ :

$$
R^{j}=k_{j} \cdot \prod_{i} n_{i} \quad\left(\mathrm{~cm}^{-3} \mathrm{~s}^{-1}\right) .
$$




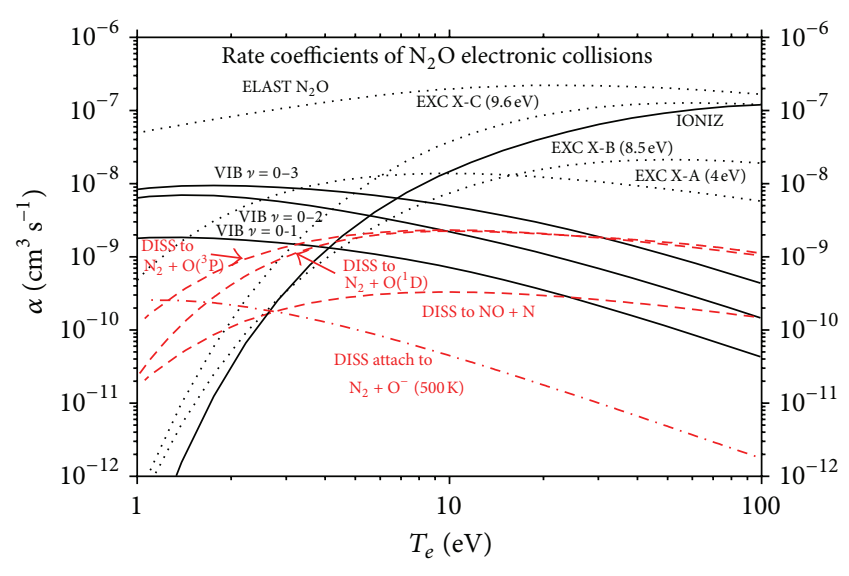

FIGURE 1: Rate coefficients of $\mathrm{N}_{2} \mathrm{O}$ electronic collisions. Red curves belong to dissociative processes.

An additional pressure term is needed, which follows the perfect gas law and is written numerically as

$$
\sum_{i=1}^{\mathrm{NTOT}} n_{i}=\frac{p}{\left(k_{B} \cdot T_{\mathrm{GAS}}\right)} \cdot 10^{-6}\left(\mathrm{~cm}^{-3}\right),
$$

where $n_{i}$ is the density of the species $i$ given in $\mathrm{cm}^{-3}, p$ is the pressure which, exceptionally for (8), is given in Pa units, $k_{B}$ is the Boltzmann constant in $\mathrm{J} \cdot \mathrm{K}^{-1}$, and $T_{\mathrm{GAS}}$ is the gas temperature in $\mathrm{K}$. An additional term for the pressure of ions should be retained for higher power and ionization calculations.

\section{Main Processes Involved in a $\mathbf{N}_{2} \mathbf{O}$ Plasma and Calculation/Evaluation of Their Rates}

We describe in this section the main processes included in the PaBE kinetic system, important for the description of the plasma. Data used in the PoBE equation are investigated in Section 4. A review of the used electron collisions rates is given schematically in Figure 1. Elastic collision and excitation rates which are described in Section 4 are included in Figure 1. Note that coefficients for all dissociative processes are given by curves in red.

We introduced a total number of eighteen species in the $\mathrm{PaBE}$, consisting of twelve neutral ones, $\mathrm{N}_{2} \mathrm{O}, \mathrm{N}_{2}(\nu=0-5)$, $\mathrm{O}_{2}, \mathrm{~N}, \mathrm{O}\left({ }^{3} \mathrm{P}\right), \mathrm{O}\left({ }^{1} \mathrm{D}\right)$, and $\mathrm{NO}$, of five positive ions $\mathrm{N}_{2} \mathrm{O}^{+}, \mathrm{N}_{2}{ }^{+}$, $\mathrm{O}_{2}^{+}, \mathrm{N}^{+}$, and $\mathrm{O}^{+}$and of one negative ion $\mathrm{O}^{-}$. These species are present in various physical situations we are interested in. Table 1 gives a synoptic view of the processes in which they appear. Table 1 includes in general more processes than those contained in similar tables of $[7,10]$.

In Tables 2 to 5 we report in detail the sixty-two processes which we use in the $\mathrm{N}_{2} \mathrm{O}$ GM. The processes are ordered following four sets. Data also used in the energy loss calculation are indicated with stars in the last column.

The corresponding reaction rates were taken into consideration when writing down the eighteen PaBE equations which allow for evaluating the species densities for each $n_{e}$,
$T_{e}$ set. We expect these reactions to be the most important for the considered applications, related to typical plasma cases (i), (ii), and (iii) which are described in Section 5. The model allows for evaluating the plasma $n_{e}$ and $T_{e}$ and its constituents densities as they vary with the pressure, the absorbed power, and the flow rate. For specific applications, it is possible to introduce more species and additional reactions in order to include more constituents and to enlarge the physical conditions domain.

The set of reactions we use is larger than the one proposed initially by Date et al. [23] and used subsequently by Shutov et al. [7]. Collisions of $\mathrm{O}\left({ }^{1} \mathrm{D}\right)$ with $\mathrm{N}_{2} \mathrm{O}$ and $\mathrm{N}_{2}$ have been included, like in [7]. Moreover, we included the rearrangement collisions of $\mathrm{O}\left({ }^{1} \mathrm{D}\right)$ with $\mathrm{NO}$ and the deexcitation ones of $\mathrm{O}\left({ }^{1} \mathrm{D}\right)$ with $\mathrm{O}_{2}$ as in [1, page 273]. However, the reactions involving $\mathrm{NO}_{2}$ previously used by de los Arcos et al. [10] in a slightly reduced reaction set are here neglected. Note that [10] contains also an extended bibliographic study on the subject, not reproduced here. In what concerns the considered species, $\mathrm{O}\left({ }^{1} \mathrm{D}\right)$ which constitutes the second GL of oxygen, has been introduced in $[7,23]$ because plasma etching was the aimed application. This species has been also introduced here as it can be quite present (see [14, 15]) and may play an important role in the total oxygen ionization, an important process which was not introduced in $[7,23]$. We do include the excitation/deexcitation of $\mathrm{O}\left({ }^{1} \mathrm{D}\right)$ by electronic collision. These reactions, often omitted in previous $\mathrm{N}_{2} \mathrm{O}$ work, are important for the $\mathrm{O}\left({ }^{1} \mathrm{D}\right)$ population which directly contributes to the $\mathrm{N}_{2} \mathrm{O}$ dissociation. Moreover, we added the $\mathrm{N}_{2}^{+}, \mathrm{O}_{2}{ }^{+}, \mathrm{N}^{+}$, and $\mathrm{O}^{+}$ions to the initial set of species used by Date et al. [23], as $\mathrm{N}_{2}, \mathrm{O}_{2}, \mathrm{~N}$, and $\mathrm{O}$ may become predominant plasma species in low and intermediate pressures and therefore their ions are important, both in order to calculate correctly the plasma density and also because they need to be precisely characterized when we consider various space applications. In the latter applications, often exist quite ionized plasma regions where the electron temperatures of interest may be high, leading to ionization percentages clearly higher than those of the PR cases also considered here.

Rate coefficients for electron collision processes were calculated by integrating the cross sections from available references (see, e.g., $[1,23-38]$ and references therein) in the range from threshold to $500 \mathrm{eV}$. The corresponding rates were parameterized with polynomials in a $T_{e}$ range from 0.2 to $100 \mathrm{eV}$, except when otherwise stated.

For heavy particle collisions, we used directly the rate coefficients given in $[1,7,14,15,38-40]$. Reactions include various neutralization processes. No charge exchange reactions were included in the final form of our GM presented here. This was also the case in [41] with collisions of oxygen species. Our trial calculations including charge exchange between oxygen species have not shown big differences in the GM results for the studied physical conditions.

Rate coefficient values for the processes introduced in the model are briefly discussed in the following. Data needed for modeling of $\mathrm{N}_{2}$ and $\mathrm{O}_{2}$ plasmas have been discussed and collected in dedicated databases. Their evaluation and 
TABLE 1: Global description of the reactions included in the $\mathrm{N}_{2} \mathrm{O}$ plasma kinetic system.

\begin{tabular}{|c|c|c|c|}
\hline No. & Process & Description & Rate \\
\hline \multicolumn{4}{|c|}{ Electron impact ionization (rates in $\mathrm{cm}^{3} \mathrm{~s}^{-1}$ ) } \\
\hline 1 & $\mathrm{~N}_{2} \mathrm{O}, \mathrm{N}_{2}, \mathrm{O}_{2}, \mathrm{~N}, \mathrm{O}\left({ }^{3} \mathrm{P}\right), \mathrm{O}\left({ }^{1} \mathrm{D}\right)+\mathrm{e}^{-} \rightarrow \mathrm{N}_{2} \mathrm{O}^{+}, \mathrm{N}_{2}^{+}, \mathrm{O}_{2}^{+}, \mathrm{N}^{+}, \mathrm{O}^{+}+2 \mathrm{e}^{-}$ & $\mathrm{N}_{2} \mathrm{O}, \mathrm{N}_{2}, \mathrm{O}_{2}, \mathrm{~N}, \mathrm{O}\left({ }^{3} \mathrm{P}\right), \mathrm{O}\left({ }^{1} \mathrm{D}\right)$ ionizations & $k_{I, X}$ \\
\hline \multicolumn{4}{|c|}{ Electron impact dissociation (rates in $\mathrm{cm}^{3} \mathrm{~s}^{-1}$ ) } \\
\hline 2 & $\mathrm{~N}_{2} \mathrm{O}+\mathrm{e}^{-} \rightarrow \mathrm{N}_{2}+\mathrm{O}\left({ }^{3} \mathrm{P}\right)+\mathrm{e}^{-}$ & $\mathrm{N}_{2} \mathrm{O}$ diss. by $\mathrm{e}^{-}$impact leading to $\mathrm{N}_{2}+\mathrm{O}\left({ }^{3} \mathrm{P}\right)$ & $k_{\mathrm{DlN}_{2} \mathrm{O}}$ \\
\hline 3 & $\mathrm{~N}_{2} \mathrm{O}+\mathrm{e}^{-} \rightarrow \mathrm{N}_{2}+\mathrm{O}\left({ }^{1} \mathrm{D}\right)+\mathrm{e}^{-}$ & $\mathrm{N}_{2} \mathrm{O}$ diss. by $\mathrm{e}^{-}$impact leading to $\mathrm{N}_{2}+\mathrm{O}\left({ }^{1} \mathrm{D}\right)$ & $k_{\mathrm{D} 1 \mathrm{~N}_{2} \mathrm{OBIS}}$ \\
\hline 4 & $\mathrm{~N}_{2} \mathrm{O}+\mathrm{e}^{-} \rightarrow \mathrm{NO}+\mathrm{N}+\mathrm{e}^{-}$ & $\mathrm{N}_{2} \mathrm{O}$ diss. by $\mathrm{e}^{-}$impact leading to $\mathrm{NO}+\mathrm{N}$ & $k_{{\mathrm{D} 2 \mathrm{~N}_{2} \mathrm{O}}}$ \\
\hline 5 & $\mathrm{~N}_{2} \mathrm{O}+\mathrm{e}^{-} \rightarrow \mathrm{N}_{2}+\mathrm{O}^{-}$ & $\mathrm{N}_{2} \mathrm{O}$ dissociative attachment & $k_{{\mathrm{D} 3 \mathrm{~N}_{2} \mathrm{O}}}$ \\
\hline 6 & $\mathrm{~N}_{2}+\mathrm{e}^{-} \rightarrow 2 \mathrm{~N}+\mathrm{e}^{-}$ & $\mathrm{N}_{2}$ dissociation (see Table 3 ) & $k_{\mathrm{DISS}, \mathrm{N}_{2}}$ \\
\hline 7 & $\mathrm{O}_{2}+\mathrm{e}^{-} \rightarrow 2 \mathrm{O}+\mathrm{e}^{-}$ & $\mathrm{O}_{2}$ dissociation (see Table 4) & $k_{\mathrm{DISS}, \mathrm{O}_{2}}$ \\
\hline \multicolumn{4}{|c|}{ Electronic excitation/deexcitation (rates in $\mathrm{cm}^{3} \mathrm{~s}^{-1}$ ) } \\
\hline 8 & $\mathrm{~N}_{2}(\nu=0)+\mathrm{e}^{-} \leftrightarrow \mathrm{N}_{2}(\nu=i)+\mathrm{e}^{-}\{i=1-5\}$ & $\mathrm{N}_{2}$ vibrational excitation/deexcitation & $k_{\mathrm{XVIBN}_{2}}$ \\
\hline 9 & $\mathrm{O}\left({ }^{3} \mathrm{P}\right)+\mathrm{e}^{-} \leftrightarrow \mathrm{O}\left({ }^{1} \mathrm{D}\right)+\mathrm{e}^{-}$ & $\mathrm{O}\left({ }^{1} \mathrm{D}\right)$ excitation/deexcitation & $k_{\mathrm{XOD}}$ \\
\hline \multicolumn{4}{|c|}{ Heavy particle collisions: dissociation (rates in $\mathrm{cm}^{3} \mathrm{~s}^{-1}$ ) } \\
\hline 10 & $\mathrm{~N}_{2} \mathrm{O}+\mathrm{O}\left({ }^{1} \mathrm{D}\right) \rightarrow \mathrm{N}_{2}+\mathrm{O}_{2}$ & $\mathrm{~N}_{2} \mathrm{O}$ diss. with $\mathrm{O}\left({ }^{1} \mathrm{D}\right)$ leading to $\mathrm{N}_{2}+\mathrm{O}_{2}$ & $k_{{\mathrm{D} 4 \mathrm{~N}_{2} \mathrm{O}}}$ \\
\hline 11 & $\mathrm{~N}_{2} \mathrm{O}+\mathrm{O}\left({ }^{1} \mathrm{D}\right) \rightarrow 2 \mathrm{NO}$ & $\mathrm{N}_{2} \mathrm{O}$ diss. with $\mathrm{O}\left({ }^{1} \mathrm{D}\right)$ leading to $2 \mathrm{NO}$ & $k_{{\mathrm{D} 5 \mathrm{~N}_{2} \mathrm{O}}}$ \\
\hline \multicolumn{4}{|c|}{ Heavy particle collisions: deexcitation (rates in $\mathrm{cm}^{3} \mathrm{~s}^{-1}$ ) } \\
\hline 12 & $\mathrm{~N}_{2}+\mathrm{O}\left({ }^{1} \mathrm{D}\right) \rightarrow \mathrm{N}_{2}+\mathrm{O}\left({ }^{3} \mathrm{P}\right)$ & $\mathrm{O}\left({ }^{1} \mathrm{D}\right)$ deexcitation with $\mathrm{N}_{2}$ & $k_{\mathrm{N}_{2} \mathrm{OD}}$ \\
\hline 13 & $\mathrm{O}_{2}+\mathrm{O}\left({ }^{1} \mathrm{D}\right) \rightarrow \mathrm{O}_{2}+\mathrm{O}\left({ }^{3} \mathrm{P}\right)$ & $\mathrm{O}\left({ }^{1} \mathrm{D}\right)$ deexcitation with $\mathrm{O}_{2}$ & $k_{\mathrm{O}_{2} \mathrm{OD}}$ \\
\hline \multicolumn{4}{|c|}{ Heavy particle collisions: rearrangement (rates in $\mathrm{cm}^{3} \mathrm{~s}^{-1}$ ) } \\
\hline 14 & $\mathrm{NO}+\mathrm{N} \rightarrow \mathrm{O}+\mathrm{N}_{2}$ & $\mathrm{NO}$ rearrangement leading to $\mathrm{O}+\mathrm{N}_{2}$ & $k_{\text {REARN }}$ \\
\hline 15 & $\mathrm{NO}+\mathrm{O}\left({ }^{1} \mathrm{D}\right) \rightarrow \mathrm{N}+\mathrm{O}_{2}$ & $\mathrm{NO}$ rearrangement leading to $\mathrm{N}+\mathrm{O}_{2}$ & $k_{\text {REAROD }}$ \\
\hline \multicolumn{4}{|c|}{ Neutralization (rates in $\mathrm{cm}^{3} \mathrm{~s}^{-1}$ ) } \\
\hline 16 & $\mathrm{~N}_{2} \mathrm{O}^{+}, \mathrm{N}_{2}^{+}, \mathrm{O}_{2}^{+}, \mathrm{O}^{+}+\mathrm{O}^{-} \rightarrow \mathrm{N}_{2} \mathrm{O}, \mathrm{N}_{2}, \mathrm{O}_{2}, \mathrm{O}+\mathrm{O}$ & $\mathrm{O}^{-}$neutralization by $\mathrm{N}_{2} \mathrm{O}^{+}, \mathrm{N}_{2}^{+}, \mathrm{O}_{2}^{+}, \mathrm{O}^{+}$ & $k_{\mathrm{R}, X}$ \\
\hline \multicolumn{4}{|c|}{$\mathrm{O}^{-}$recombination (rates in $\mathrm{cm}^{3} \mathrm{~s}^{-1}$ ) } \\
\hline 17 & $\mathrm{~N}_{2}(\nu=4,5)+\mathrm{O}^{-} \rightarrow \mathrm{N}_{2}(\nu=0)+\mathrm{O}+\mathrm{e}^{-}$ & $\mathrm{O}^{-}$recombination with $\mathrm{N}_{2}(\nu=4,5)$ & $k_{\mathrm{RN}_{2} \mathrm{OM}}$ \\
\hline 18 & $\mathrm{O}+\mathrm{O}^{-} \rightarrow \mathrm{O}_{2}+\mathrm{e}^{-}$ & $\mathrm{O}^{-}$recombination with $\mathrm{O}$ & $k_{\mathrm{R} 4 \mathrm{OM}}$ \\
\hline \multicolumn{4}{|c|}{ Reactions on the wall (rates in $\mathrm{s}^{-1}$ ) } \\
\hline 19 & $\mathrm{~N}_{2} \mathrm{O}^{+}, \mathrm{N}_{2}^{+}, \mathrm{O}_{2}^{+}, \mathrm{N}^{+}, \mathrm{O}^{+} \stackrel{\text { wall }}{\longrightarrow} \mathrm{N}_{2} \mathrm{O}, \mathrm{N}_{2}, \mathrm{O}_{2}, \mathrm{~N}, \mathrm{O}$ & $\mathrm{N}_{2} \mathrm{O}, \mathrm{N}_{2}, \mathrm{O}_{2}, \mathrm{~N}, \mathrm{O}$ recomb. on the wall & $k_{\mathrm{RW}, X}$ \\
\hline 20 & $\mathrm{~N}_{2}(\nu) \stackrel{\text { wall }}{\longrightarrow} \mathrm{N}_{2}(\nu-1)$ & $\mathrm{N}_{2}(\nu)$ deexcitation on the wall & $k_{\mathrm{DXW}, \mathrm{N}_{2} \mathrm{~V}}$ \\
\hline 21 & $\mathrm{O}\left({ }^{1} \mathrm{D}\right) \stackrel{\text { wall }}{\longrightarrow} \mathrm{O}\left({ }^{3} \mathrm{P}\right)$ & $\mathrm{O}\left({ }^{1} \mathrm{D}\right)$ deexcitation on the wall & $k_{\mathrm{DXWOD}}$ \\
\hline 22 & $\mathrm{~N}, \mathrm{O} \stackrel{\text { wall }}{\longrightarrow}(1 / 2) \mathrm{N}_{2},(1 / 2) \mathrm{O}_{2}$ & $\mathrm{~N}_{2}, \mathrm{O}_{2}$ formation on the wall & $k_{\mathrm{FW}, \mathrm{X}}$ \\
\hline
\end{tabular}

TABLE 2: Reactions involving $\mathrm{N}_{2} \mathrm{O}$ and $\mathrm{NO}$ species considered in the $\mathrm{N}_{2} \mathrm{O}$ plasma kinetic system.

\begin{tabular}{|c|c|c|c|c|}
\hline No. & Process & Description & Rate & PoBE \\
\hline \multicolumn{5}{|c|}{ Electron collisions (rates in $\mathrm{cm}^{3} \mathrm{~s}^{-1}$ ) } \\
\hline 1 & $\mathrm{~N}_{2} \mathrm{O}+\mathrm{e}^{-} \rightarrow \mathrm{N}_{2} \mathrm{O}^{+}+2 \mathrm{e}^{-}$ & $\mathrm{N}_{2} \mathrm{O}$ ionization & $k_{\mathrm{IN}_{2} \mathrm{O}}$ & * \\
\hline 2 & $\mathrm{~N}_{2} \mathrm{O}+\mathrm{e}^{-} \rightarrow \mathrm{N}_{2}+\mathrm{O}\left({ }^{3} \mathrm{P}\right)+\mathrm{e}^{-}$ & $\mathrm{N}_{2} \mathrm{O}$ diss. by $\mathrm{e}^{-}$impact, diss 1 & $k_{\mathrm{DIN}_{2} \mathrm{O}}$ & $*$ \\
\hline 3 & $\mathrm{~N}_{2} \mathrm{O}+\mathrm{e}^{-} \rightarrow \mathrm{N}_{2}+\mathrm{O}\left({ }^{1} \mathrm{D}\right)+\mathrm{e}^{-}$ & $\mathrm{N}_{2} \mathrm{O}$ diss. by e $\mathrm{e}^{-}$impact, diss 1 bis & $k_{\mathrm{DIN}_{2} \mathrm{OBIS}}$ & * \\
\hline 4 & $\mathrm{~N}_{2} \mathrm{O}+\mathrm{e}^{-} \rightarrow \mathrm{NO}+\mathrm{N}+\mathrm{e}^{-}$ & $\mathrm{N}_{2} \mathrm{O}$ diss. by e $\mathrm{e}^{-}$impact, diss 2 & $k_{{\mathrm{D} 2 \mathrm{~N}_{2} \mathrm{O}}}$ & \\
\hline 5 & $\mathrm{~N}_{2} \mathrm{O}+\mathrm{e}^{-} \rightarrow \mathrm{N}_{2}+\mathrm{O}^{-}$ & $\mathrm{N}_{2} \mathrm{O}$ diss. attachment, diss 3 & $k_{{\mathrm{D} 3 \mathrm{~N}_{2} \mathrm{O}}}$ & \\
\hline \multicolumn{5}{|c|}{ Heavy particle collisions (rates in $\mathrm{cm}^{3} \mathrm{~s}^{-1}$ ) } \\
\hline 6 & $\mathrm{~N}_{2} \mathrm{O}+\mathrm{O}\left({ }^{1} \mathrm{D}\right) \rightarrow \mathrm{N}_{2}+\mathrm{O}_{2}$ & $\mathrm{~N}_{2} \mathrm{O}$ diss. with $\mathrm{O}\left({ }^{1} \mathrm{D}\right)$, diss 4 & $k_{\mathrm{D}_{4} \mathrm{~N}_{2} \mathrm{O}}$ & \\
\hline 7 & $\mathrm{~N}_{2} \mathrm{O}+\mathrm{O}\left({ }^{1} \mathrm{D}\right) \rightarrow 2 \mathrm{NO}$ & $\mathrm{N}_{2} \mathrm{O}$ diss. with $\mathrm{O}\left({ }^{1} \mathrm{D}\right)$, diss 5 & $k_{{\mathrm{D} 5 \mathrm{~N}_{2} \mathrm{O}}}$ & \\
\hline 8 & $\mathrm{NO}+\mathrm{N} \rightarrow \mathrm{O}+\mathrm{N}_{2}$ & $\mathrm{NO}$ rearrangement giving $\mathrm{O}$ & $k_{\text {REARN }}$ & \\
\hline 9 & $\mathrm{NO}+\mathrm{O}\left({ }^{1} \mathrm{D}\right) \rightarrow \mathrm{N}+\mathrm{O}_{2}$ & NO rearrangement giving $\mathrm{N}$ & $k_{\text {REAROD }}$ & \\
\hline 10 & $\mathrm{~N}_{2} \mathrm{O}^{+}+\mathrm{O}^{-} \rightarrow \mathrm{N}_{2} \mathrm{O}+\mathrm{O}$ & $\mathrm{N}_{2} \mathrm{O}$ recombination & $k_{\mathrm{RN}_{2} \mathrm{O}}$ & \\
\hline \multicolumn{5}{|c|}{ Reactions on the wall (rates in $\mathrm{s}^{-1}$ ) } \\
\hline 11 & $\mathrm{~N}_{2} \mathrm{O}^{+} \stackrel{\text { wall }}{\longrightarrow} \mathrm{N}_{2} \mathrm{O}$ & $\mathrm{N}_{2} \mathrm{O}$ recombination on the wall & $k_{\mathrm{RWN}_{2} \mathrm{O}}$ & \\
\hline
\end{tabular}


TABLE 3: Reactions involving nitrogen species considered in the $\mathrm{N}_{2} \mathrm{O}$ plasma kinetic system.

\begin{tabular}{|c|c|c|c|c|}
\hline No. & Process & Description & Rate & PoBE \\
\hline \multicolumn{5}{|c|}{ Electron collisions (rates in $\mathrm{cm}^{3} \mathrm{~s}^{-1}$ ) } \\
\hline 1 & $\mathrm{~N}_{2}+\mathrm{e}^{-} \rightarrow \mathrm{N}_{2}^{+}+2 \mathrm{e}^{-}$ & $\mathrm{N}_{2}$ ionization & $k_{\mathrm{IONIZ}_{2} \mathrm{~N}_{2}}$ & * \\
\hline 2 & $\mathrm{~N}_{2}+\mathrm{e}^{-} \rightarrow 2 \mathrm{~N}+\mathrm{e}^{-}$ & $\mathrm{N}_{2}$ dissociation & $k_{\mathrm{DISS}, \mathrm{N}_{2}}$ & * \\
\hline 3 & $\mathrm{~N}+\mathrm{e}^{-} \rightarrow \mathrm{N}^{+}+2 \mathrm{e}^{-}$ & $\mathrm{N}$ ionization & $k_{\mathrm{IONIZ,N}}$ & * \\
\hline 4 & $\mathrm{~N}_{2}(\nu=0)+\mathrm{e}^{-} \rightarrow \mathrm{N}_{2}(\nu=1)+\mathrm{e}^{-}$ & $\mathrm{N}_{2}$ vib. exc. $(0-1)$ & $k_{\mathrm{XVIBN}_{2}, 01}$ & * \\
\hline 5 & $\mathrm{~N}_{2}(\nu=0)+\mathrm{e}^{-} \rightarrow \mathrm{N}_{2}(\nu=2)+\mathrm{e}^{-}$ & $\mathrm{N}_{2}$ vib. exc. $(0-2)$ & $k_{\mathrm{XVIBN}_{2}, 02}$ & * \\
\hline 6 & $\mathrm{~N}_{2}(\nu=0)+\mathrm{e}^{-} \rightarrow \mathrm{N}_{2}(\nu=3)+\mathrm{e}^{-}$ & $\mathrm{N}_{2}$ vib. exc. $(0-3)$ & $k_{\mathrm{XVIBN}_{2}, 03}$ & * \\
\hline 7 & $\mathrm{~N}_{2}(\nu=0)+\mathrm{e}^{-} \rightarrow \mathrm{N}_{2}(\nu=4)+\mathrm{e}^{-}$ & $\mathrm{N}_{2}$ vib. exc. $(0-4)$ & $k_{\mathrm{XVIBN}_{2}, 04}$ & * \\
\hline 8 & $\mathrm{~N}_{2}(\nu=0)+\mathrm{e}^{-} \rightarrow \mathrm{N}_{2}(\nu=5)+\mathrm{e}^{-}$ & $\mathrm{N}_{2}$ vib. exc. (0-5) & $k_{\mathrm{XVIBN}_{2}, 05}$ & * \\
\hline 9 & $\mathrm{~N}_{2}(\nu=1)+\mathrm{e}^{-} \rightarrow \mathrm{N}_{2}(\nu=0)+\mathrm{e}^{-}$ & $\mathrm{N}_{2}$ vib. deexc. (1-0) & $k_{\text {DXVIBN }_{2}, 10}$ & \\
\hline 10 & $\mathrm{~N}_{2}(\nu=2)+\mathrm{e}^{-} \rightarrow \mathrm{N}_{2}(\nu=0)+\mathrm{e}^{-}$ & $\mathrm{N}_{2}$ vib. deexc. $(2-0)$ & $k_{\text {DXVIBN }_{2}, 20}$ & \\
\hline 11 & $\mathrm{~N}_{2}(\nu=3)+\mathrm{e}^{-} \rightarrow \mathrm{N}_{2}(\nu=0)+\mathrm{e}^{-}$ & $\mathrm{N}_{2}$ vib. deexc. (3-0) & $k_{\mathrm{DXVIBN}_{2}, 30}$ & \\
\hline 12 & $\mathrm{~N}_{2}(\nu=4)+\mathrm{e}^{-} \rightarrow \mathrm{N}_{2}(\nu=0)+\mathrm{e}^{-}$ & $\mathrm{N}_{2}$ vib. deexc. (4-0) & $k_{\text {DXVIBN }_{2}, 40}$ & \\
\hline 13 & $\mathrm{~N}_{2}(\nu=5)+\mathrm{e}^{-} \rightarrow \mathrm{N}_{2}(\nu=0)+\mathrm{e}^{-}$ & $\mathrm{N}_{2}$ vib. deexc. (5-0) & $k_{\text {DXVIBN }_{2,50}}$ & \\
\hline 14 & $\mathrm{~N}_{2}(\nu=1)+\mathrm{e}^{-} \rightarrow \mathrm{N}_{2}^{+}+2 \mathrm{e}^{-}$ & $\mathrm{N}_{2}$ ionization from $(\nu=1)$ & $k_{\mathrm{IONIZ,N}}, \mathrm{V} 1$ & \\
\hline 15 & $\mathrm{~N}_{2}(\nu=2)+\mathrm{e}^{-} \rightarrow \mathrm{N}_{2}^{+}+2 \mathrm{e}^{-}$ & $\mathrm{N}_{2}$ ionization from $(\nu=2)$ & $k_{\mathrm{IONIZ,N}, \mathrm{V} 2}$ & \\
\hline 16 & $\mathrm{~N}_{2}(\nu=3)+\mathrm{e}^{-} \rightarrow \mathrm{N}_{2}^{+}+2 \mathrm{e}^{-}$ & $\mathrm{N}_{2}$ ionization from $(\nu=3)$ & $k_{\mathrm{IONIZ,N}, \mathrm{V} 3}$ & \\
\hline 17 & $\mathrm{~N}_{2}(\nu=4)+\mathrm{e}^{-} \rightarrow \mathrm{N}_{2}^{+}+2 \mathrm{e}^{-}$ & $\mathrm{N}_{2}$ ionization from $(\nu=4)$ & 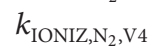 & \\
\hline 18 & $\mathrm{~N}_{2}(\nu=5)+\mathrm{e}^{-} \rightarrow \mathrm{N}_{2}^{+}+2 \mathrm{e}^{-}$ & $\mathrm{N}_{2}$ ionization from $(\nu=5)$ & $k_{\mathrm{IONIZ,N}, \mathrm{V} 5}$ & \\
\hline 19 & $\mathrm{~N}_{2}(\nu=1)+\mathrm{e}^{-} \rightarrow 2 \mathrm{~N}+\mathrm{e}^{-}$ & $\mathrm{N}_{2}$ diss. from $(\nu=1)$ & $k_{\mathrm{DISS}, \mathrm{N}_{2}, \mathrm{~V} 1}$ & \\
\hline 20 & $\mathrm{~N}_{2}(\nu=2)+\mathrm{e}^{-} \rightarrow 2 \mathrm{~N}+\mathrm{e}^{-}$ & $\mathrm{N}_{2}$ diss. from $(\nu=2)$ & $k_{\mathrm{DIS}, \mathrm{N}_{2}, \mathrm{~V} 2}$ & \\
\hline 21 & $\mathrm{~N}_{2}(\nu=3)+\mathrm{e}^{-} \rightarrow 2 \mathrm{~N}+\mathrm{e}^{-}$ & $\mathrm{N}_{2}$ diss. from $(\nu=3)$ & $k_{\mathrm{DISS}, \mathrm{N}_{2}, \mathrm{~V} 3}$ & \\
\hline 22 & $\mathrm{~N}_{2}(\nu=4)+\mathrm{e}^{-} \rightarrow 2 \mathrm{~N}+\mathrm{e}^{-}$ & $\mathrm{N}_{2}$ diss. from $(\nu=4)$ & $k_{\mathrm{DISS}, \mathrm{N}_{2}, \mathrm{~V} 4}$ & \\
\hline 23 & $\mathrm{~N}_{2}(\nu=5)+\mathrm{e}^{-} \rightarrow 2 \mathrm{~N}+\mathrm{e}^{-}$ & $\mathrm{N}_{2}$ diss. from $(\nu=5)$ & $k_{\mathrm{DISS}, \mathrm{N}_{2}, \mathrm{~V} 5}$ & \\
\hline \multicolumn{5}{|c|}{ Reactions on the wall (rates in $\mathrm{s}^{-1}$ ) } \\
\hline 24 & $\mathrm{~N}_{2}^{+} \stackrel{\text { wall }}{\longrightarrow} \mathrm{N}_{2}$ & $\mathrm{~N}_{2}{ }^{+}$recombination on the wall & $k_{\mathrm{RW}, \mathrm{N}_{2}}$ & \\
\hline 25 & $\mathrm{~N} \stackrel{\text { wall }}{\longrightarrow}(1 / 2) \mathrm{N}_{2}$ & $\mathrm{~N}_{2}$ formation on the wall & $k_{\mathrm{FW}, \mathrm{N}_{2}}$ & \\
\hline 26 & $\mathrm{~N}^{+} \stackrel{\text { wall }}{\longrightarrow} \mathrm{N}$ & $\mathrm{N}^{+}$recombination on the wall & $k_{\mathrm{RW}, \mathrm{N}}$ & \\
\hline 27 & $\mathrm{~N}_{2}(\nu) \stackrel{\text { wall }}{\longrightarrow} \mathrm{N}_{2}(\nu-1)$ & $\mathrm{N}_{2}(\nu)$ deexcitation on the wall & $k_{\mathrm{DXW}, \mathrm{N}_{2} \mathrm{~V}}$ & \\
\hline
\end{tabular}

application to dedicated GMs for $\mathrm{N}_{2}$ and $\mathrm{O}_{2}$ will be made available separately $[16,18]$.

3.1. $\mathrm{N}_{2} \mathrm{O}$ Ionization. Concerning the reaction rates for the $\mathrm{N}_{2} \mathrm{O}$ ionization, reaction no. 1 of Table 2, the cross section from Kim et al. [25] was integrated previously by Shutov et al. [7] for $T_{e}$ from 2.4 to $2.8 \mathrm{eV}$. We compared the cross section from Kim et al. [25], Dupljanin et al. [26], Rapp and Englander-Golden [27], Iga et al. [28], the Deutsch-Märk formula (see for instance [42, page 84]), and a semiclassical two-parameter formula reported in [43], as adapted for molecules. Recent cross sections by Dupljanin et al. [26] were integrated to obtain the rate coefficient. The latter are parameterized with a polynomial of order seven. The considered cross sections are compared in Figure 2.

3.2. $\mathrm{N}_{2} \mathrm{O}$ Dissociation Leading to $\mathrm{N}_{2}$ and Oxygen Species Products. Dissociation of the $\mathrm{N}_{2} \mathrm{O}$ by electron impact, reactions nos. 2 and 3 of Table 2, constitutes the main dissociation channel of $\mathrm{N}_{2} \mathrm{O}$. Cross section for reaction no. 2 was plotted in
[23]. We integrated this cross section to get the rate coefficient in a temperature region going from $0.2 \mathrm{eV}$ to $100 \mathrm{eV}$, assuming a Maxwellian distribution. We compared the obtained rate with the values coming from the formula $k_{{\mathrm{D} 1, \mathrm{~N}_{2} \mathrm{O}}}=1.48$. $10^{-8} \cdot T_{e}^{0.182} \cdot \exp \left(-5.25 / T_{e}\right)$ given by Shutov et al. [7] based on results obtained from Cleland and Hess [38]. Validity of this formula was restricted between $2 \mathrm{eV}$ and $10 \mathrm{eV}$. This comparison is shown in Figure 3 as an example of our $\mathrm{N}_{2} \mathrm{O}$ data evaluation work. In Figure 3, the values of de los Arcos et al. [10] and those of [38], as reported in [10], are also plotted for comparison.

In the $2 \mathrm{eV}$ region, after integration of the cross section provided by [23] we obtain dissociation rates $30 \%$ lower than those of Shutov et al. [7]. The difference is increasing with the temperature and becomes of one order of magnitude for $10 \mathrm{eV}$. Our values are the same with those of [10] for $T_{e}=2 \mathrm{eV}$ but become inevitably higher with increasing $T_{e}$, because in [10] a constant value of rate coefficient was used. For the same reason, our values are neatly lower than those of [10] for low $T_{e}$. Moreover, we find the same rate value with [38] for a $T_{e}$ 
TABLE 4: Reactions involving oxygen species considered in the $\mathrm{N}_{2} \mathrm{O}$ plasma kinetic system.

\begin{tabular}{|c|c|c|c|c|}
\hline No. & Process & Description & Rate & PoBE \\
\hline \multicolumn{5}{|c|}{ Electron collisions: ionization (rates in $\mathrm{cm}^{3} \mathrm{~s}^{-1}$ ) } \\
\hline 1 & $\mathrm{O}_{2}+\mathrm{e}^{-} \rightarrow \mathrm{O}_{2}^{+}+2 \mathrm{e}^{-}$ & $\mathrm{O}_{2}$ ionization & $k_{\mathrm{IO}_{2}}$ & * \\
\hline 2 & $\mathrm{O}\left({ }^{3} \mathrm{P}\right)+\mathrm{e}^{-} \rightarrow \mathrm{O}^{+}+2 \mathrm{e}^{-}$ & $\mathrm{O}\left({ }^{3} \mathrm{P}\right)$ ionization & $k_{\mathrm{IOP}}$ & $*$ \\
\hline 3 & $\mathrm{O}\left({ }^{1} \mathrm{D}\right)+\mathrm{e}^{-} \rightarrow \mathrm{O}^{+}+2 \mathrm{e}^{-}$ & $\mathrm{O}\left({ }^{1} \mathrm{D}\right)$ ionization & $k_{\mathrm{IOD}}$ & \\
\hline \multicolumn{5}{|c|}{ Electron collisions: excitation and deexcitation (rates in $\mathrm{cm}^{3} \mathrm{~s}^{-1}$ ) } \\
\hline 4 & $\mathrm{O}\left({ }^{3} \mathrm{P}\right)+\mathrm{e}^{-} \rightarrow \mathrm{O}\left({ }^{1} \mathrm{D}\right)+\mathrm{e}^{-}$ & $\mathrm{O}\left({ }^{1} \mathrm{D}\right)$ excitation & $k_{\mathrm{XOD}}$ & * \\
\hline 5 & $\mathrm{O}\left({ }^{1} \mathrm{D}\right)+\mathrm{e}^{-} \rightarrow \mathrm{O}\left({ }^{3} \mathrm{P}\right)+\mathrm{e}^{-}$ & $\mathrm{O}\left({ }^{1} \mathrm{D}\right)$ deexcitation & $k_{\mathrm{DXOD}}$ & \\
\hline \multicolumn{5}{|c|}{ Electronic dissociations and recombinations (rates in $\mathrm{cm}^{3} \mathrm{~s}^{-1}$ ) } \\
\hline 6 & $\mathrm{O}_{2}+\mathrm{e}^{-} \rightarrow 2 \mathrm{O}\left({ }^{3} \mathrm{P}\right)+\mathrm{e}^{-}$ & $\mathrm{O}_{2}$ dissociation, diss. 1 & $k_{\mathrm{D} 1 \mathrm{OPP}}$ & $*$ \\
\hline 7 & $\mathrm{O}_{2}+\mathrm{e}^{-} \rightarrow \mathrm{O}\left({ }^{3} \mathrm{P}\right)+\mathrm{O}\left({ }^{1} \mathrm{D}\right)+\mathrm{e}^{-}$ & $\mathrm{O}_{2}$ dissociation, diss. 1 bis & $k_{\mathrm{D} 1 \mathrm{OPD}}$ & $*$ \\
\hline 8 & $\mathrm{O}_{2}+\mathrm{e}^{-} \rightarrow \mathrm{O}^{-}+\mathrm{O}^{+}+\mathrm{e}^{-}$ & $\mathrm{O}_{2}$ dissociation, diss. 3 & $k_{{\mathrm{D} 3 \mathrm{O}_{2}}_{2}}$ & \\
\hline 9 & $\mathrm{O}_{2}+\mathrm{e}^{-} \rightarrow \mathrm{O}\left({ }^{3} \mathrm{P}\right)+\mathrm{O}^{+}+2 \mathrm{e}^{-}$ & $\mathrm{O}_{2}$ dissociation, diss. 4 & $k_{\mathrm{D}_{4} \mathrm{O}_{2}}$ & \\
\hline 10 & $\mathrm{O}_{2}+\mathrm{e}^{-} \rightarrow \mathrm{O}\left({ }^{3} \mathrm{P}\right)+\mathrm{O}^{-}$ & $\mathrm{O}_{2}$ dissociation, diss. 2 & $k_{\mathrm{D} 2 \mathrm{O}_{2}}$ & \\
\hline 11 & $\mathrm{O}^{-}+\mathrm{e}^{-} \rightarrow \mathrm{O}\left({ }^{3} \mathrm{P}\right)+2 \mathrm{e}^{-}$ & $\mathrm{O}^{-}$recombination with $\mathrm{e}^{-}$, rec. 1 & $k_{\mathrm{RlOM}}$ & \\
\hline 12 & $\mathrm{O}_{2}^{+}+\mathrm{e}^{-} \rightarrow 2 \mathrm{O}$ & $\mathrm{O}_{2}^{+}$dissociative recomb. & $k_{\mathrm{DRO}_{2} \mathrm{P}}$ & \\
\hline \multicolumn{5}{|c|}{ Heavy particle collision: deexcitation (rates in $\mathrm{cm}^{3} \mathrm{~s}^{-1}$ ) } \\
\hline 13 & $\mathrm{O}_{2}+\mathrm{O}\left({ }^{1} \mathrm{D}\right) \rightarrow \mathrm{O}_{2}+\mathrm{O}\left({ }^{3} \mathrm{P}\right)$ & $\mathrm{O}\left({ }^{1} \mathrm{D}\right)$ deexcitation with $\mathrm{O}_{2}$ & $k_{\mathrm{O}_{2} \mathrm{OD}}$ & \\
\hline \multicolumn{5}{|c|}{ Heavy particle collision: recombination (rates in $\mathrm{cm}^{3} \mathrm{~s}^{-1}$ ) } \\
\hline 14 & $\mathrm{O}^{-}+\mathrm{O}^{+} \rightarrow 2 \mathrm{O}\left({ }^{3} \mathrm{P}\right)$ & $\mathrm{O}^{-}$recombination with $\mathrm{O}^{+}$, rec. 2 & $k_{\mathrm{R} 2 \mathrm{OM}}$ & \\
\hline 15 & $\mathrm{O}^{-}+\mathrm{O}_{2}^{+} \rightarrow \mathrm{O}\left({ }^{3} \mathrm{P}\right)+\mathrm{O}_{2}$ & $\mathrm{O}^{-}$recombination with $\mathrm{O}_{2}^{+}$, rec. 3 & $k_{\mathrm{R} 3 \mathrm{OM}}$ & \\
\hline 16 & $\mathrm{O}^{-}+\mathrm{O} \rightarrow \mathrm{O}_{2}+\mathrm{e}^{-}$ & $\mathrm{O}^{-}$recombination with $\mathrm{O}$, rec. 4 & $k_{\mathrm{R} 4 \mathrm{OM}}$ & \\
\hline \multicolumn{5}{|c|}{ Reactions on the wall (rates in $\mathrm{s}^{-1}$ ) } \\
\hline 17 & $\mathrm{O}_{2}^{+} \stackrel{\text { wall }}{\longrightarrow} \mathrm{O}_{2}$ & $\mathrm{O}_{2}$ recombination on the wall & $k_{\mathrm{RWO}_{2}}$ & \\
\hline 18 & $\mathrm{O}^{+} \stackrel{\text { wall }}{\longrightarrow} \mathrm{O}\left({ }^{3} \mathrm{P}\right)$ & O recombination on the wall & $k_{\mathrm{RWO}}$ & \\
\hline 19 & $\mathrm{O}\left({ }^{1} \mathrm{D}\right) \stackrel{\text { wall }}{\longrightarrow} \mathrm{O}\left({ }^{3} \mathrm{P}\right)$ & $\mathrm{O}\left({ }^{1} \mathrm{D}\right)$ deexcitation on the wall & $k_{\mathrm{DXWOD}}$ & \\
\hline 20 & $\mathrm{O}\left({ }^{3} \mathrm{P}\right) \stackrel{\text { wall }}{\longrightarrow}(1 / 2) \mathrm{O}_{2}$ & $\mathrm{O}_{2}$ formation on the wall & $k_{\mathrm{FWO}_{2}}$ & \\
\hline 21 & $\mathrm{O}\left({ }^{1} \mathrm{D}\right) \stackrel{\text { wall }}{\longrightarrow}(1 / 2) \mathrm{O}_{2}$ & $\mathrm{O}_{2}$ formation on the wall & $k_{\mathrm{FWO}_{2}}$ & \\
\hline
\end{tabular}

TABLE 5: Reactions between nitrogen and oxygen species considered in the $\mathrm{N}_{2} \mathrm{O}$ plasma kinetic system.

\begin{tabular}{|c|c|c|c|}
\hline No. & Process & Description & Rate \\
\hline \multicolumn{4}{|c|}{$\mathrm{O}^{-}$recombination with $\mathrm{N}_{2}(\nu)$ (rates in $\mathrm{cm}^{3} \mathrm{~s}^{-1}$ ) } \\
\hline 1 & $\mathrm{~N}_{2}(\nu=4-5)+\mathrm{O}^{-} \rightarrow \mathrm{N}_{2}(\nu=0)+\mathrm{O}$ & $\mathrm{O}^{-}$recombination with $\mathrm{N}_{2}(\nu)$ & $k_{\mathrm{RN}_{2} \mathrm{OM}}$ \\
\hline \multicolumn{4}{|c|}{ Neutralization (rates in $\mathrm{cm}^{3} \mathrm{~s}^{-1}$ ) } \\
\hline 2 & $\mathrm{~N}_{2}^{+}+\mathrm{O}^{-} \rightarrow \mathrm{N}_{2}+\mathrm{O}\left({ }^{3} \mathrm{P}\right)$ & $\mathrm{N}_{2}^{+}$neutralization with $\mathrm{O}^{-}$ & $k_{\mathrm{R} 3 \mathrm{OM}}$ \\
\hline \multicolumn{4}{|c|}{ Heavy particle collisions: deexcitation (rates in $\mathrm{cm}^{3} \mathrm{~s}^{-1}$ ) } \\
\hline 3 & $\mathrm{~N}_{2}+\mathrm{O}\left({ }^{1} \mathrm{D}\right) \rightarrow \mathrm{N}_{2}+\mathrm{O}\left({ }^{3} \mathrm{P}\right)$ & $\mathrm{O}\left({ }^{1} \mathrm{D}\right)$ deexcitation with $\mathrm{N}_{2}$ & $k_{\mathrm{N}_{2} \mathrm{OD}}$ \\
\hline
\end{tabular}

of $6 \mathrm{eV}$ but a rather big discrepancy for $3 \mathrm{eV}$. Figure 3 clearly illustrates that the data for reaction no. 2 of $\mathrm{N}_{2} \mathrm{O}$ are badly known. Using the relative magnitude of the rates of reaction no. 3 in comparison with reaction no. 2 , a cross section seven times lower was used in [23], while a rate coefficient factor of one order of magnitude is mentioned in [7] and a rate of about three times lower is used in [10]. In the present work, in order to evaluate the rate of the dissociative excitation, reaction no. 3 in Table 2, we shifted the cross section threshold of reaction no. 2 of about $2 \mathrm{eV}$ which is the difference between the two levels excitation energies, before integration over a Maxwellian distribution, keeping the same value of cross section. The so obtained result is also shown in Figure 3.

3.3. $\mathrm{N}_{2} \mathrm{O}$ Dissociation Leading to $\mathrm{NO}$ and $\mathrm{N}$. For the electron impact dissociation of $\mathrm{N}_{2} \mathrm{O}$, reaction no. 4 of Table 2 , a cross section is provided in [23]. After integrating it, comparison with the rate coefficient values given in Shutov et al. [7], also coming from a formula based on [38] cross section, shows a significant discrepancy. This comparison is illustrated in Figure 4. Values of Cleland and Hess [38] for $3 \mathrm{eV}$ and $6 \mathrm{eV}$ are also shown in Figure 4. We see that values of [7] are generally 


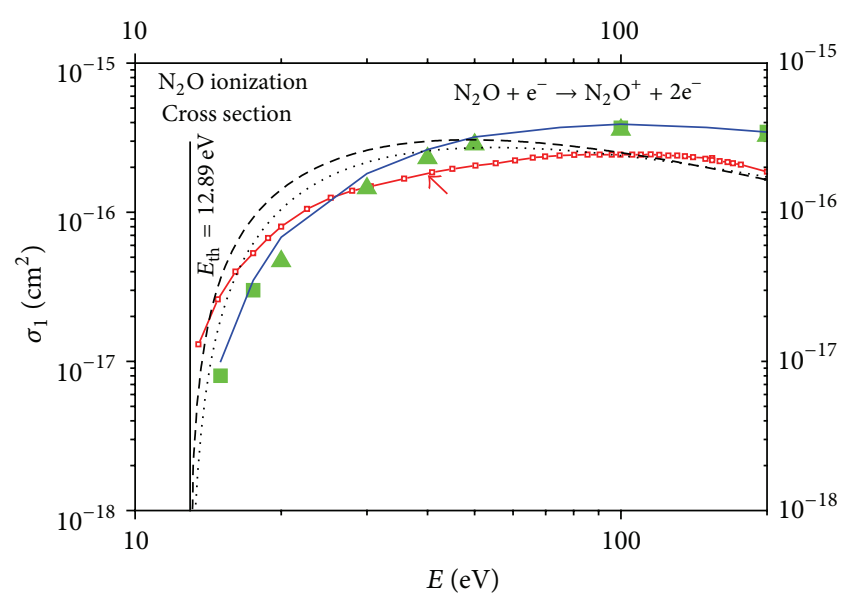

— Kim et al., J. Chem. Phys. 106 3, 1997 (BEB)

$-\square-$ Exp. and Param. Dupljanin et al., Plasma Sources Sci Technol 19 02005, 2010

- Exp. Rapp and Englander-Golden, J. Chem. Phys. 43 1464, 1965 (from Kim et al. 1997)

$\Delta$ Exp. Iga et al., J. Geophys. Res. 101 9261, 1996 (from Kim et al. 1997)

- - - Deutsch-Märk formula

2 -param formula $(\alpha=1 ., \beta=0.8, \xi=4)$

Figure 2: Comparison of the $\mathrm{N}_{2} \mathrm{O}$ ionization cross sections.

in disagreement with ours, except for $3 \mathrm{eV}$, where the curves of the two sets of data cross. Rate value of [38] is identical to our for a $T_{e}$ of $6 \mathrm{eV}$.

3.4. $\mathrm{N}_{2} \mathrm{O}$ Dissociative Attachment. For the dissociative attachment, reaction no. 5 of Table 2, cross section calculated by Chaney and Christophorou [44] as reported in Christophorou and Olthoff [29] has been followed by a recent experimental evaluation from Dupljanin et al. [26]. We integrated the cross section provided by [26] valid for $273 \mathrm{~K}$ over a maxwellian distribution. Note that contribution of the excited states is included in the cross sections of $[26,29]$. As the provided cross sections correspond to defined gas temperatures ( $273 \mathrm{~K}$ for [26] and $295 \mathrm{~K}$ to $1040 \mathrm{~K}$ for [29]), to obtain values for $T_{\mathrm{GAS}}=300 \mathrm{~K}$ and $500 \mathrm{~K}$, we followed the theoretical data of [29]. We find a big discrepancy with the rate given by Shutov et al. [7], who integrated the cross section of Younis et al. [45] to obtain values in the $T_{e}$ range from 2.4 to $2.8 \mathrm{eV}$ represented by a simple slope. Our evaluation suggests that the cross section from [45] and, accordingly, also the rate given by Shutov et al. [7] may be underestimated up to two orders of magnitude. Comparison of rates obtained from cross sections from $[26,29]$ for $300 \mathrm{~K}$ is shown in Figure 5, together with values for $T_{\mathrm{GAS}}=500 \mathrm{~K}$ which we also used.

3.5. $\mathrm{N}_{2} \mathrm{O}$ Dissociation by Collision with $\mathrm{O}\left({ }^{1} \mathrm{D}\right)$. For reactions nos. 6 and 7 of Table 2, we used the rate values from Kossyi et al. [40] which are very close to previous experimental values of Atkinson et al. [46]. These values from [40] were

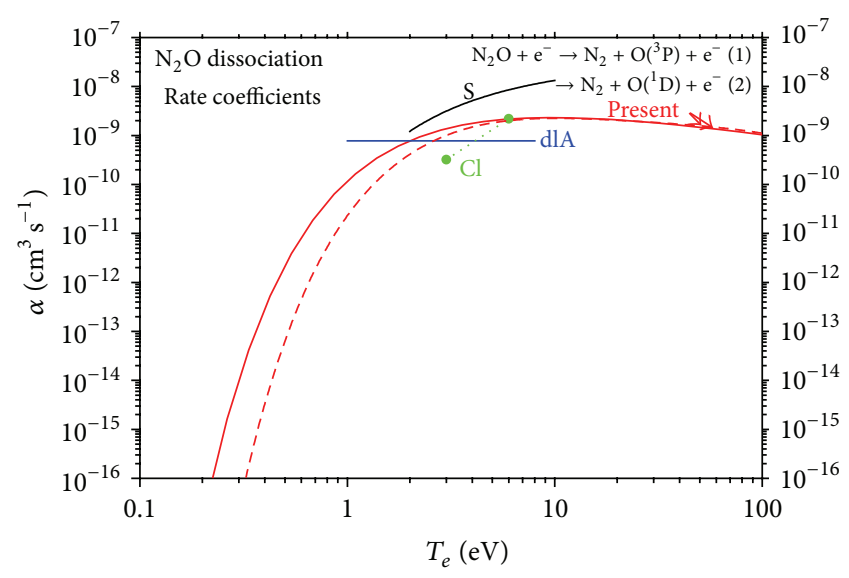

Present work: (red)

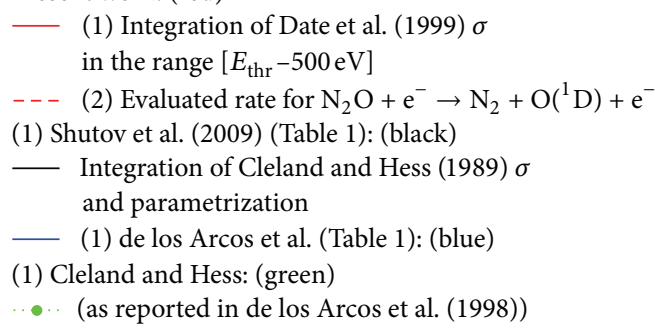

FIgUre 3: Rate coefficients of the $\mathrm{N}_{2} \mathrm{O}$ dissociation leading to $\mathrm{N}_{2}$ plus $\mathrm{O}$ products.

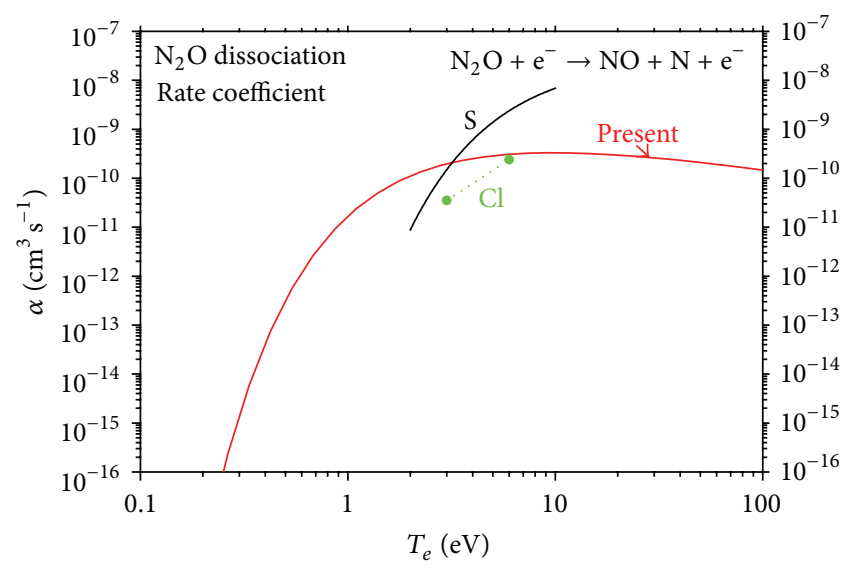

$$
\begin{aligned}
& \text { Present work: (red) } \\
& \quad \text { Integration of Date et al. (1999) } \sigma \\
& \text { cross section in the range [ } \left.E_{\mathrm{thr}}-500 \mathrm{eV}\right] \\
& \text { Shutov et al. (2009) (Table 1): (black) } \\
& \text { Cleland and Hess: (green) } \\
& \text { Formula based on Cleland and Hess (1989) } \sigma \\
& \text { (as reported in de los Arcos et al. (1998)) }
\end{aligned}
$$

FIGURE 4: Rate coefficient of the $\mathrm{N}_{2} \mathrm{O}$ dissociation leading to $\mathrm{NO}$ plus $\mathrm{N}$ products.

used instead of those proposed in [7]. They are also shown in Figure 5.

3.6. NO Rearrangement. For the NO rearrangement reaction with N, no. 8 of Table 2, we used data proposed in [40]. Rates fitted by Shutov et al. [7] to the values of Gamallo et al. [39] 


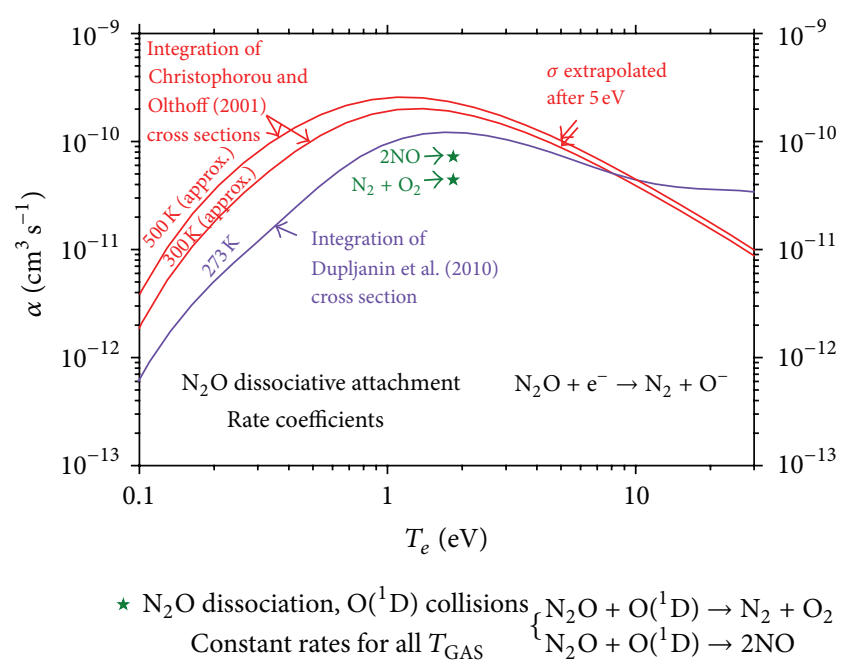

FIgURE 5: Rate coefficients of the $\mathrm{N}_{2} \mathrm{O}$ dissociative attachment and of the $\mathrm{N}_{2} \mathrm{O}$ dissociation, $\mathrm{O}\left({ }^{1} \mathrm{D}\right)$ collisions.

in the range of $200 \mathrm{~K}$ to $5000 \mathrm{~K}$ are very comparable with the values of [40] that we used. For the NO rearrangement reaction with $\mathrm{O}$, no. 9 of Table 2 , we also used the rates coming from [40].

3.7. Neutralizations of $\mathrm{O}^{-}$by $\mathrm{N}_{2} \mathrm{O}^{+}, \mathrm{N}_{2}{ }^{+}$, and $\mathrm{O}_{2}{ }^{+}$. For the $\mathrm{N}_{2} \mathrm{O}^{+}$neutralization process no. 10 of Table 2 , it is possible to use the rate given by Shutov et al. [7], also coming from [40]. The same value is proposed also for $\mathrm{N}_{2}{ }^{+}$and $\mathrm{O}_{2}{ }^{+}$species neutralization. However, we preferred to adopt the more recent value proposed in [47] and reported in [1] for $\mathrm{O}_{2}{ }^{+}$. The same value was used also for the other two neutralization reactions with $\mathrm{N}_{2}^{+}$and $\mathrm{N}_{2} \mathrm{O}^{+}$.

3.8. $\mathrm{N}_{2}$ and $\mathrm{O}_{2}$ Ionization. For the ionization of $\mathrm{N}_{2}$ and of $\mathrm{O}_{2}$, reactions nos. 1 of Table 3 and of Table 4 , respectively, we integrated the experimental cross sections of Armentrout et al. [48] coming from Christophorou and Olthoff [29] for the $\mathrm{N}_{2}$ and this of Straub et al. for the $\mathrm{O}_{2}$ [49]. Existing experimental values from other sources, both for $\mathrm{N}_{2}$ and $\mathrm{O}_{2}$, are in very good agreement with the ones we used. For the ionization from $\mathrm{N}_{2}$ vibrational levels, we calculated the rates according to a procedure which was also used in the following case of the $\mathrm{N}_{2}$ dissociation.

3.9. $\mathrm{N}_{2}$ Dissociation. Dissociation of $\mathrm{N}_{2}$ molecules by electron impact, reactions no. 2 and nos. 19-23 of Table 3, was included in our model by integrating the cross section of Cosby [24]. We considered that the main dissociation channel leads to a mixture of the $\mathrm{N}\left({ }^{3} \mathrm{P}\right)$ and $\mathrm{N}\left({ }^{1} \mathrm{D}\right)$ products even if the latter level was not explicitly introduced. To evaluate the dissociation (and ionization) from the vibrational states we displaced the cross section for $v=0$ both in energy and magnitude. The factors used for the shift in magnitude are given in column $E_{\gamma=0}^{D} / E_{\gamma=i}^{D}$ of Table 8 .
3.10. $\mathrm{N}_{2}$ Vibrational Excitation. For the excitation from $\mathrm{N}_{2}(\nu=0)$ to the vibrational state $v=1$, reaction no. 4 of Table 3, we used the experimental cross section values from Itikawa [33] measured by Brunger et al. [50]. For the excitations from $v=0$ to $v=2$ to 5 , reactions nos. 5 to 8 of Table 3 , we shifted the excitation cross section of $\nu=0$ to $v=1$ both in energy and in magnitude. The parameters of the shift were based on the maximum values of the cross sections of Phelps and Pitchford [31]. The obtained cross sections were integrated over Maxwellian distribution as well as the cross sections from [31] to obtain the corresponding rate coefficients. Rates obtained by this evaluation were slightly higher than the ones obtained from the integration of the cross sections given by Phelps and Pitchford [31].

3.11. N Ionization. For the electron collision ionization of $\mathrm{N}$, the cross section for $\mathrm{N}\left({ }^{4} \mathrm{~S}\right)$, the first GL, was used only in the energy loss calculation described in Section 4. It was evaluated and parameterized using the Drawin formula [43] duly adapted and subsequently integrated to obtain the ionization rates. However, in the kinetic system, we used the cross section given by Kim and Desclaux [32] for a mixture of about $70 \%$ of $\mathrm{N}\left({ }^{4} \mathrm{~S}\right)$ and $30 \%$ of $\mathrm{N}\left({ }^{2} \mathrm{D}\right)$. This cross section leads to higher values for the ionization rate. Using this value instead of the one for $\mathrm{N}\left({ }^{4} \mathrm{~S}\right)$ leads to pure $\mathrm{N}_{2}$ discharge results in rather good agreement with those of the literature [12, 17], where the level ${ }^{4} \mathrm{~S},{ }^{2} \mathrm{D},{ }^{2} \mathrm{P}$ were explicitly introduced.

3.12. $\mathrm{O}_{2}$ Dissociation. For oxygen dissociation, processes nos. 6-9 of Table 4 , the rate coefficients were taken from Lieberman and Lichtenberg [1], a selection encompassing rates from various sources. Although they were originally recommended for the range of $1 \mathrm{eV}$ to $7 \mathrm{eV}$, we used those values also for higher energies.

3.13. $\mathrm{O}_{2}$ Dissociative Attachment. To obtain the rates related to process no. 10 of Table 4, we integrated the cross section of Christophorou and Olthoff [29] for $T_{\mathrm{GAS}}=300 \mathrm{~K}$ which results from the theoretical work of O'Malley [51] and the experimental results of Henderson et al. [52]. We also shifted this cross section to obtain a second value applicable for $500 \mathrm{~K}$. We used the first one in applying our model in the case of the discharge studied by de los Arcos et al. [10] (Section 6) and the second one for the application tackled by Shutov et al. [7] study (Section 5) and for the propulsion applications of Section 8. In Figure 6, the rate coefficients which we obtained for $300 \mathrm{~K}$ and $500 \mathrm{~K}$ are compared to the values given in $[1,14]$.

3.14. Recombination by Electronic Collision $/ \mathrm{O}_{2}{ }^{+}$Dissociative Recombination $/ \mathrm{O}\left({ }^{1} \mathrm{D}\right)$ Deexcitation by $\mathrm{O}_{2}$ Collision. For reactions nos. 11-13 of Table 4, we used the rates given in [1].

3.15. $\mathrm{O}^{+}$and $\mathrm{O}_{2}^{+}$Neutralization. For neutralization rates, processes no. 14 and 15 of Table 4, two sets of data exist. The first set, given by Gudmundsson et al. in 2000 [53], is very similar to the one used in Gudmundsson et al. 2001 [14] and is 


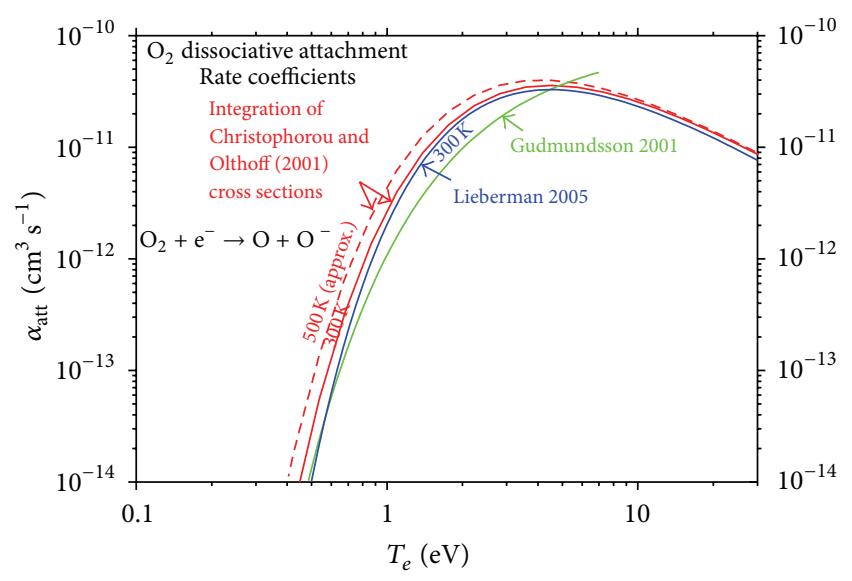

Present work, integration of cross sections:

_ Christophorou and Olthoff (2001) for $300 \mathrm{~K}$

- - - Value assumed for $500 \mathrm{~K}$

Comparison with formulas from the literature:

_ Lieberman and Lichtenberg (2005) for $300 \mathrm{~K}$

_ Gudmundsson et al. (2001)

FIGURE 6: $\mathrm{O}_{2}$ dissociative attachment rate coefficients.

in good agreement with values proposed by Kossyi et al. [40]. The second, proposed later by Gudmundsson and Lieberman in 2004 [47] and used in the $\mathrm{Ar} / \mathrm{O}_{2}$ model in 2007 [15], is reported in [1]. The second set is based on experimental values of Hayton and Peart [54] and of Padgett and Peart [55] and it is about one order of magnitude lower than the first. Evidently, the first set gives electronegativity values much lower than the second one, especially for a pressure around 10 mTorr. In the present model, we use the most recent values reported in [1].

3.16. $\mathrm{O}^{-}$Recombination on $\mathrm{N}_{2}(\nu=4,5)$. We introduced reaction no. 1 of Table $5, \mathrm{~N}_{2}(\nu)+\mathrm{O}^{-} \rightarrow \mathrm{N}_{2}+\mathrm{O}+\mathrm{e}^{-}$, as an inverse process of reaction no. 5 of Table $2, \mathrm{~N}_{2} \mathrm{O}+\mathrm{e}^{-} \rightarrow \mathrm{N}_{2}+$ $\mathrm{O}^{-}$. In the literature, some rates are proposed for reaction $\mathrm{N}_{2}{ }^{*}$ $+\mathrm{O}^{-} \rightarrow \mathrm{N}_{2}+\mathrm{O}+\mathrm{e}^{-}$, where $\mathrm{N}_{2}{ }^{*}$ is an electronically excited state. As we did not introduce electronically excited states of $\mathrm{N}_{2}$ in the kinetic system, we made the arbitrary choice of involving the higher vibrational levels $\nu=4,5$ in this reaction. However, we introduced an invariable rate coefficient $k=$ $2 \cdot 10^{-11} \mathrm{~cm}^{3} \mathrm{~s}^{-1}$ instead of the value $k=2.2 \cdot 10^{-9} \mathrm{~cm}^{3} \mathrm{~s}^{-1}$ proposed by Kossyi et al. [40] for the excited $\mathrm{N}_{2}(\mathrm{~A})$ state. This value was chosen estimating that about $10 \%$ of $\mathrm{N}_{2}$ species are in the levels $v=4,5$, and about $0.1 \%$ of $\mathrm{N}_{2}$ species are in electronically excited states.

No reaction was included for $\mathrm{O}_{2}{ }^{*}+\mathrm{O}^{-} \rightarrow \mathrm{O}_{3}+\mathrm{e}^{-}$nor for $\mathrm{O}_{2}{ }^{*}+\mathrm{O}^{-} \rightarrow \mathrm{O}_{2}+\mathrm{O}+\mathrm{e}^{-}$as these reactions are expected to be negligible for pressures lower than 100 mTorr.

3.17. $O\left({ }^{1} D\right)$ Deexcitation on $N_{2}(\nu=0)$. For reaction no. 3 of Table 5 , we used a rate coefficient $k=4 \cdot 10^{-11}$. $\exp \left(107 / T_{\mathrm{GAS}}\right) \mathrm{cm}^{3} \mathrm{~s}^{-1}$ exclusively for the level $\mathrm{N}_{2}(\nu=0)$. We estimate that introducing this rate for $\mathrm{N}_{2}(\nu=0)$ species compensates the introduction of a rate $k=1.8$.
TABLE 6: $\mathrm{N}_{2} \mathrm{O}$ excited levels considered in the $\mathrm{N}_{2} \mathrm{O}$ energy loss $\varepsilon_{C, \mathrm{~N}_{2} \mathrm{O}}$ calculation.

\begin{tabular}{lccc}
\hline Vibrational level & $E^{(*)}(\mathrm{eV})$ & Electronic level & $E^{(*)}(\mathrm{eV})$ \\
\hline $\mathrm{X}^{1} \Sigma_{g}{ }^{+}(\nu=0)$ & 0.000 & $\mathrm{~A}^{3} \Sigma_{u}{ }^{+}$ & 4.00 \\
$\mathrm{X}^{1} \Sigma_{g}{ }^{+}(\nu=1)$ & 0.073 & $\mathrm{~B}^{3} \Pi_{g}$ & 8.50 \\
$\mathrm{X}^{1} \Sigma_{g}{ }^{+}(\nu=2)$ & 0.159 & $\mathrm{C}^{3} \Pi_{u}$ & 9.60 \\
$\mathrm{X}^{1} \Sigma_{g}{ }^{+}(\nu=3)$ & 0.276 & & \\
\hline
\end{tabular}

${ }^{(*)}$ Energy values are those given in [26].

$10^{-11} \cdot \exp \left(107 / T_{\mathrm{GAS}}\right) \mathrm{cm}^{3} \mathrm{~s}^{-1}$ for all the $\mathrm{N}_{2}$ species without distinction of their vibrational state as was recommended by Kossyi et al. [40]. Note that de los Arcos et al. [10] have used a constant rate of $k=2.0 \cdot 10^{-11} \mathrm{~cm}^{3} \mathrm{~s}^{-1}$ which is near to the value of [40].

3.18. Recombination and Reformation on the Wall. Recombination of positive ions $\mathrm{N}_{2} \mathrm{O}^{+}, \mathrm{N}_{2}{ }^{+}, \mathrm{O}_{2}{ }^{+}, \mathrm{N}^{+}$, and $\mathrm{O}^{+}$on the wall was estimated by means of the effective rate coefficient of the heterogeneous decay of positive ions, as described in detail in [1] and also briefly mentioned by Shutov et al. [7]. For evaluating the $\mathrm{N}_{2}$ and $\mathrm{O}_{2}$ formation on the wall, reactions nos. 25 of Table 3 and nos. 20-21 of Table 4, we used the wall recombination formula $\kappa=\left[\Lambda^{2} / D+2 V(2-\gamma) / A \nu \gamma\right]^{-1}$ from [15].

\section{Structure, Excitation, Elastic Collisions, and Collisional Energy Loss of the Main $\mathrm{N}_{2} \mathrm{O}$ Plasma Constituents: $\mathrm{N}_{2} \mathrm{O}, \mathrm{N}_{2}, \mathrm{O}_{2}, \mathrm{~N}$, and $\mathrm{O}$}

We address here particularly the structure of the main plasma constituents, elastic collisions, and excitations and the calculation of their collisional energy losses. Rates of ionization, a key process for collisional energy losses, were already addressed in Section 3.

4.1. $\mathrm{N}_{2} \mathrm{O}$ Electronic and Vibrational Excitation. Let us consider the main states of the $\mathrm{N}_{2} \mathrm{O}$ molecule $\left(X^{1} \Sigma_{g}{ }^{+}\right)$with its first ionization state $\mathrm{N}_{2} \mathrm{O}^{+}\left(X^{2} \Sigma_{g}^{+}\right)$. These are included in the $\mathrm{PaBE}$ as separate species. Six excited states of $\mathrm{N}_{2} \mathrm{O}$ were introduced for the evaluation of the corresponding energy loss coefficient $\varepsilon_{C}$, appearing in the PoBE. They consist in three vibrationally excited states plus three electronically excited states mentioned by Dupljanin et al. [26] see Table 6 . The ionization energy of the ground level $X^{1} \Sigma_{g}^{+}(\nu=0)$ is $12.894 \mathrm{eV}$ according to [26]. The excitation energies coming also from [26] are given in Table 6.

Electronic and vibrational excitation rates of $\mathrm{N}_{2} \mathrm{O}$ molecules were obtained by integration over a Maxwellian distribution of the cross sections compiled in [26]. The elastic collision rate, to be also added in the $\varepsilon_{C, \mathrm{~N}_{2} \mathrm{O}}$ evaluation, was based on the total elastic scattering cross section given in [29] which was also integrated over a Maxwellian distribution. We also calculated dissociation and ionization rates which must be included in the $\varepsilon_{{\mathrm{C}, \mathrm{N}_{2} \mathrm{O}}}$ calculation on the basis of the cross sections addressed previously (nos. 1-3 in Table 2). 
TABLE 7: List of additional $\mathrm{N}_{2} \mathrm{O}$ reactions used only in the $\varepsilon_{C, \mathrm{~N}_{2} \mathrm{O}}$ calculation.

\begin{tabular}{|c|c|c|}
\hline No. & Process & Description \\
\hline 1 & $\mathrm{~N}_{2} \mathrm{O}+\mathrm{e}^{-} \rightarrow \mathrm{N}_{2} \mathrm{O}+\mathrm{e}^{-}$ & $\mathrm{N}_{2} \mathrm{O}$ elastic collisions \\
\hline 2 & $\mathrm{~N}_{2} \mathrm{O}(\mathrm{X}, v=0)+\mathrm{e}^{-} \rightarrow \mathrm{N}_{2} \mathrm{O}(\mathrm{X}, v=1)+\mathrm{e}^{-}$ & $\mathrm{N}_{2} \mathrm{O}$ vibrational excitation 1 \\
\hline 3 & $\mathrm{~N}_{2} \mathrm{O}(\mathrm{X}, v=0)+\mathrm{e}^{-} \rightarrow \mathrm{N}_{2} \mathrm{O}(\mathrm{X}, v=2)+\mathrm{e}^{-}$ & $\mathrm{N}_{2} \mathrm{O}$ vibrational excitation 2 \\
\hline 4 & $\mathrm{~N}_{2} \mathrm{O}(\mathrm{X}, v=0)+\mathrm{e}^{-} \rightarrow \mathrm{N}_{2} \mathrm{O}(\mathrm{X}, v=3)+\mathrm{e}^{-}$ & $\mathrm{N}_{2} \mathrm{O}$ vibrational excitation 3 \\
\hline 5 & $\mathrm{~N}_{2} \mathrm{O}(\mathrm{X})+\mathrm{e}^{-} \rightarrow \mathrm{N}_{2} \mathrm{O}\left(\mathrm{A}^{3} \Sigma_{u}^{+}\right)+\mathrm{e}^{-}$ & $\mathrm{N}_{2} \mathrm{O}$ electronic excitation to $\mathrm{A}^{3} \Sigma_{u}^{+}$ \\
\hline 6 & $\mathrm{~N}_{2} \mathrm{O}(\mathrm{X})+\mathrm{e}^{-} \rightarrow \mathrm{N}_{2} \mathrm{O}\left(\mathrm{B}^{3} \Pi_{g}\right)+\mathrm{e}^{-}$ & $\mathrm{N}_{2} \mathrm{O}$ electronic excitation to $\mathrm{B}^{3} \Pi_{g}$ \\
\hline 7 & $\mathrm{~N}_{2} \mathrm{O}(\mathrm{X})+\mathrm{e}^{-} \rightarrow \mathrm{N}_{2} \mathrm{O}\left(\mathrm{C}^{3} \Pi_{u}\right)+\mathrm{e}^{-}$ & $\mathrm{N}_{2} \mathrm{O}$ electronic excitation to $\mathrm{C}^{3} \Pi_{u}$ \\
\hline
\end{tabular}

TABLE 8: List of the $\mathrm{N}_{2}$ states considered in the $\varepsilon_{c}$ calculation. Level descriptions from Itikawa [33]. All energies are in $\mathrm{eV}$.

\begin{tabular}{|c|c|c|c|c|c|c|c|c|}
\hline Level & $E^{X, \text { Allan }}$ & $E^{X, \text { Hasted }}$ & $E^{X, \text { Phelps(1) }}$ & $E^{X, \operatorname{Phelps}(2)}$ & $E^{D,(\text { Cosby })}$ & $E_{\gamma=0}^{D} / E_{\gamma=i}^{D}$ & $E^{I,(\text { Hasted })}$ & $E_{\gamma=0}^{I} / E_{\gamma=i}^{I}$ \\
\hline $\mathrm{X}^{1} \Sigma_{g}^{+}(\nu=0)$ & & & & & 9.7537 & 1.00 & 15.581 & 1.00 \\
\hline $\mathrm{X}^{1} \Sigma_{g}^{+}(\nu=1)$ & 0.29 & & 0.29 & $1.65 / 0.29^{(3)}$ & $9.46^{*}$ & 1.03 & $15.291^{*}$ & 1.02 \\
\hline $\mathrm{X}^{1} \Sigma_{g}^{+}(\nu=2)$ & 0.58 & & 0.59 & 1.80 & $9.17^{*}$ & 1.06 & $15.001^{*}$ & 1.04 \\
\hline $\mathrm{X}^{1} \Sigma_{g}^{+}(\nu=3)$ & 0.85 & & 0.88 & 2.00 & $8.90^{*}$ & 1.10 & $14.731^{*}$ & 1.06 \\
\hline $\mathrm{X}^{1} \Sigma_{g}^{+}(\nu=4)$ & 1.15 & & 1.17 & 2.10 & $8.60^{*}$ & 1.13 & $14.431^{*}$ & 1.08 \\
\hline $\mathrm{X}^{1} \Sigma_{g}^{+}(\nu=5)$ & 1.42 & & 1.47 & 2.20 & $8.33^{*}$ & 1.17 & $14.161^{*}$ & 1.10 \\
\hline $\mathrm{X}^{1} \Sigma_{g}{ }^{+}(\nu=6)$ & 1.69 & & 1.76 & 2.30 & & & & \\
\hline $\mathrm{X}^{1} \Sigma_{g}^{+}(\nu=7)$ & 1.95 & & 2.06 & 2.40 & & & & \\
\hline $\mathrm{X}^{1} \Sigma_{g}^{+}(\nu=8)$ & 2.20 & & 2.35 & 2.60 & & & & \\
\hline $\mathrm{A}^{3} \Sigma_{u}^{+}(\nu=0)$ & & 6.15 & & & & & & \\
\hline $\mathrm{A}^{3} \Sigma_{u}^{+}(\nu=0-4)$ & & & 6.17 & 7.00 & & & & \\
\hline $\mathrm{B}^{3} \Pi_{g}$ & & 7.20 & 7.35 & 8.00 & & & & \\
\hline $\mathrm{W}^{3} \Delta_{u}$ & & 7.35 & 7.36 & 7.30 & & & & \\
\hline $\mathrm{A}^{3} \Sigma_{u}^{+}(\nu=5-9)$ & & & 7.00 & 8.10 & & & & \\
\hline $\mathrm{A}^{3} \Sigma_{u}^{+}(\nu=10)$ & & & 7.80 & 9.00 & & & & \\
\hline $\mathrm{B}^{\prime 3} \Sigma_{u}^{-}$ & & 8.00 & 8.16 & 9.00 & & & & \\
\hline $\mathrm{a}^{\prime 1} \Sigma_{u}^{-}$ & & 8.20 & 8.40 & 9.00 & & & & \\
\hline $\mathrm{a}^{1} \Pi_{g}$ & & 8.40 & 8.55 & 9.00 & & & & \\
\hline $\mathrm{w}^{1} \Delta_{u}$ & & 8.70 & 8.89 & 9.00 & & & & \\
\hline $\mathrm{C}^{3} \Pi_{u}$ & & 10.90 & 11.03 & 11.50 & & & & \\
\hline$E^{3} \Sigma_{g}^{+}$ & & 11.85 & 11.87 & 11.92 & & & & \\
\hline $\mathrm{a}^{\prime \prime 1} \Sigma_{g}^{+}$ & & & 12.25 & 13.00 & & & & \\
\hline
\end{tabular}

No more dissociation and attachment have been included in the $\varepsilon_{C, N_{2} \mathrm{O}}$ calculation, because we verified that their influence is unimportant for the overall $\varepsilon_{C, N_{2} \mathrm{O}}$ value. Cross sections integrations were made in general in the energy range from threshold up to $500 \mathrm{eV}$, for the ionization and electronic excitation. Whenever the cross sections are quickly falling to negligible values, the integration was restricted to a shorter range. This is the case for the elastic and vibrational cross sections. We estimate that the obtained rates lead to $\varepsilon_{C, \mathrm{~N}_{2} \mathrm{O}}$ values valid from $0.2 \mathrm{eV}$ up to to $100 \mathrm{eV}$.

The list of additional reactions involved in the $\varepsilon_{C, N_{2} \mathrm{O}}$ calculation is shown in Table 7. Adding reactions of this Table 7 to those contained in Table 2 marked with a star, we obtain a set to be compared with Table 1 of Younis et al. [45]. Four dissociations giving excited species are contained in the latter table instead of two given in our case.

4.2. $N_{2}, N$ Main Nitrogen Compounds. Special care was taken for the evaluation of molecular nitrogen data, as $\mathrm{N}_{2}$ was found to be predominantly created in the $\mathrm{N}_{2} \mathrm{O}$ plasma discharge, at least in the studied conditions (ii) and (iii) described in Section 5, in which the $\mathrm{N}_{2} \mathrm{O}$ dissociation is sustained. In so doing, the GL state of the neutral $\mathrm{N}_{2}\left(X^{1} \Sigma_{g}{ }^{+}\right)$, including its first vibrationally excited $(\nu=1-5)$ states and its first ion in the ground state $\mathrm{N}_{2}{ }^{+}\left(X^{2} \Sigma_{g}{ }^{+}\right)$, was included in the $\mathrm{PaBE}$. Also, the first GL of the neutral atomic nitrogen 
TABLE 9: Additional processes involving the $\mathrm{N}_{2}$ species (only for $\varepsilon_{C, \mathrm{~N}_{2}}$ calculation).

\begin{tabular}{lll}
\hline No. & Process & Description \\
\hline 1 & $\mathrm{~N}_{2}+\mathrm{e}^{-} \rightarrow \mathrm{N}_{2}+\mathrm{e}^{-}$ & $\mathrm{N}_{2}$ elastic collisions \\
2 & $\mathrm{~N}_{2}(\mathrm{X}, v=0)+\mathrm{e}^{-} \rightarrow \mathrm{N}_{2}(\mathrm{X}, v=6)+\mathrm{e}^{-}$ & $\mathrm{N}_{2}$ vibrational excitation 6 \\
3 & $\mathrm{~N}_{2}(\mathrm{X}, v=0)+\mathrm{e}^{-} \rightarrow \mathrm{N}_{2}(\mathrm{X}, v=7)+\mathrm{e}^{-}$ & $\mathrm{N}_{2}$ vibrational excitation 7 \\
4 & $\mathrm{~N}_{2}(\mathrm{X}, v=0)+\mathrm{e}^{-} \rightarrow \mathrm{N}_{2}(\mathrm{X}, v=8)+\mathrm{e}^{-}$ & $\mathrm{N}_{2}$ vibrational excitation 8 \\
5 & $\mathrm{~N}_{2}(\mathrm{X})+\mathrm{e}^{-} \rightarrow \mathrm{N}_{2}(\mathrm{~A})+\mathrm{e}^{-}$ & $\mathrm{N}_{2}$ A excitation, in three parts \\
6 & $\mathrm{~N}_{2}(\mathrm{X})+\mathrm{e}^{-} \rightarrow \mathrm{N}_{2}(\mathrm{~B})+\mathrm{e}^{-}$ & $\mathrm{N}_{2} \mathrm{~B}$ excitation \\
7 & $\mathrm{~N}_{2}(\mathrm{X})+\mathrm{e}^{-} \rightarrow \mathrm{N}_{2}(\mathrm{~W})+\mathrm{e}^{-}$ & $\mathrm{N}_{2}$ W excitation \\
8 & $\mathrm{~N}_{2}(\mathrm{X})+\mathrm{e}^{-} \rightarrow \mathrm{N}_{2}\left(\mathrm{~B}^{\prime}\right)+\mathrm{e}^{-}$ & $\mathrm{N}_{2} \mathrm{~B}^{\prime}$ excitation \\
9 & $\mathrm{~N}_{2}(\mathrm{X})+\mathrm{e}^{-} \rightarrow \mathrm{N}_{2}\left(\mathrm{a}^{\prime}\right)+\mathrm{e}^{-}$ & $\mathrm{N}_{2} \mathrm{a}^{\prime}$ excitation \\
10 & $\mathrm{~N}_{2}(\mathrm{X})+\mathrm{e}^{-} \rightarrow \mathrm{N}_{2}(\mathrm{a})+\mathrm{e}^{-}$ & $\mathrm{N}_{2}$ a excitation \\
11 & $\mathrm{~N}_{2}(\mathrm{X})+\mathrm{e}^{-} \rightarrow \mathrm{N}_{2}(\mathrm{w})+\mathrm{e}^{-}$ & $\mathrm{N}_{2}$ w excitation \\
12 & $\mathrm{~N}_{2}(\mathrm{X})+\mathrm{e}^{-} \rightarrow \mathrm{N}_{2}(\mathrm{C})+\mathrm{e}^{-}$ & $\mathrm{N}_{2} \mathrm{C}$ excitation \\
13 & $\mathrm{~N}_{2}(\mathrm{X})+\mathrm{e}^{-} \rightarrow \mathrm{N}_{2}(\mathrm{E})+\mathrm{e}^{-}$ & $\mathrm{N}_{2}$ E excitation \\
14 & $\mathrm{~N}_{2}(\mathrm{X})+\mathrm{e}^{-} \rightarrow \mathrm{N}_{2}\left(\mathrm{a}^{\prime \prime}\right)+\mathrm{e}^{-}$ & $\mathrm{N}_{2} \mathrm{a}^{\prime \prime}$ excitation \\
15 & $\mathrm{~N}_{2}+\mathrm{e}^{-} \rightarrow \mathrm{N}+\mathrm{N}^{+}+\mathrm{e}^{-}$ & $\mathrm{N}_{2}$ dissociation with simple ionization \\
16 & $\mathrm{~N}_{2}+\mathrm{e}^{-} \rightarrow \mathrm{N}^{+}+\mathrm{N}^{+}+\mathrm{e}^{-}$ & $\mathrm{N}_{2}$ dissociation with double ionization \\
\hline
\end{tabular}

$\mathrm{N}\left({ }^{4} \mathrm{~S}\right)$ and also GL of its first ion $\mathrm{N}^{+}\left({ }^{3} \mathrm{P}\right)$, coming from the $\mathrm{N}_{2} \mathrm{O}$ dissociation process (no. 4 of Table 2) and from the $\mathrm{N}_{2}$ dissociation processes (nos. 2, 19-23 of Table 3), were included.

In PoBE (2) an increased number of $\mathrm{N}_{2}$ vibrational and electronic levels, 22 species in total, were included in the energy loss calculation. The main data for the included species according to various authors are compared in Table 8. In this table, the first column shows the level description taken from Itikawa [33]. The second up to the fifth column give the excitation energies coming from various authors including Allan [34], Hasted [35], Phelps and Pitchford [31], and Engelhardt et al. [56]. Dissociation energy of $\mathrm{N}_{2} \mathrm{GL}$ was taken from Cosby [24] and ionization energy from [35].

Although dissociation/ionization energies are from Cosby [24]/Hasted [35], vibrational excitation energies from Allan [34] have been used to obtain the threshold energies of the dissociation/ionization processes from vibrationally excited levels, marked by stars in Table 8 .

Calculation of $\varepsilon_{C, N_{2}}$ includes eight vibrational excitation rates and twelve electronic excitation rates as well as three dissociation processes. Elastic and ionization rates were also included in this calculation. A list of additional processes included in calculating the energy loss of $\mathrm{N}_{2}$ is given in Table 9, while processes of Table 3 marked by a star are used both in the PoBE and PaBE.

Data for the elastic collision (no. 1 of Table 9) are taken from [35]. The vibrational excitation cross sections of $\mathrm{N}_{2}(X, v=0) \rightarrow \mathrm{N}_{2}(X, v=6-8)$ were integrated using the values of [31]. For the excitation of electronic states we made an evaluation of the cross sections based on values coming from [30, 31]. For processes 15 and 16, dissociation with simple and double ionization, we integrated the cross sections of Tian and Vidal [37]. Note that those authors also give an ionization cross section of $\mathrm{N}_{2}$, which is very close to the values of [48] used here. $\varepsilon_{C, N_{2}}$ results obtained with these data will be presented and commented in Section 4.4.
TABLE 10: Additional processes involving the $\mathrm{N}$ species (only for $\varepsilon_{C, \mathrm{~N}}$ calculation).

\begin{tabular}{|c|c|c|}
\hline \multicolumn{2}{|c|}{ No. Process } & \multirow{2}{*}{$\begin{array}{l}\text { Description } \\
\text { N elastic collisions }\end{array}$} \\
\hline 1 & $\mathrm{~N}+\mathrm{e}^{-} \rightarrow \mathrm{N}+\mathrm{e}^{-}$ & \\
\hline 2 & $\mathrm{~N}+\mathrm{e}^{-} \rightarrow \mathrm{N}(3 s)+\mathrm{e}^{-}$ & $\mathrm{N}$ excitation of the excited state $3 \mathrm{~s}$ \\
\hline 3 & $\mathrm{~N}+\mathrm{e}^{-} \rightarrow \mathrm{N}(3 p)+\mathrm{e}^{-}$ & $\mathrm{N}$ excitation of the excited state $3 p$ \\
\hline 4 & $\mathrm{~N}+\mathrm{e}^{-} \rightarrow \mathrm{N}(3 d)+\mathrm{e}^{-}$ & \\
\hline 5 & $\begin{array}{l}\mathrm{N}+\mathrm{e}^{-} \rightarrow \mathrm{N}\left(2 s^{1} 2 p^{4}\right)+ \\
\mathrm{e}^{-}\end{array}$ & $\begin{array}{l}\mathrm{N} \text { excitation of the inner shell } \\
2 s^{1} 2 p^{4}\end{array}$ \\
\hline 6 & $\begin{array}{l}\mathrm{N}+\mathrm{e}^{-} \rightarrow \mathrm{N}\left(2 p^{3}{ }^{2} \mathrm{D}\right)+ \\
\mathrm{e}^{-}\end{array}$ & $\begin{array}{l}\mathrm{N} \text { excitation of the ground state } \\
\left(2 p^{3} \mathrm{D}\right)\end{array}$ \\
\hline & $\begin{array}{l}\mathrm{N}+\mathrm{e}^{-} \rightarrow \mathrm{N}\left(2 p^{3}{ }^{2} \mathrm{P}\right)+ \\
\mathrm{e}^{-}\end{array}$ & $\begin{array}{l}\mathrm{N} \text { excitation of the ground state } \\
\left(2 p^{3} \mathrm{P}\right)\end{array}$ \\
\hline
\end{tabular}

Analogous work was made for the atomic species N, for which the list of the additional reactions, taken into consideration in the energy loss calculations in addition to those listed in Table 3 , is given in Table 10. We included effects of elastic collisions (process no. 1 of Table 10) that we calculated using the theoretical cross section of Bauer and Browne, as reported in Neynaber et al. [36]. Also, we included excitations of the three outer shell excited states, namely, $2 s^{2} 2 p^{2} 3 s, 3 p$, and $3 d$ as well as the $2 s^{1} 2 p^{4}$ inner shell state and we added the excitations of the ground level compounds $\left(2 p^{3}\right.$ $\left.{ }^{2} \mathrm{D}\right)$ and $\left(2 p^{3}{ }^{2} \mathrm{P}\right)$ as was the case in [12].

\subsection{Molecular and Atomic Oxygen and NO Formed in the Discharge}

(i) The GL of the oxygen molecule $\mathrm{O}_{2}\left(X^{3} \Sigma_{g}{ }^{-}\right)$and its first ion $\mathrm{O}_{2}{ }^{+}$were already included in the PaBE set, on the basis of a previous study of discharges in $\mathrm{O}_{2}$, [18], together with the GLs of the neutral atomic oxygen $\mathrm{O}\left({ }^{3} \mathrm{P}\right)$ and $\mathrm{O}\left({ }^{1} \mathrm{D}\right)$, the negative ion $\mathrm{O}^{-}\left({ }^{2} \mathrm{P}\right)$ 
and the positive ion $\mathrm{O}^{+}$. In the concomitant energy loss calculation of $\mathrm{O}_{2}$, we took in consideration one elastic collision, two vibrational excitations, four electronic excitations, and two dissociations. The simple formula given in [1] was used for the elastic rate evaluation. Vibrational and electronic excitation energies and rate coefficients formulas were those of [57] as quoted in [19]. We also used the dissociation rate coefficients given in [1] coming from [58]. The used rates were considered being valid in the $T_{e}$ region from 1 to about $7 \mathrm{eV}$. Accordingly, $\varepsilon_{\mathrm{C}, \mathrm{O}_{2}}$ values calculated in [18] and used also here are only approximate for high $T_{e}$ values.

(ii) For the atomic oxygen we used here the $\varepsilon_{C, O}$ values reported in [1].

(iii) The GL of the nitric oxide $\mathrm{NO}\left(X^{2} \Pi\right)$ was also introduced in the PaBE, as at least the GL of the $\mathrm{NO}$ molecule species is expected to be present. Here, the $\mathrm{NO}$ is mainly formed by dissociation of the $\mathrm{N}_{2} \mathrm{O}$ (reactions nos. 4 and 7, Table 2). It is destroyed by rearrangement when colliding with the $\mathrm{N}$ atoms (reaction no. 8 of Table 2) and $\mathrm{O}$ atoms (reaction no. 9 of Table 2). The total amount of NO present in the discharge is then strongly related to the densities of the $\mathrm{N}$ and $\mathrm{O}$ atomic species. However, the electron collision energy loss due to the NO molecule was neglected as the latter is present in a much lower amount than the other species for all the studied conditions.

4.4. Evaluation of the Collisional Energy Losses. In calculating the various $\varepsilon_{C}$ parameters, the most important energy losses due to elastic and inelastic electron collisions with the corresponding species have been taken into consideration. We expect that the energy losses coming from the electron collisions with $\mathrm{N}_{2} \mathrm{O}$ are important whenever it is not severely dissociated. The collisional energy losses in the $\mathrm{N}_{2} \mathrm{O}$ case, noted $\varepsilon_{C, \mathrm{~N}_{2} \mathrm{O}}$, are given by

$$
\begin{aligned}
& \varepsilon_{C, \mathrm{~N}_{2} \mathrm{O}}=E_{\mathrm{IONIZ,N}_{2} \mathrm{O}}+E_{{\mathrm{ELAS}, \mathrm{N}_{2} \mathrm{O}}} \frac{k_{{\text {ELAS }, \mathrm{N}_{2} \mathrm{O}}}}{k_{{\mathrm{IONIZ,} \mathrm{N}_{2} \mathrm{O}}}} \\
& +\sum_{i} E_{\mathrm{EXC}, \mathrm{N}_{2} \mathrm{O}, i} \frac{k_{{\mathrm{EXC}, \mathrm{N}_{2} \mathrm{O}, i}}}{k_{\mathrm{IONIZ}, \mathrm{N}_{2} \mathrm{O}}} \\
& +\sum_{\nu} E_{\mathrm{VIB}, \mathrm{N}_{2} \mathrm{O}, v} \frac{k_{\mathrm{VIB}, \mathrm{N}_{2} \mathrm{O}, v}}{k_{\mathrm{IONIZ, \textrm {N } _ { 2 } \mathrm { O }}}} \\
& +\sum_{j} E_{\mathrm{DISS}, \mathrm{N}_{2} \mathrm{O}, j} \frac{k_{{\mathrm{DISS}, \mathrm{N}_{2} \mathrm{O}, j}}}{k_{{\mathrm{IONIZ}, \mathrm{N}_{2} \mathrm{O}}_{\mathrm{O}}}} .
\end{aligned}
$$

As we threat here a molecule, energy losses by electron impact due to elastic scattering and to ionization and dissociation of the ground state and also to excitation at least of the lower vibrational and electronic excitation states have in general to be taken into account. For the $\mathrm{N}$ and $\mathrm{O}$ subproducts, electronic excitation, elastic scattering, and

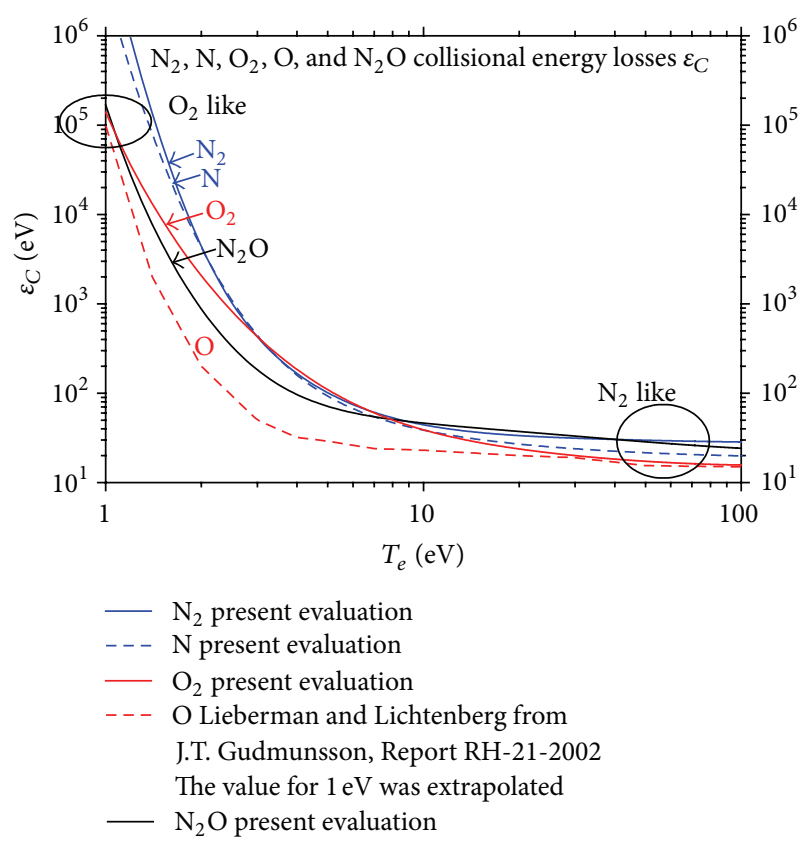

FIgURE 7: Comparison of the collisional energy losses for $\mathrm{N}_{2} \mathrm{O}$ with those of $\mathrm{N}_{2}, \mathrm{~N}, \mathrm{O}_{2}$, and $\mathrm{O}$.

ionization are composing the corresponding energy loss terms. Energy losses from the atomic and molecular ions were not considered at this stage, as we are here dealing with relatively lowly ionized plasma. For the highly ionized "core" region of HPTs the Landau damping approximation $\varepsilon_{C, X}=$ $2 E_{I}^{X}$ can be used, as was also the case in [2].

Collisional energy losses for the $\mathrm{N}_{2} \mathrm{O}$ molecule following equation (9) are shown in Figure 7 in comparison with those of $\mathrm{N}_{2}, \mathrm{~N}, \mathrm{O}_{2}$, and $\mathrm{O}$ species. Energy losses for $\mathrm{N}_{2} \mathrm{O}$ calculations include those due to elastic collisions, three vibrational states, three electronic excited states, and two dissociation processes. Importance of introducing enough vibrational and electronic excitations as well as the relevant dissociation processes has been demonstrated. Here, the first dissociation process corresponds to the reaction no. 2 of Table 2 leading to the $\mathrm{O}$ compound in its first ground state ${ }^{3} \mathrm{P}$, whereas the second one corresponds to reaction no. 3 with the $\mathrm{O}$ atom in another ground level ${ }^{1} \mathrm{D}$.

In what concerns $\mathrm{N}_{2}$ species, calculated values showed the significant influence of the two first vibrational and two first electronic states of $\mathrm{N}_{2}$ on the overall $\varepsilon_{C, \mathrm{~N}_{2}}$ value. Results vary considerably also when including one, two, and three dissociation processes. We also investigated the relative influence of the eight lower vibrational states on the results and we observed that including five vibrational levels in the calculations gives a satisfactory result, very close to the one with eight states. For the energy losses coming from electron collisions with $\mathrm{N}$, we included excitation to two ground levels, $\mathrm{N}\left({ }^{2} \mathrm{D}\right)$ and $\mathrm{N}\left({ }^{2} \mathrm{P}\right)$, and to four excited states. Results agree well with those obtained in [12].

Our collisional energy losses $\varepsilon_{C}$ of $\mathrm{O}_{2}$ species, coming from the electron collision with $\mathrm{O}_{2}$, were compared to those 
of Gudmundsson [58] as quoted in [1, page 80], showing a good agreement. This was somehow expected, as we used some of the existing rates, also used in [58].

In comparing $\varepsilon_{C}$ values corresponding to the five species $\mathrm{N}_{2} \mathrm{O}, \mathrm{N}_{2}, \mathrm{~N}, \mathrm{O}_{2}$, and $\mathrm{O}$ illustrated in Figure 7, we observe that the values for the $\mathrm{N}_{2} \mathrm{O}$ molecule are very near to those corresponding to $\mathrm{O}$ for the low $T_{e}$, while they become close to those of $\mathrm{N}_{2}$ for high $T_{e}$. While we evaluated $\varepsilon_{C, X}$ values for various species $X$, it has to be stressed that each level population constitutes only a factor in the sum corresponding to the total collisional energy loss calculation (see (2) of Section 2).

For energies lower than $8 \mathrm{eV}$, which are often of interest here, the $\varepsilon_{C, N_{2} \mathrm{O}}$ values of $\mathrm{N}_{2} \mathrm{O}$ become more and more low than those of $\mathrm{N}_{2}$. In the low temperature region they are quite comparable to the values corresponding to $\mathrm{O}_{2}$ and become close to those of $\mathrm{O}$ for very low $T_{e}$. For high energies (near to $100 \mathrm{eV}$ ), the $\varepsilon_{C, \mathrm{~N}_{2} \mathrm{O}}$ value is close to the one of $\mathrm{N}_{2}$ as it was expected. Indeed, for high energies the $\varepsilon_{C}$ values tend to the ionization energy plus a contribution of the dissociation energy, as the dissociation thresholds are often lower than the ionization ones. Globally, we can say that the $\varepsilon_{C}$ values around the $1 \mathrm{eV}$ to $2 \mathrm{eV}$ region are mainly due to the vibrational excitation processes, elastic processes playing also an important role for low energies; the values in the $3-8 \mathrm{eV}$ region are mainly due to the electronic excitation processes and in the $8 \mathrm{eV}$ to $100 \mathrm{eV}$ region they are due to both electronic excitation and dissociation processes.

Electronic ionization processes have been introduced in Section 3. Their participation in the overall energy loss was found considerable in all the energy regions, with their rates being present in terms belonging to equations analogous to (9), adapted for the $\mathrm{N}_{2}, \mathrm{~N}, \mathrm{O}_{2}$, and $\mathrm{O}$ species.

\section{Regimes of $\mathbf{N}_{\mathbf{2}} \mathbf{O}$ Discharges}

Taking into consideration existing experimental and theoretical results in conjunction with those of our GM, the presence of the $\mathrm{N}_{2} \mathrm{O}$ and its products in the plasma can be roughly described by distinguishing the following three main regimes.

(i) The Plasma Is Mostly Composed of $\mathrm{N}_{2} \mathrm{O}$ Molecules. This happens when the absorbed power is very low and/or the pressure is quite high. Sustained flow rates can lead to such a physical condition; compare [23]. The exact ranges of values of power, pressure, and flow rates also depend on the device form factor and size. In this situation, the molecular properties of $\mathrm{N}_{2} \mathrm{O}$ and principally the excitation of electronic and vibrational levels, as well as the $\mathrm{N}_{2} \mathrm{O}$ ionization process, are of big importance in the overall description of the physical situation. Diminishing the flow rate constitutes a simple way to pass to the next case (ii).

(ii) The $\mathrm{N}_{2} \mathrm{O}$ Species Are Quite Dissociated in the Plasma. This is typically the case of a plasma reactor in an intermediate pressure regime, with both length $L$ and radius $R$ of $15 \mathrm{~cm}$, for absorbed powers varying from 250 to $500 \mathrm{~W}$ in presence of a flow rate typically of $60 \mathrm{sccm} . \mathrm{N}_{2}$ and $\mathrm{O}_{2}$ species are also within the main compounds of the plasma besides $\mathrm{N}_{2} \mathrm{O}$. Such a situation, studied here with our GM, was also previously addressed by Shutov et al. [7]. Our GM results for this case are comparable to those of [7], which are discussed and compared with ours in Section 6. A quite similar situation case is encountered in the "mantle" region of a relatively low absorbed power HPT; say of $100 \mathrm{~W}$ or less. The corresponding flow rate is about $12 \mathrm{sccm}$ and the pressure of a few mTorr. This similarity of the low power HPT with those of the PR physical conditions prevailing here is partially due to the small radius of the former, around $1 \mathrm{~cm}$, leading to a reduced total plasma volume. We estimate that low power absorption in the "mantle" region of a HPT corresponds to a situation where the PR plasma absorbs an intermediate amount of power (150-500 W) in a big volume. The expected $T_{e}$ and the ionization and dissociation percentages of the main constituents as well are then comparable.

Concerning the dissociation of the main $\mathrm{N}_{2} \mathrm{O}$ products, namely, $\mathrm{N}_{2}$ and $\mathrm{O}_{2}$ species, leading to nitrogen and oxygen atomic subproducts, it is found to become important with diminishing pressure. Specifically, products of $\mathrm{N}_{2}$ dissociation have been studied in detail recently $[12,17]$ in two typical cases of PR. A $\mathrm{N}_{2}$ dissociation of around $50 \%$ was found for a pressure of 5 mTorr. Dissociation was found to decrease with pressure to reach about $5 \%$ to $10 \%$ at 20 mTorr.

(iii) The $\mathrm{N}_{2} \mathrm{O}$ Species Are Almost Totally Dissociated. For high absorbed power (e.g., in the HPT "core" region similar to this of Ar feeding case studied in [2]), the ionization degree may become very high. However, the ionization degree may remain low if the flow rate is high. Hence, situation (iii) is typical for high absorbed power and low pressure regimes associated with low flow rates. In such a situation, the plasma becomes mainly a high power or/and low pressure $\mathrm{N}_{2} / \mathrm{O}_{2}$ plasma under the influence of electron collisions with heavy particles and notably of those leading to dissociation. Therefore, electronic collisions involving the $\mathrm{N}_{2}$ and $\mathrm{O}_{2}$ products gain importance. With the latter having a low dissociation energy $\left(E_{\mathrm{DISS}_{,} \mathrm{O}_{2}}=5.12 \mathrm{eV},[1]\right)$ the atomic oxygen may become particularly abundant. The $\mathrm{N}_{2}$ dissociation products may also appear in significant amounts, especially for high $T_{e}$, due to its higher dissociation energy $\left(E_{{\mathrm{DISS}, \mathrm{N}_{2}}}=12.0 \mathrm{eV}\right.$, for the primary dissociation mechanism leading to $\mathrm{N}\left({ }^{2} \mathrm{D}\right)+$ $\mathrm{N}\left({ }^{4} \mathrm{~S}\right)$ fragments, [24]). $\mathrm{N}_{2}$ and $\mathrm{O}_{2}$ species abundances vary considerably following their reformation on the wall depending on the device geometry and the material of the wall.

Although becoming more important in (iii), $\mathrm{N}_{2}$ and $\mathrm{O}_{2}$ dissociation is already present in conditions like those described in (ii). As the $\mathrm{O}_{2}$ dissociates easier than $\mathrm{N}_{2}$, atomic oxygen lines are commonly observed in spectra acquired in plasmas under such conditions together with the intense molecular $\mathrm{N}_{2}$ bands (see [59]). The $\mathrm{N}_{2}$ bands and the atomic $\mathrm{O}$ lines become more pronounced when plasma conditions pass from type (ii) to type (iii), although in conditions pertaining to high power the $\mathrm{N}_{2}$ molecules are quite dissociated. Under the aforementioned (ii) and (iii) conditions, reactions involving the $\mathrm{N}_{2}$ and $\mathrm{O}_{2}$ products and their excited states $\mathrm{N}_{2}{ }^{*}$ and $\mathrm{O}_{2}{ }^{*}$ and also their subproducts both in ground and excited states (mainly $\mathrm{N}, \mathrm{N}^{*}, \mathrm{O}, \mathrm{O}^{*}$, and $\mathrm{O}^{-}$) are important. In view of its preponderance in the $\mathrm{N}_{2} \mathrm{O}$ molecule, nitrogen 
becomes the predominant species of the plasma, while atomic $\mathrm{O}$ is also quite present. The quantity of oxygen species admixture confers to the plasma significantly different global properties due to electronegativity, as illustrated in Figures 15 and 17, Section 8. Results corresponding to $\mathrm{N}_{2}$ have been obtained recently by Kang et al. [17] and by Thorsteinsson and Gudmundsson [12]. We obtained similar results [16] for $\mathrm{N}_{2}$ plasma discharges by a dedicated GM.

$\mathrm{A} \mathrm{N}_{2} \mathrm{O}$ fed plasma reactor at rather high pressures (about 0.5 Torr to 1 Torr) has been studied previously by Date et al. [23], investigating a plasma in conditions between our (i) and (ii) cases described previously. As the authors kept rather big flow rate values, the $\mathrm{N}_{2} \mathrm{O}$ was dissociated only in a small percentage. Atomic lines in the UV and especially in the VUV region are very important as they largely contribute to plasma cooling in various applications (see, e.g., [60] for the Ar plasma case). Dissociative excitation of $\mathrm{N}_{2} \mathrm{O}$ leading to emission in the Vacuum Ultraviolet (VUV) spectral region was studied recently by Malone et al. [61] in an electron impact collision chamber. These authors identified the main N I, N II, O I, and O II lines in the wavelength region from $80 \mathrm{~nm}$ to $180 \mathrm{~nm}$, with the most intense lines belonging to the N I species. Results of [61] illustrate the importance of plasma radiation in the VUV region, addressing atomic spectral lines from species formed after dissociation of the initial molecular $\mathrm{N}_{2} \mathrm{O}, \mathrm{N}_{2}$, and $\mathrm{O}_{2}$ species. They concern plasma conditions of type (iii), as an electron gun furnishes a high power to a plasma confined in a low or intermediate pressure vacuum chamber. These conditions are similar to those expected to prevail in the "core" region of a HPT, with a high $T_{e}$ and considerable ionization degree.

When absorbed power increases, plasma is passing from conditions of type (i) to (ii) and to (iii) one, and the ionization percentage increases, leading to a high $T_{e}$ plasma. In this case, inclusion of more ionized species may become necessary, while the dissociation plays a very important role. The dissociation-recombination equilibrium is strongly related to the wall recombination processes. The latter depends greatly on the device geometry and wall material. In the GM, the wall material is described by the sticking coefficient, which is unfortunately often badly known.

Keeping in mind that the present work aims to characterize various plasma devices, it should be noted that throughout (i) to (iii) cases, inclusion of excited states in the GM $\left(\mathrm{N}_{2} \mathrm{O}^{*}\right.$ for high pressures and also $\mathrm{N}_{2}{ }^{*}, \mathrm{O}_{2}{ }^{*}, \mathrm{NO}^{*}$ and $\mathrm{N}^{*}$, and $\mathrm{O}^{*}$ for lower pressures/higher power) allows for comparison of the model results with experimental measurements based on Optical Emission Spectroscopy (OES) diagnostics. This was already made in the simpler case of Ar plasma OES, using an Ar GM in correlation with a C-R model. Both models are available and have been described elsewhere, [2, 62]. Also, puffing of gases in small amount can improve OES, verifying at the same time the GM results.

Preliminary measurements in different type of devices contributed to the corroboration of our theoretical estimations concerning rare gases and nitrogen plasmas. These include observations in an air fed plasma reactor [59] and in a capillary tube fed with Ar. Both experiments have been performed in the LPGP Laboratory of the University

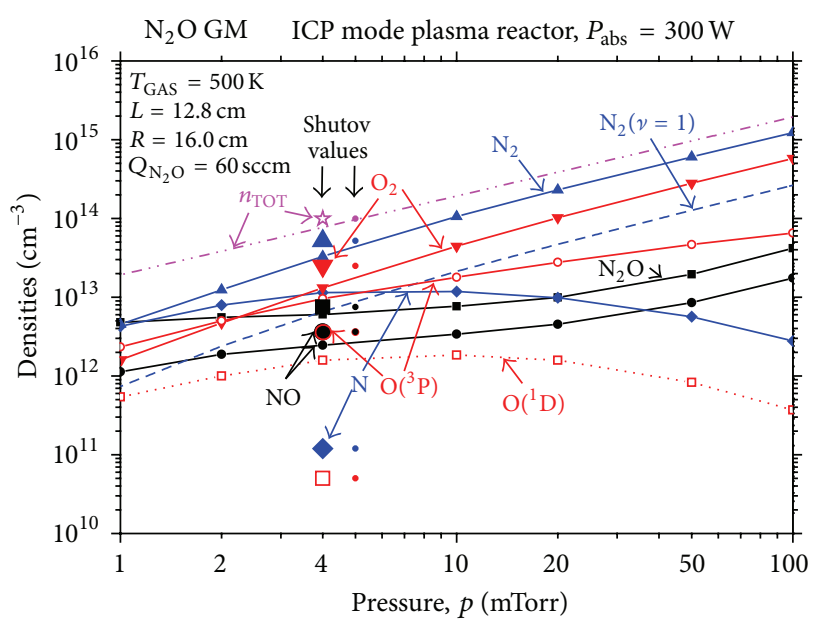

FIgURE 8: Variation of the densities of neutral species as a function of pressure varying from $1 \mathrm{~m}$ Torr to 100 mTorr. Absorbed power is fixed at $300 \mathrm{~W}$.

Paris-Sud in Orsay, France. Also, measurements have been made in an inductively coupled plasma (ICP) torch, fed with various gases, including rare gases $(\mathrm{He}, \mathrm{Ne}$, and $\mathrm{Ar}$ ) and their mixtures and $\mathrm{N}_{2}$ (and its mixture with rare gases), and in air environment, available in the LAEPT Laboratory of the University of Clermont-Ferrand, France; see, for example, $[4,6]$ for Helium and [63] for Neon feedings. Spectra of Arair mixture (95-5\%) were also obtained in an HPT build in the CISAS institute of the University of Padova, Italy, in the frame of the HPH.com project of the EC [64]. Although none of these plasmas concern $\mathrm{N}_{2} \mathrm{O}$ feeding, they contained a significant number of common products. Consequently, nitrogen and oxygen spectra acquired in air discharges can be comparable to those encountered in $\mathrm{N}_{2} \mathrm{O}$ fed plasmas.

\section{Results of GM for $\mathrm{N}_{2} \mathrm{O}$ Plasma Reactors}

In order to compare our results for $\mathrm{N}_{2} \mathrm{O}$ plasma reactors with experimental and theoretical ones existing in the literature, we calculated GM results in conditions similar to those chosen by Shutov et al. [7] for a PR of length $L=12.8 \mathrm{~cm}$ and radius $R=16.0 \mathrm{~cm}$, fed with a flow rate of $Q_{\mathrm{N}_{2} \mathrm{O}}=60 \mathrm{sccm}$. In this experiment, the gas temperature was considered to be $T_{\mathrm{GAS}}=500 \mathrm{~K}$ and the absorbed power was varied from $P_{\mathrm{abs}}=250 \mathrm{~W}$ up to $500 \mathrm{~W}$ with a fixed pressure of 4 mTorr.

6.1. Variation with the Pressure. Results of our GM in conditions similar to those of [7] and for a pressure varying from 1 mTorr up to 100 mTorr are shown in Figures 8 and 9, which report species densities $n_{e}$ and $n_{X}$ (where $X$ stands for all the encountered species), and in Figure 10, which reports the electron temperature $T_{e}$, the ionization percentage, the remaining $\mathrm{N}_{2} \mathrm{O}$ percentage, and the electronegativity. For calculations corresponding to Figures 8, 9, and 10 the absorbed power was fixed at $300 \mathrm{~W}$ and the flow rate at $60 \mathrm{sccm}$. We also varied the pressure for higher absorbed powers. The obtained results vary with the pressure in a similar way. 


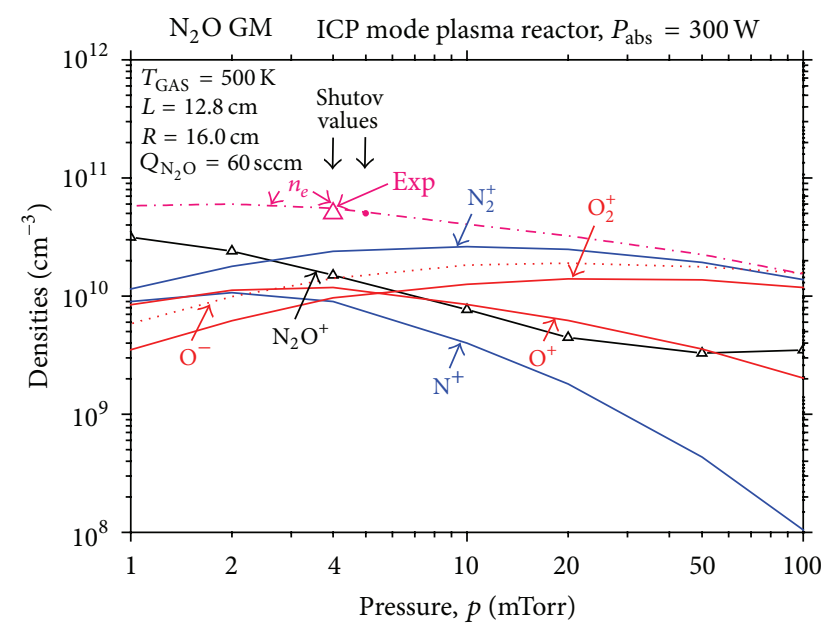

FIGURE 9: Variation of the densities of charged species as a function of pressure varying from $1 \mathrm{mTorr}$ to $100 \mathrm{mTorr}$. Absorbed power is fixed at $300 \mathrm{~W}$.

Our results for $n_{e}$ and $n_{X}$ contained in Figures 8 and 9 show that the main constituents of the plasma are here $\mathrm{N}_{2}$, $\mathrm{O}_{2}, \mathrm{~N}, \mathrm{O}$, and $\mathrm{N}_{2} \mathrm{O}$. For pressures higher than 4 mTorr, $\mathrm{N}_{2}$ and $\mathrm{O}_{2}$ are the prevailing species. For low pressure, atomic $\mathrm{N}$ and $\mathrm{O}$ are present in a very important amount, but for $100 \mathrm{mTorr}$ their densities become correspondingly between three and one orders of magnitude lower than the densities of $\mathrm{N}_{2}$ and $\mathrm{O}_{2}$. The $\mathrm{N}_{2} \mathrm{O}$ density increases slowly up to 10 mTorr and faster for higher pressures. The remaining $\mathrm{N}_{2} \mathrm{O}$ percentage decreases with the pressure (see Figure 10). This effect is due to the fact that while the flow rate remains constant the pumping efficiency must increase for low pressures in order to maintain a lower gas density. Hence, the residence time is lower for low pressure and $\mathrm{N}_{2} \mathrm{O}$ tends to be less dissociated even if the $T_{e}$ is higher. This is illustrated in Figure 10. On the opposite, $\mathrm{N}_{2}$ and $\mathrm{O}_{2}$ species are less dissociated for high pressures because their $\mathrm{O}$ and $\mathrm{N}$ products form again $\mathrm{N}_{2}$ and $\mathrm{O}_{2}$ on the wall in a very important amount; hence the pumping has a less pronounced effect on them as explained elsewhere [10]. For all pressures, the sum of the nitrogen atoms contained in the totality of the calculated species is twice the sum of the oxygen ones, as all nitrogen and oxygen species come from the decomposition of $\mathrm{N}_{2} \mathrm{O}$ and the pumping is considered to be the same for all species. Concerning the NO species, densities are much smaller than those of the other neutral molecular densities, because the rate coefficient of reaction no. 4 of Table 2 is much smaller than the one of reactions nos. 2 and 3 of the same table. Also, NO is destroyed by collisions with $\mathrm{N}$ and $\mathrm{O}$, which are present in considerable amount (reactions nos. 8 and 9 of Table 2). The vibrational states of $\mathrm{N}_{2}$ are quite populated. This is illustrated with the first vibrational state density, which is given separately in Figure 8, because it is the most populated among the excited ones. Inspection of Figure 8 indicates that $20 \%$ of $\mathrm{N}_{2}$ is typically expected to be in the first vibrational excitation state. Concerning the charged species, we see that the $n_{e}$ is slightly decreasing with pressure, while the ionization percentage is drastically decreasing, up to three

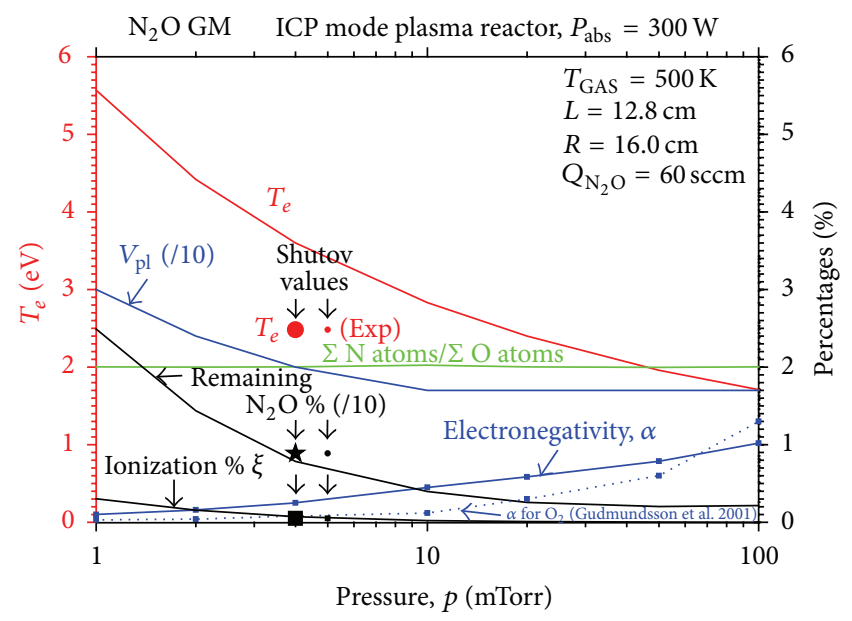

FIGURE 10: Variation of $T_{e}$, ionization and dissociation percentages, electronegativity, and plasma potential as a function of pressure varying from 1 mTorr to 100 mTorr. Absorbed power fixed at $300 \mathrm{~W}$.

orders of magnitude (see Figure 10). Our calculations show that $\mathrm{N}_{2}{ }^{+}$and $\mathrm{O}_{2}{ }^{+}$increase with the pressure, varying from 1 mTorr up to 100 mTorr. At the same time, densities of $\mathrm{N}_{2}$ and $\mathrm{O}_{2}$ increase by more than two orders of magnitude. This variation is also illustrated in Figures 8 and 9. Inversely, as we can also see in Figure 9, the $\mathrm{N}^{+}$and $\mathrm{O}^{+}$densities are important for low pressures. However, they diminish fast when the pressure increases and become between one and two orders of magnitude lower than those of $\mathrm{N}_{2}{ }^{+}$and $\mathrm{O}_{2}{ }^{+}$ for a pressure of 100 mTorr. The $\mathrm{O}^{-}$density is lower than the one of $\mathrm{O}^{+}$for 1 mTorr but increases continuously with pressure. Eventually, the $\mathrm{O}^{-}$density becomes comparable to the electron density and to the $\mathrm{N}_{2}{ }^{+}$density for 100 mTorr with an electronegativity around 1 (see Figure 10). For all pressures the $\mathrm{O}_{2}{ }^{+}$density is slightly lower than this of $\mathrm{O}^{-}$.

In order to compare our results for $\mathrm{N}_{2} \mathrm{O}, \mathrm{N}_{2}, \mathrm{O}_{2}, \mathrm{~N}, \mathrm{O}$, and NO species densities presented in Figure 8 with calculations and $n_{e}$ probe measurements obtained by Shutov et al. [7], values for 4 mTorr given in Figure 2 of [7] are reported in Figure 8 . They are shown by big symbols, namely, triangles for $\mathrm{N}_{2}$, inversed triangles for $\mathrm{O}_{2}$, squares for $\mathrm{N}_{2} \mathrm{O}$, full circles for $\mathrm{NO}$, hollow circles for $\mathrm{O}\left({ }^{3} \mathrm{P}\right)$, hollow squares for $\mathrm{O}\left({ }^{1} \mathrm{D}\right)$, and diamonds for $\mathrm{N}$. All the aforementioned species densities are theoretical. Moreover, the big pink empty triangle in Figure 9 indicates an experimental $\mathrm{N}_{2} \mathrm{O}^{+}$value from [7]; because in [7] $n_{e}$ is about equal to $n_{\mathrm{N}_{2} \mathrm{O}^{+}}$, the measured $n_{e}$ values were taken as equal to the $\mathrm{N}_{2} \mathrm{O}^{+}$ones throughout this reference. In our model we introduced explicitly many different types of ions; therefore $n_{e} \neq n_{\mathrm{N}_{2} \mathrm{O}^{+}}$according to the quasi-neutrality equation (1). We also repeat (indicated by small circles) the values of densities corresponding to 5 mTorr positions, by shifting of $1 \mathrm{~m}$ Torr the values attributed to 4 mTorr by Shutov et al. [7], as we believe that after dissociation the pressure in the experiment could be slightly higher than 4 mTorr. Throughout the figures of this section, theoretical values from [7] and experimental $n_{e}$ value are indicated by two black vertical arrows. In Figures 8 and 9, our results for species for which densities are also given in [7] are represented by small 
TABLE 11: Sensitivity of various PR parameters for a pressure of 5 mTorr, including the configuration available in the experiment [7].

\begin{tabular}{|c|c|c|c|c|c|c|}
\hline Parameters values & $\begin{array}{l}1 \\
n_{e}\end{array}$ & $\begin{array}{c}2 \\
n_{\mathrm{N}_{2} \mathrm{O}} / n_{\mathrm{TOT}} \\
\end{array}$ & $\begin{array}{c}3 \\
n_{\mathrm{N}} / n_{\mathrm{N}+\mathrm{N}_{2}}\end{array}$ & $\begin{array}{c}4 \\
n_{\mathrm{O}} / n_{\mathrm{O}+\mathrm{O}_{2}}\end{array}$ & $\begin{array}{c}5 \\
n_{\mathrm{O}^{-}} / n_{e} \\
\end{array}$ & $\begin{array}{l}6 \\
T_{e} \\
\end{array}$ \\
\hline$P_{\mathrm{abs}}: 250-500 \mathrm{~W}^{*}$ & $\begin{array}{c}\uparrow 2.20 \\
{[\uparrow \mathbf{1 . 3 1} / \mathbf{1 . 3 6}]}\end{array}$ & $\begin{array}{c}\downarrow 2.03 \\
{[\downarrow 2.77]}\end{array}$ & $\begin{array}{c}\uparrow 2.17 \\
{[\uparrow 2.29]}\end{array}$ & $\begin{array}{c}\uparrow 2.19 \\
{[\uparrow \mathbf{1 . 1 9}]}\end{array}$ & $\downarrow 2.93$ & $\begin{array}{c}\uparrow 1.00 \\
{[\uparrow 1.17]}\end{array}$ \\
\hline$Q_{\mathrm{N}_{2} \mathrm{O}}: 20-80 \mathrm{sccm}$ & $\downarrow 1.08^{* *}$ & $\uparrow 4.67$ & $\downarrow 1.46$ & $\downarrow 1.16$ & $\uparrow 2.09$ & $\downarrow 1.02$ \\
\hline$\gamma_{\mathrm{N}}: 0.02 / 0.07$ & $\uparrow 1.13$ & $\downarrow 1.11$ & $\downarrow 1.83$ & $\uparrow 1.06$ & $\downarrow 1.19$ & $\uparrow 1.00$ \\
\hline$\gamma_{\mathrm{O}}: 0.17 / 0.50$ & $\downarrow 1.05$ & $\uparrow 1.32$ & $\downarrow 1.14$ & $\downarrow 1.99$ & $\uparrow 1.69$ & $\uparrow 1.00$ \\
\hline
\end{tabular}

${ }^{*}$ Values from [7] are included in first row(bold brackets) except for $n_{\mathrm{O}^{-}} / n_{e}$.

${ }^{* *}$ Small peak at $40 \mathrm{sccm}$ before decreasing.

symbols. Consequently, data from [7] are noted with similar symbols to ours but bigger. Points of our results are joined by lines, only to ease the eye. Plain curves not associated with symbols represent our density results for ions $\left(\mathrm{N}_{2}{ }^{+}, \mathrm{N}^{+}, \mathrm{O}_{2}{ }^{+}\right.$, $\mathrm{O}^{+}$, and $\mathrm{O}^{-}$) which were not given in [7]. Our $n_{e}$ results are plotted with a thick pink dash-dotted line giving different values for electrons and $\mathrm{N}_{2} \mathrm{O}^{+}$, which was not the case for [7]. Moreover, although we calculated densities of five vibrational states of $\mathrm{N}_{2}$, only this of the first one is represented in Figure 8 by a thin blue dashed line. In general, nitrogen densities are plotted in blue, whereas in Figures 8 and 9 oxygen densities are in red and the $\mathrm{N}_{2} \mathrm{O}, \mathrm{N}_{2} \mathrm{O}^{+}$, and $\mathrm{NO}$ values are in black.

When comparing our results with those of Shutov et al. [7] in Figures 8 and 9 for the pressure of 4 mTorr (supposedly corresponding to a final pressure of around 5 mTorr), we see that $\mathrm{N}_{2} \mathrm{O}, \mathrm{N}_{2}, \mathrm{O}_{2}$, and $\mathrm{O}\left({ }^{3} \mathrm{P}\right)$ results are in rather good agreement. Still, there is a slight difference on the $\mathrm{N}_{2}$ densities and a big discrepancy in the $\mathrm{N}$ densities. After introducing dissociation of the $\mathrm{N}_{2}$ product we found an important part of $\mathrm{N}_{2}$ being dissociated. We believe that this is the reason why we obtain $\mathrm{N}$ densities much higher than those of [7]. Here, it should be reminded that the $\mathrm{N}_{2}\left(\right.$ and $\left.\mathrm{O}_{2}\right)$ dissociation percentages strongly depend on the wall constitution, hence on the sticking coefficients used. In the present case, we used $\gamma=0.02$ for $\mathrm{N}$ and $\gamma=0.17$ for $\mathrm{O}$. These values come from standard studies of PR [14, 15, 17] for walls composed of stainless steel with quartz windows. As in [7] lower values are proposed, we also tried these and they lead to higher dissociation percentages. Concerning the NO species, values similar to ours were obtained in [7]. In fact, even if fewer $\mathrm{N}$ species destroying the NO (reaction no. 8 of Table 2) are present in [7] calculations, also fewer $\mathrm{O}\left({ }^{1} \mathrm{D}\right)$ species dissociating $\mathrm{N}_{2} \mathrm{O}$ towards $\mathrm{NO}$ (reaction no. 7 of Table 2) are present. Moreover, we used different rates for reaction no. 4 of Table 2 which also leads to NO formation. These three differences tend to equilibrate and we finally obtain NO densities close to those of [7]. Concerning the charged species, the main observation is that the $n_{e}$ values given by our model are very similar to those measured in [7].

The electronegativity is also calculated by our model. Results are plotted in Figure 10 with plain blue lines. In Figure 10 the obtained $\mathrm{N}_{2} \mathrm{O}$ percentage is given in conjunction with the calculated $T_{e}$ plotted with a plain red line. $T_{e}$ is continuously diminishing with increasing pressure, as shown in Figure 10. The remaining $\mathrm{N}_{2} \mathrm{O}$ percentage is represented in Figure 10 by a black curve. For comparison, the values of [7] are also shown in Figure 10, by a red circle for the $T_{e}$ and by a black star for the remaining $\mathrm{N}_{2} \mathrm{O}$ percentage. We observe that the remaining $\mathrm{N}_{2} \mathrm{O}$ percentage is decreasing with the pressure as discussed previously. Plasma potential is also represented by a blue line.

6.2. Sensitivity of the Results to the Absorbed Power, Flow Rate, and Sticking Coefficients. Sensitivity of the results obtained for the same conditions as those of Figures 8 and 9, namely, a reactor of length $L=12.8 \mathrm{~cm}$ and radius $R=16.0 \mathrm{~cm}$, around a flow rate of $Q_{\mathrm{N}_{2} \mathrm{O}}=60 \mathrm{sccm}$, and an absorbed power $P_{\mathrm{abs}}=300 \mathrm{~W}$ for a gas temperature $T_{\mathrm{GAS}}=500 \mathrm{~K}$, is addressed in Table 11. In this table, increase (decrease) in the obtained results is indicated by upper (lower) arrows. The number situated at the right of each arrow indicates the factor of increase (decrease) of the results. Table 11 corresponds to a pressure fixed at $5 \mathrm{mTorr}$.

Variation of the results when the absorbed power increases from $250 \mathrm{~W}$ up to $500 \mathrm{~W}$ is contained in the first row of Table 11. In this line of the table, we see that the $n_{e}$ is higher for an absorbed power of $500 \mathrm{~W}$ than it was for $250 \mathrm{~W}$, as expected due to the increase in power absorbed by the plasma. Results for $300 \mathrm{~W}$ shown in Figures 8 and 9 lie within the values of the first row of Table 11.

$\mathrm{N}_{2} \mathrm{O}, \mathrm{N}_{2}$, and $\mathrm{O}_{2}$ species are more dissociated when absorbed power increases, as is shown in column 2 of Table 11 (percentage of remaining $\mathrm{N}_{2} \mathrm{O}, n_{\mathrm{N}_{2} \mathrm{O}} / n_{\mathrm{TOT}}$ is shown in this column instead of dissociations) and in columns 3 and 4 (dissociation percentages of $\mathrm{N}_{2}$ and of $\mathrm{O}_{2}$ ). Also, atomic species densities of the created $\mathrm{N}$ and $\mathrm{O}$ (composed of $\mathrm{O}\left({ }^{3} \mathrm{P}\right.$ ) and $\mathrm{O}\left({ }^{1} \mathrm{D}\right)$ ) for $500 \mathrm{~W}$ are about the double of those obtained for $250 \mathrm{~W}$. Note that in Table $11, n_{\mathrm{N}}$ and $n_{\mathrm{O}}$ stand for the density of atomic nitrogen and oxygen formed in the discharge by the various dissociation processes. The corresponding variations of the electronic density, of electronegativity $(\alpha=$ $\left.n_{\mathrm{O}^{-}} / n_{e}\right)$, and of $T_{e}$ are also shown in columns 1,5 , and 6 of Table 11. Electron density, remaining $\mathrm{N}_{2} \mathrm{O}$ percentage, and dissociation percentages variations from Shutov et al. [7] are also given inside bold brackets in Table 11 for comparison. These are varying similarly to our results. It has to be noted that in results from [7], electron density was put equal to this of $\mathrm{N}_{2} \mathrm{O}^{+}$, while in our model we used the aforementioned quasi-neutrality condition. The two slightly different values of $n_{e}$ variation according to [7] are due to small $n_{\mathrm{TOT}}$ changes 
in the experiment following the $P_{\mathrm{abs}}$ values. Besides the increase in both electron density and dissociation of $\mathrm{N}_{2}, \mathrm{O}_{2}$, and $\mathrm{N}_{2} \mathrm{O}$ with the absorbed power as shown in columns 3, 4 , and 2 (remaining $\mathrm{N}_{2} \mathrm{O}$ density diminishes) of Table 11 , the densities of all positive ions, not shown in Table 11, increase. However, it was found that $\mathrm{N}_{2} \mathrm{O}^{+}$density decreases. The $\mathrm{O}^{-}$density slightly decreases, due to small increase in $\mathrm{O}^{-}$neutralization, whereas the $\mathrm{O}^{-}$formation by electronic impact for the conditions encountered here is diminishing. The calculated electronegativity (see column 5 of Table 11) is small and slightly decreasing, as expected for a pressure of 5 mTorr. $T_{e}$ remains about the same. Oxygen plasmas are typically "recombination dominated" for low pressures and high electron densities according to [41]. Decrease in $\mathrm{O}^{-}$ density with increasing power was also observed recently in $[15,19]$. We verified that this is also the case for the $\mathrm{N}_{2} \mathrm{O}$ PR working at low pressure and high power, for which we found an electronegativity of less than 0.2 for $500 \mathrm{~W}$. We also verified the aforementioned observation of [41] in the case of low pressure high electron density plasmas.

Results obtained when the flow rate varies from $20 \mathrm{sccm}$ up to $80 \mathrm{sccm}$ are also illustrated in the second row of Table 11 for the same pressure as before, namely, 5 mTorr, and a fixed absorbed power of $300 \mathrm{~W}$. We found that for a flow rate varying from $20 \mathrm{sccm}$ to $80 \mathrm{sccm}$, most of the species densities present only small variations, except for the $\mathrm{N}_{2} \mathrm{O}$ and also $\mathrm{N}_{2} \mathrm{O}^{+}$and $\mathrm{NO}$ densities (not shown in the table), which increase by more than a factor of four. As a consequence of the $\mathrm{N}_{2} \mathrm{O}$ increase with the flow rate, the $\mathrm{O}^{-}$density also increases by about a factor of two (see column 5 ), while the $n_{e}$ slightly decreases (see column 1 ). We observe in Table 11 that while the remaining $\mathrm{N}_{2} \mathrm{O}$ percentage increases with the flow rate, the $T_{e}$ remains approximately constant. The ionization percentage decreases, as expected in view of the $n_{e}$ concomitant decrease shown in column 1 of the table. Notably, variations observed here are inverse to those belonging to the first row for except a small diminishing of $T_{e}$. Hence, absorbed power is in antagonism to the flow rate, showing an inverse effect. For the presented range of parameters, a general observation is that results vary very smoothly when the same values of $\gamma$ are kept.

The two last rows of Table 11 illustrate sensitivity of the results as a function of a couple of $\mathrm{N}$ and $\mathrm{O}$ sticking coefficients values $\gamma_{\mathrm{N}}$ and $\gamma_{\mathrm{O}}$ available in the literature. When $\gamma_{N}$ increases by a factor of 3.5 , the remaining $\mathrm{N}_{2} \mathrm{O}$ percentage decreases and the $n_{e}$ and the $\mathrm{O}_{2}$ dissociation percentages slightly increase, while the $\mathrm{N}$ percentage diminishes considerably. The electronegativity is decreasing in this case. Also, when $\gamma_{\mathrm{O}}$ increases by almost a factor of three, less atomic oxygen (about half) is present in the discharge (column 4). Consequently, less $\mathrm{O}\left({ }^{1} \mathrm{D}\right)$ species are present to destroy the $\mathrm{N}_{2} \mathrm{O}$, so the remaining $\mathrm{N}_{2} \mathrm{O}$ percentage increases (column 2). The $n_{e}$ is slightly decreasing, leading to a slight diminishing of $\mathrm{N}_{2}$ dissociation percentage. $T_{e}$ variations for 5 mTorr pressure are shown in Table 11.

A glimpse of the physical meaning of the sticking coefficients can be obtained by considering their correlation with the power and the feeding variations. Variations observed for absorbed power increase coincide with those from $\gamma_{\mathrm{N}}$ increase, except for $\mathrm{N}$, which is specifically diminishing. Also, increase in feeding leads to variations coordinated with those from $\gamma_{\mathrm{O}}$ increase, except for the $T_{e}$ which remains stable.

In a general way, we can say that our variation results with power, flow rate, and $\mathrm{N}$ sticking coefficients $\gamma_{\mathrm{N}}$ and $\gamma_{\mathrm{O}}$ are compatible with those contained in Table 8 of [12], which were evaluated for pure $\mathrm{N}_{2}$ feeding.

\section{Study of Hollow Cathode $\mathrm{N}_{2} \mathrm{O}$ Plasma Discharges}

We applied our GM to the study of $\mathrm{N}_{2} \mathrm{O}$ plasmas contained in two typical hollow cathode experiments described in $[8,10]$. The main difference between the two experiments consists in the pressure values. It begins from 200 mTorr for the first experiment and goes to 1400 mTorr for the second. An intermediate pressure of 700 mTorr is also addressed in [10] that we will not treat here. Reference [8] contains an up to date review of the available extended work on the subject, which we do not repeat here.

7.1. $\mathrm{N}_{2} \mathrm{O}$ Hollow Cathode Discharge of $p=200$ mTorr, Length $L=7 \mathrm{~cm}$, and Radius $R=3 \mathrm{~cm}$; See [8]. Our model is applied to the $\mathrm{N}_{2} \mathrm{O}$ hollow cathode glow discharge of length $L=7 \mathrm{~cm}$ and radius $R=3 \mathrm{~cm}$ as described in [8]. The pressure of $p=200 \mathrm{~m}$ Torr is the lower one within the experimental conditions studied by Yousif and Mondragon [8]. Although higher pressure (up to 1.1 Torr) measurements are also described in [8], we compare here our results only for the lower pressure case of 200 mTorr. In the experiment of [8], the applied power was $14 \mathrm{~W}$, corresponding to an absorbed power of $10 \mathrm{~W}$ if we assume that $70 \%$ of the available power is absorbed by the plasma. The gas temperature used in our calculations was $T_{\mathrm{GAS}}=400 \mathrm{~K}$. No information about $T_{\mathrm{GAS}}$ was given in [8]. $n_{e}$ values of [8] were obtained by probe measurements. According to [8], a "collisionless $n_{e}$ " value was directly measured, while the collisional $n_{e}$ one was evaluated by including the influence of the plasma sheath on the probe.

Characterization of the plasma for various flow rates is very important for applications. Therefore, we calculated $n_{e}$ and $T_{e}$ values when the flow rate varies from $2 \mathrm{sccm}$ to $10 \mathrm{sccm}$. Our results are represented in Figure 11 with plain lines. The absorbed power was fixed at $10 \mathrm{~W}$. Values from [8] are also given in Figure 11, plotted by dashed lines, which indicate artificially constant values, as the authors did not mention to which flow rate value the values of the experiment correspond. In our calculations, we observe a slight increase in the $T_{e}$ and a diminishing of the $n_{e}$. This is to compare with the diminishing of $n_{e}$ illustrated in Table 11. Analogous results for higher absorbed power Ar fed HPT plasmas have been presented in [2].

7.2. Hollow Cathode $\mathrm{N}_{2} \mathrm{O}$ Discharge of $p=1400$ mTorr, Length $L=9 \mathrm{~cm}$, and Radius $R=0.8 \mathrm{~cm}$; See [10]. After applying our model to the study of a relatively low pressure hollow cathode case (200 mTorr) we examine a higher pressure cathode 


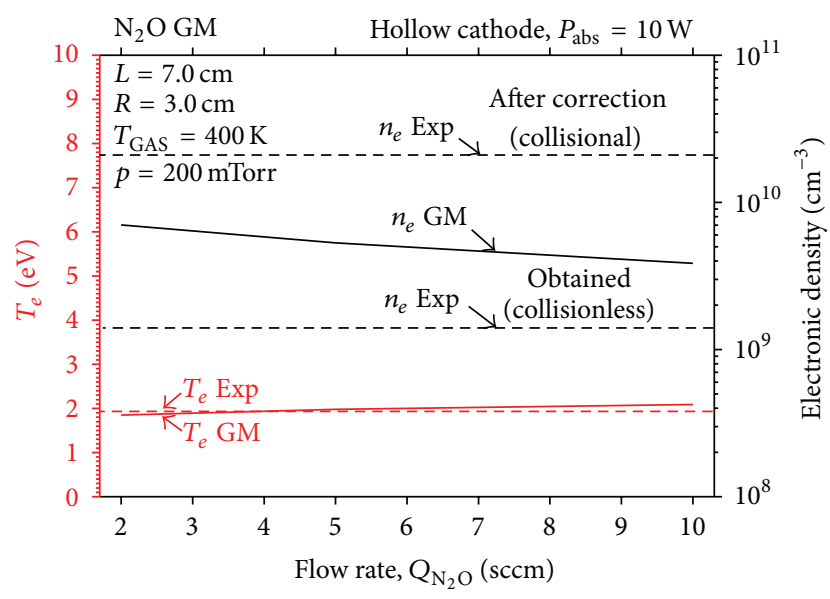

Plain lines: present results

Dashed lines: Yousif and Mondragon Exp

FIGURE 11: Variation of the $n_{e}$ and $T_{e}$ when flow rate varies from $2 \mathrm{sccm}$ to $10 \mathrm{sccm}$.

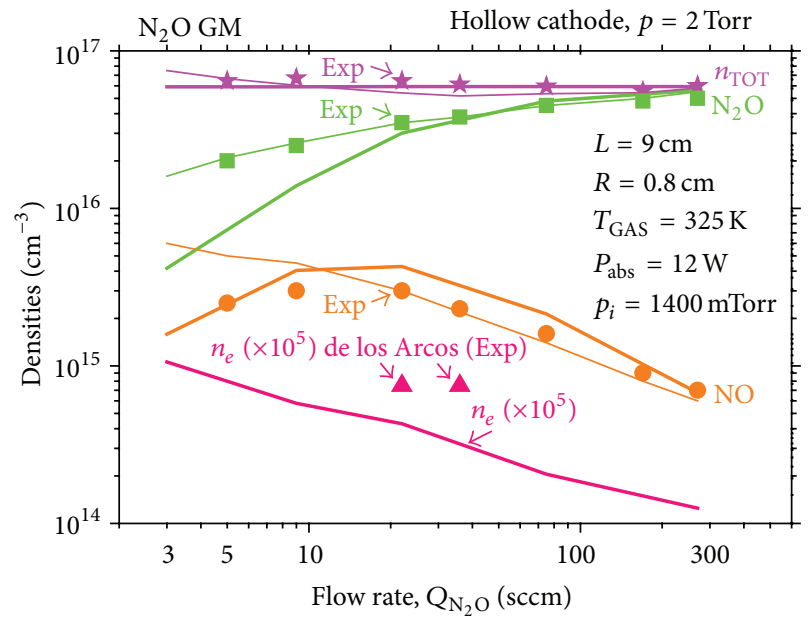

Thick lines: present results Symbols: de los Arcos Exp Thin lines: de los Arcos theory

FIgURE 12: Variation of the $\mathrm{N}_{2} \mathrm{O}, \mathrm{NO}$, and electron and total density of species when flow rate varies from $3 \mathrm{sccm}$ to $270 \mathrm{sccm}$.

discharge. In so doing, our results are compared with those described in [10], concerning a device with slightly smaller volume than that of the experiment addressed in Section 7.1, of length $L=9 \mathrm{~cm}$ and radius $R=0.8 \mathrm{~cm}$. In [10], variations of the plasma parameters for a flow rate varying from $3 \mathrm{sccm}$ to $265 \mathrm{sccm}$ with an applied power increasing from $5 \mathrm{~W}$ to $56 \mathrm{~W}$ were studied. Our model provides description of the plasma in those physical conditions assuming varying pumping speeds, resulting in a pressure after dissociation of 2 Torr corresponding to the "starting" one of 1400 mTorr. The cylinder with the aforementioned length $L=9 \mathrm{~cm}$ and radius $R=0.8 \mathrm{~cm}$ is contained in an external cylindrical stainless steel chamber of length $L=20 \mathrm{~cm}$ and radius $R=1.2 \mathrm{~cm}$. $T_{e}$ and $n_{e}$ values have been measured by Langmuir probes and neutral densities were measured by infrared spectroscopy.

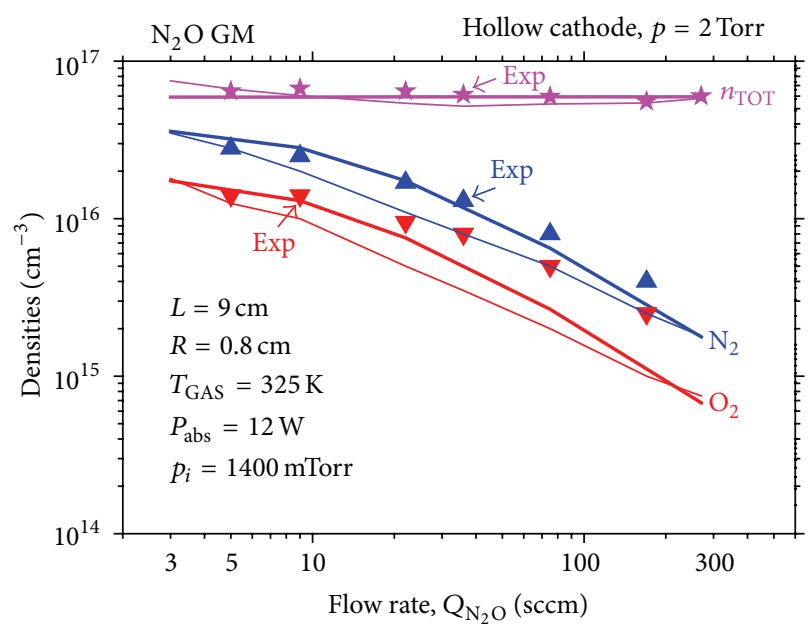

Thick lines: present results Symbols: de los Arcos Exp Thin lines: de los Arcos theory

Figure 13: As in Figure 12 but for $\mathrm{N}_{2}, \mathrm{O}_{2}$, and total density.

Mass spectrometry addressed $\mathrm{N}_{2} \mathrm{O}, \mathrm{N}_{2}, \mathrm{O}_{2}$, and $\mathrm{NO}$ species. de los Arcos et al. [10] have also made calculations which allowed a comparison with their experimental results.

Species densities calculated by our model are shown in Figures 12 and 13 as a function of the flow rate going from $3 \mathrm{sccm}$ to $270 \mathrm{sccm}$ and an absorbed power fixed at $12 \mathrm{~W}$. For this case, we retained the pressure of 2 Torr, calculated for a gas temperature $T_{\mathrm{GAS}}=325 \mathrm{~K}$ and the experimentally measured "starting pressure" (total density of species) of $p=1400$ mTorr. We use a constant total density of species, also represented in Figures 12 and 13 by a thick magenta line, as the final pressure was fixed in our calculations. Therefore, the experimental (magenta stars) and theoretical (thin magenta line) values of [10] are almost constant even if the flow rate varies. For a flow rate of $3 \mathrm{sccm}$, the $\mathrm{N}_{2} \mathrm{O}$ density calculated by our model has a very low value of $n_{\mathrm{N}_{2} \mathrm{O}}=4.2$. $10^{15} \mathrm{~cm}^{-3}$. However, the $\mathrm{N}_{2} \mathrm{O}$ density increases continuously with the flow rate and becomes preponderant for $270 \mathrm{sccm}$, as shown in Figure 12. To simplify Figure 12, the densities of the important molecular products $\mathrm{N}_{2}$ and $\mathrm{O}_{2}$ are represented separately in Figure 13. These densities decrease progressively with the flow rate, becoming comparable to this of NO for $270 \mathrm{sccm}$. The $\mathrm{N}$ and $\mathrm{O}$ densities and the positive ion densities are not represented because they have very low values, becoming negligible at $270 \mathrm{sccm}$, as expected in view of the big pressure of 2 Torr. Also, the electron density decreases with the flow rate. Theoretical and experimental results of [10] for the variation of the $\mathrm{N}_{2} \mathrm{O}$ and $\mathrm{NO}$ densities are represented in Figure 12, together with experimental values of the $n_{e}$ from [10]. The latter correspond to measurements at the central position of the cathode. Note that results for other positions have also been measured in [10]. Results of [10] for the variation of the $\mathrm{N}_{2}$ and $\mathrm{O}_{2}$ densities are represented in Figure 13. These are occasionally in good agreement with experiment and with our results. Still, for the $\mathrm{N}_{2} \mathrm{O}$ density important discrepancies appear, notably at low flow rates. 
The absorbed power value remains unclear, as no specific information was given about by the authors. However, measured experimental $T_{e}$ and $n_{e}$ can be used for comparison instead of the absorbed power which we introduced in our calculations. In Figures 12 and 13, we used a $P_{\text {abs }}$ of $12 \mathrm{~W}$ for all the flow rates, which corresponds to an invariant absorption percentage of less than $50 \%$ of the applied power, although we believe that the part of the power absorbed by the plasma may be in fact lower for small flow rates and higher for big ones.

Our results for variations of the $T_{e}$ and of the remaining $\mathrm{N}_{2} \mathrm{O}$ percentage, not represented here, show an increase in $T_{e}$ with the flow rate from $1.5 \mathrm{eV}$ for $3 \mathrm{sccm}$ up to $2.8 \mathrm{eV}$ for $270 \mathrm{sccm}$. A similar increase in the $T_{e}$ with the flow rate being previously obtained by a GM meant for argon discharges study [2]. The calculated remaining $\mathrm{N}_{2} \mathrm{O}$ percentages, increasing with the flow rate from about $7 \%$ to $95 \%$, indicate a wide range of $\mathrm{N}_{2} \mathrm{O}$ decomposition which is conformal with the $\mathrm{N}_{2} \mathrm{O}$ percentage variation, also observed in the PR case (see Table 11).

Comparisons shown in Figures 12 and 13 suggest that our model is furthermore applicable to rather high pressure discharges and that it is suitable to study the density and $T_{e}$ variations in a wide flow rate region (here from $3 \mathrm{sccm}$ to $270 \mathrm{sccm}$ ) corresponding to an extended $\mathrm{N}_{2} \mathrm{O}$ decomposition percentages range. Moreover, they indicate that there is an analogy between the studied here hollow cathode glow discharge and small plasma thrusters, as their dimensions and hence their optimum functioning flow rates are quite similar. Pressure was rather high in the cathode experiment, as was also the case in, for example, an ICP "micro-thruster" mentioned in [65] working in pressures up to 7 Torr. In the latter device, the power was quite similar (5 W-40 W) and the flow rates slightly higher (from few tens to few hundreds of $\mathrm{sccm}$ ) than those studied in [10].

Note that $\mathrm{N}_{2} \mathrm{O}$ density results of our GM for a lower pressure of $p=700$ mTorr have been found being in good agreement with experimental results from [10] for low and intermediate absorbed powers (from $3 \mathrm{~W}$ up to $21 \mathrm{~W}$ ).

\section{Modeling Discharges Fed with $\mathrm{N}_{2} / \mathbf{O}_{2}$ Mixtures}

Following our results discussed in Sections 6 and 7, for a large domain of pressures and of absorbed energies, discharges in $\mathrm{N}_{2} \mathrm{O}$ may lead quantitatively to a $\mathrm{N}_{2}$ and $\mathrm{O}_{2}$ mixture in an approximate percentage of $2: 1$, with $\mathrm{N}_{2} \mathrm{O}$ becoming very scarce when its electron collision dissociation becomes important. This result suggests that we should further investigate the properties of discharges in $\mathrm{N}_{2} / \mathrm{O}_{2}$ mixtures and compare the results with those obtained for $\mathrm{N}_{2} \mathrm{O}$ feeding. We present here GM results for $\mathrm{N}_{2} / \mathrm{O}_{2}$ mixtures using the model and data described previously, but with $\mathrm{N}_{2} / \mathrm{O}_{2}$ feeding instead of the $\mathrm{N}_{2} \mathrm{O}$ one. Addressing a PR with geometry and conditions similar to those used in Section 6 allows a direct comparison of the results for $\mathrm{N}_{2} / \mathrm{O}_{2}$ feeding with those which were obtained for $\mathrm{N}_{2} \mathrm{O}$ feeding. We first present our results for an $\mathrm{N}_{2}$ and $\mathrm{O}_{2}$ mixture in a percentage close to this obtained

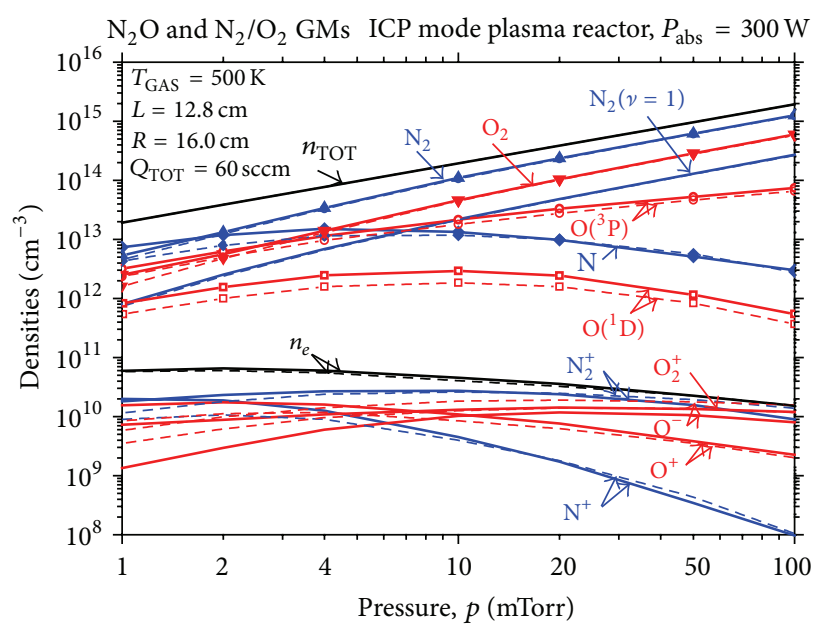

Thick plain lines: $\mathrm{N}_{2} / \mathrm{O}_{2}$ with $2: 1\left[\mathrm{~N}_{2}\right]:\left[\mathrm{O}_{2}\right]$

Thin dashed lines: $\mathrm{N}_{2} \mathrm{O}$

FIGURE 14: Comparison of the variations of the densities of species for $\mathrm{N}_{2} / \mathrm{O}_{2}$ (plain lines) and for $\mathrm{N}_{2} \mathrm{O}$ (short dashed lines) feedings with $Q_{\mathrm{N}_{2}}=2 \cdot Q_{\mathrm{O}_{2}}$. Pressure varies from $1 \mathrm{~m}$ Torr to $100 \mathrm{mTorr}$.

with $\mathrm{N}_{2} \mathrm{O}$ feeding when $\mathrm{N}_{2} \mathrm{O}$ is largely dissociated. In this case we use a typical flow rate $Q_{\mathrm{N}_{2}}=2 \cdot Q_{\mathrm{O}_{2}}$, often noted as $2: 1\left[\mathrm{~N}_{2}\right]:\left[\mathrm{O}_{2}\right]$. Furthermore, in view of the importance of the air discharges and notably of their interest in aerospace and electric propulsion applications, we address a second feeding case with an $\mathrm{N}_{2} / \mathrm{O}_{2}$ percentage close to this of the air composition, having a flow rate $Q_{\mathrm{N}_{2}}=4 \cdot Q_{\mathrm{O}_{2}}(4: 1$ $\left.\left[\mathrm{N}_{2}\right]:\left[\mathrm{O}_{2}\right]\right)$. The results obtained using our models for the two flows are compared and discussed in the following. In what concerns higher pressures, we compare $\mathrm{N}_{2} / \mathrm{O}_{2}$ results calculated by our GM with those obtained by Gordiets et al. [11] for a glow discharge experiment.

8.1. $\mathrm{N}_{2} / \mathrm{O}_{2}$ Mixture Feeding with Intense $\mathrm{N}_{2} \mathrm{O}$ Decomposition: $Q_{N_{2}}=2 \cdot Q_{\mathrm{O}_{2}}$. Variation of the species densities obtained for a $\mathrm{N}_{2} / \mathrm{O}_{2}$ mixture discharge fed with flow rates of $Q_{\mathrm{N}_{2}}=$ $40 \mathrm{sccm}$ and $Q_{\mathrm{O}_{2}}=20 \mathrm{sccm}$, when the absorbed power is $300 \mathrm{~W}$, is shown in Figure 14. In general, oxygen species are represented by red color and nitrogen by blue one. As in Figures 8, 9, and 10, the pressure is varying in the range from $1 \mathrm{~m}$ Torr to 100 mTorr. In order to better illustrate the comparison of the results obtained for $\mathrm{N}_{2} \mathrm{O}$ and for $\mathrm{N}_{2} / \mathrm{O}_{2}$ mixture feedings we present in Figure 14 the corresponding calculated densities. Densities obtained for the two feeding cases are found to be in general comparable. Variations of the species densities represented by thick plain lines are quite similar to those obtained in the $\mathrm{N}_{2} \mathrm{O}$ case plotted again in Figure 14 by thin dashed lines, to ease the comparison. We see that most of the nitrogen and oxygen species densities are very close to the results obtained either for the $\mathrm{N}_{2} / \mathrm{O}_{2}$ feeding or for the $\mathrm{N}_{2} \mathrm{O}$ one. Although the main species present are $\mathrm{N}_{2}$ and $\mathrm{O}_{2}$ for pressure higher than 4 mTorr, $\mathrm{N}$ and $\mathrm{O}$ are still present in a substantial amount at the lower pressures. They become negligible for 100 mTorr for both the feeding cases. For $\mathrm{N}_{2} / \mathrm{O}_{2}$ feeding, the $\mathrm{N}_{2}$ and $\mathrm{O}_{2}$ densities 


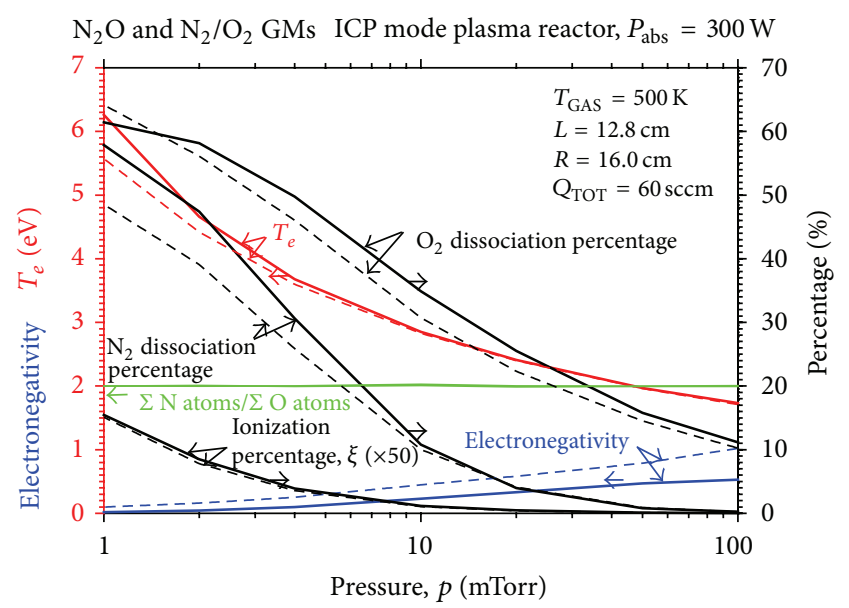

Thick plain lines: $\mathrm{N}_{2} / \mathrm{O}_{2}$ with $2: 1\left[\mathrm{~N}_{2}\right]:\left[\mathrm{O}_{2}\right]$

Thin dashed lines: $\mathrm{N}_{2} \mathrm{O}$

FIgURE 15: Comparison of the $T_{e}$, ionization, and dissociation percentages and of electronegativities for $Q_{\mathrm{N}_{2}}=2 \cdot Q_{\mathrm{O}_{2}}$ (plain lines) and for $\mathrm{N}_{2} \mathrm{O}$ (short dashed lines) feedings. Pressure varies from 1 mTorr to 100 mTorr.

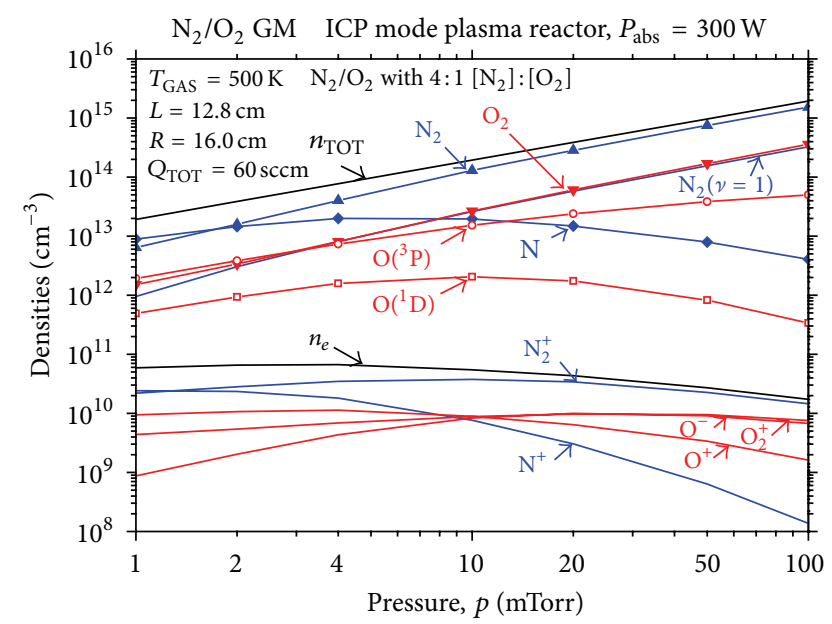

Figure 16: Densities of species for $Q_{\mathrm{N}_{2}}=4 \cdot Q_{\mathrm{O}_{2}}$ feeding. Pressure varies from $1 \mathrm{~m}$ Torr to 100 mTorr.

are slightly greater than in the $\mathrm{N}_{2} \mathrm{O}$ feeding case, as the total density remains the same while no $\mathrm{N}_{2} \mathrm{O}$ species is present. In Figure 14 we observe differences in the positive ion densities, especially for the $\mathrm{N}^{+}$and $\mathrm{O}^{+}$at low pressure and for the $\mathrm{N}_{2}^{+}$ for higher ones. For $\mathrm{N}_{2} / \mathrm{O}_{2}$ feeding, the $\mathrm{O}^{-}$density is between four and two times lower, leading to a lower electronegativity as it can be seen by inspection of Figure 15, in which thick and thin lines are used similarly to Figure 14. This was somehow expected and illustrates the relative importance of the $\mathrm{N}_{2} \mathrm{O}$ dissociative attachment, in comparison with the $\mathrm{O}_{2}$ dissociative attachment. The $n_{e}$ obtained for the mixture is very close to the one obtained for the $\mathrm{N}_{2} \mathrm{O}$ feeding, as is also illustrated in Figure 14 by black lines. This means that the energy losses of the two types of plasmas are close, at least for the present conditions where $\mathrm{N}_{2} \mathrm{O}$ molecules are quite dissociated.

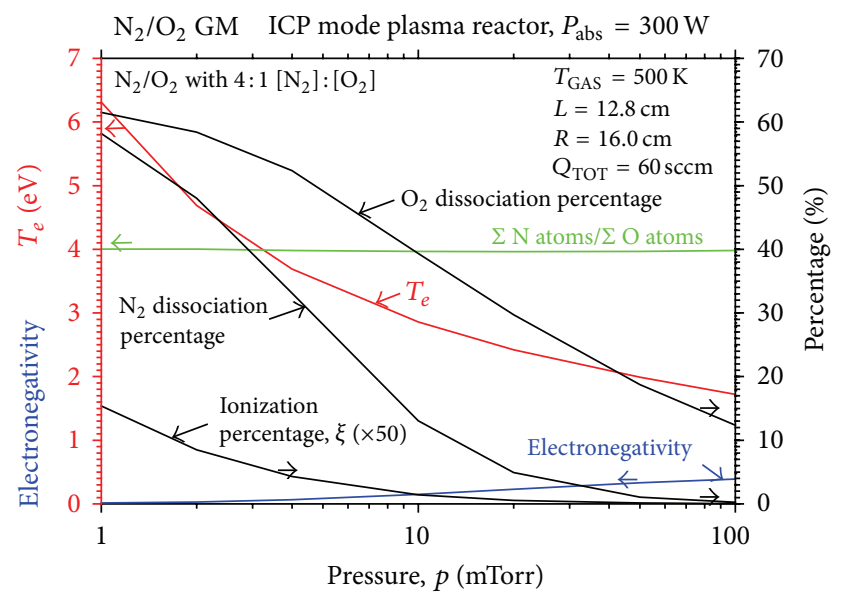

FIGURE 17: As in Figure 16 but for $T_{e}$, ionization, and dissociation percentages and electronegativity.

For feedings by $Q_{\mathrm{N}_{2}}=2 \cdot \mathrm{Q}_{\mathrm{O}_{2}}$ mixture and by $\mathrm{N}_{2} \mathrm{O}$, the obtained $T_{e}$ (in red) and ionization/dissociation percentages (in black) are shown in Figure 15, together with the electronegativity (in blue). They are plotted with plain and dashed lines correspondingly, for pressures varying from $1 \mathrm{~m}$ Torr to 100 mTorr. The obtained $T_{e}$ are slightly higher for the mixture (plain red line) than for the $\mathrm{N}_{2} \mathrm{O}$ (dashed red line) case. We see that both $\mathrm{N}_{2}$ and $\mathrm{O}_{2}$ dissociation percentages (black lines) are greater for the mixture than for the $\mathrm{N}_{2} \mathrm{O}$ feeding. The electronegativity, also represented in Figure 15, is lower for the feeding by mixture, with the difference increasing continuously with pressure.

8.2. Feeding with a $Q_{N_{2}}=4 \cdot Q_{\mathrm{O}_{2}}$ Mixture, Close to the Air Composition. Because of the importance of $Q_{\mathrm{N}_{2}}=4 \cdot Q_{\mathrm{O}_{2}}$ feeding (4:1 $\left.\left[\mathrm{N}_{2}\right]:\left[\mathrm{O}_{2}\right]\right)$, mimicking the air composition, we extended GM calculations described in Section 8.1 to such a feeding. Results can be applied, for example, to studies of reentrance or to air fed thrusters. In this latter calculation, $\mathrm{O}_{2}$ feeding is about half of the one considered previously in Section 8.1, with the $\mathrm{N}_{2}$ one increasing accordingly. GM calculations obtained for a feeding of $12 \mathrm{sccm}$ of $\mathrm{O}_{2}$ and $48 \mathrm{sccm}$ of $\mathrm{N}_{2}$ are expected to lead to clearly smaller electronegativity than in Section 8.1. Obtained results are presented in Figures 16 and 17. They are to be compared with those illustrated in Figures 14 and 15 belonging to the $Q_{\mathrm{N}_{2}}=2 \cdot Q_{\mathrm{O}_{2}}$ case. In Figure 16 we present the species density variations with the pressure, as was also the case in Figures 8, 9, and 14. For low pressures, the main species $\mathrm{N}_{2}, \mathrm{O}_{2}, \mathrm{~N}$, and $\mathrm{O}$ present in the latter figures are again present in Figure 16 showing comparable densities. In both cases, when pressure is increasing, $\mathrm{N}_{2}$ and $\mathrm{O}_{2}$ densities increase quite linearly to the detriment of $\mathrm{N}$ and $\mathrm{O}$ presence and finally become the main components of the plasma. With the pumping being considered similar for all species, the sum of all the nitrogen species equals here the sum of all the oxygen species when multiplied by four. However, $\mathrm{N}$ and $\mathrm{O}$ densities are present in different percentages because $\mathrm{O}_{2}$ dissociates easier than $\mathrm{N}_{2}$. In comparison with the previously used feeding mixture $2: 1$ 
TABLE 12: Our GM results for $n_{e}, T_{e}$, and relative $\mathrm{N}_{2}$ vibrational populations $\nu 1, v 2$, and $\nu 3$ (in bold) for an air-like discharge. Comparison with experimental and theoretical results from [11](in italic).

\begin{tabular}{lcccccccc}
\hline $\mathrm{I}(\mathrm{mA}) \operatorname{Exp}$ & $P_{\mathrm{abs}}(\mathrm{W})^{(*)}$ & $\begin{array}{c}T_{\mathrm{GAS} \mathrm{GOR}}(\mathrm{K}) \\
\operatorname{Exp} / \mathrm{Th}\end{array}$ & $\begin{array}{c}n_{e \mathrm{GOR}}{ }^{(* *)} \\
\operatorname{Exp} / \mathrm{Th}\end{array}$ & $n_{e \mathrm{GM}}{ }^{(* *)}$ & $\begin{array}{c}T_{e \mathrm{GM}} \\
(\mathrm{eV})\end{array}$ & $\nu 1_{\mathrm{GM}}{ }^{(* * *)}$ & $\nu 2_{\mathrm{GM}}{ }^{(* * *)}$ & $\nu 3_{\mathrm{GM}}{ }^{(* * *)}$ \\
\hline 80 & 15. & $880 / 930$ & $18.5 / 25$. & $\mathbf{2 6 .}$ & $\mathbf{1 . 7 9}$ & $\mathbf{1 9 \%}$ & $\mathbf{1 4 \%}$ & $\mathbf{1 0 \%}$ \\
30 & 10. & $580 / 580$ & $7.5 / 9.5$ & $\mathbf{9 . 5}$ & $\mathbf{1 . 8 4}$ & $\mathbf{1 6 \%}$ & $\mathbf{1 1 \%}$ & $\mathbf{8 \%}$ \\
15 & 5 & $530 / 470$ & $3.5 / 4.5$ & $\mathbf{3 . 7}$ & $\mathbf{1 . 8 8}$ & $\mathbf{1 0 \%}$ & $\mathbf{7 \%}$ & $\mathbf{5 \%}$ \\
\hline
\end{tabular}

(*): assumed.

$(* *)$ : electron densities in $10^{9} \mathrm{~cm}^{-3}$.

$(* * *)$ : last three columns give the relative population of the three lower excited levels.

TABLE 13: As in Table 12 but for a $\mathrm{N}_{2} / \mathrm{O}_{2}$ discharge with $2 \%$ of $\mathrm{O}_{2}$.

\begin{tabular}{lcccccccc}
\hline $\mathrm{I}(\mathrm{mA})$ & $P_{\mathrm{abs}}(\mathrm{W})^{(*)}$ & $T_{\mathrm{GAS} \mathrm{GOR}}(\mathrm{K})$ & $n_{e \mathrm{GOR}}{ }^{(* *)}$ & $n_{e \mathrm{GM}}{ }^{(* *)}$ & $T_{e \mathrm{GM}}(\mathrm{eV})$ & $\nu 1_{\mathrm{GM}} / \nu 1_{\mathrm{GOR}}{ }^{(* * *)}$ & $\nu 2_{\mathrm{GM}} / \nu 2_{\mathrm{GOR}}{ }^{(* * *)}$ & $\nu 3_{\mathrm{GM}} / \nu 3_{\mathrm{GOR}}{ }^{(* * *)}$ \\
\hline $\operatorname{Exp}$ & 15. & $800 / 1000$ & $-/ 29$. & $\mathbf{3 5 .}$ & $\mathbf{1 . 4 8}$ & $\mathbf{2 1 \% / 1 8 \%}$ & $\mathbf{1 5 \%} / \mathbf{1 4 \%}$ & $\mathbf{1 1 \% / 1 0 \%}$ \\
30 & 10. & $580 / 580$ & $9 . / 11$. & $\mathbf{1 5 .}$ & $\mathbf{1 . 4 7}$ & $\mathbf{1 8 \% / -}$ & $\mathbf{1 3 \% / -}$ & $\mathbf{9 \% / -}$ \\
15 & 5 & $500 / 490$ & $4 . / 5.1$ & $\mathbf{4 . 8}$ & $\mathbf{1 . 4 7}$ & $\mathbf{1 2 \% / 1 8 \%}$ & $\mathbf{8 \% / 1 0 \%}$ & $\mathbf{5 \% / 8 \%}$ \\
\hline
\end{tabular}

$(*),(* *)$, and $(* * *)$ as in Table 12 .

$\left[\mathrm{N}_{2}\right]:\left[\mathrm{O}_{2}\right]$, the $\mathrm{N}$ and $\mathrm{O}$ densities are correspondingly slightly higher and slightly lower for this mixture feeding case than for the previous one, as expected in view of the nitrogen and oxygen amounts present in the discharge. The $n_{e}$ obtained in both cases are rather similar, as can be seen by inspection of Figures 14 and 16. However, although a general decrease in the $\mathrm{O}^{+}, \mathrm{O}_{2}{ }^{+}$, and $\mathrm{O}^{-}$ions and an increase in the $\mathrm{N}^{+}$and $\mathrm{N}_{2}{ }^{+}$ ones when passing from the $2: 1$ percentage to the $4: 1$ one are observed, the $\mathrm{N}_{2}{ }^{+}$ions are more abundant than all the oxygen ones in the bulk of conditions.

Variations of the $T_{e}$, ionization, and dissociation percentages and of the electronegativity for $Q_{\mathrm{N}_{2}}=4 \cdot Q_{\mathrm{O}_{2}}$ feeding when the pressure varies from 1 mTorr to 100 mTorr are plotted in Figure 17.

In view of our results obtained for $\mathrm{N}_{2} \mathrm{O}$ and for $\mathrm{N}_{2} / \mathrm{O}_{2}$ mixtures feedings, we conclude that discharges in $\mathrm{N}_{2} \mathrm{O}$ behave in a similar manner to the air fed discharges in a quite large region of conditions. In high pressures, however, other reactions not considered in our GMs may play an important role in the air discharge case (cf. Gordiets et al. [11] and Laux et al. [9]) limiting the observed similarity. Results for a concrete case of $4: 1\left[\mathrm{~N}_{2}\right]:\left[\mathrm{O}_{2}\right]$ feeding with application in electric propulsion may constitute an example. Also, for very low absorbed power, the discharge equilibrium is quite different, because the $\mathrm{N}_{2} \mathrm{O}$ dissociation is then substantially lower.

8.3. $\mathrm{N}_{2} / \mathrm{O}_{2}$ Glow Discharge Experiment of $p=2$ Torr and Radius $R=0.8 \mathrm{~cm}$; See [11]. Gordiets et al. [11] studied a flowing glow discharge in various mixtures of $\mathrm{N}_{2}$ and $\mathrm{O}_{2}$, in an experiment which they analyzed using an extended set of reactions. In the kinetic model developed in [11], which follows the method of calculation proposed in [40], a quite high number of $\mathrm{N}_{2}$ vibrational levels was taken into consideration. The glow discharge device was rather analogous with the one used previously by de los Arcos et al. [10]. Our GM results for $\mathrm{N}_{2} / \mathrm{O}_{2}$ mixtures for a cylinder with radius $R=0.8 \mathrm{~cm}$ and supposed length $L=9 \mathrm{~cm}$, as no information about the latter was given, are compared to those of Gordiets et al. [11]. We used a fixed flow rate of $100 \mathrm{sccm}$, the same with the experiment and absorbed powers $P_{\mathrm{abs}}$ of $5 \mathrm{~W}, 10 \mathrm{~W}$ and $15 \mathrm{~W}$, which we associated to the currents of $15 \mathrm{~mA}, 30 \mathrm{~mA}$, and $80 \mathrm{~mA}$ reported in [11]. Moreover, the gas temperature values in our calculations are those reported for the experiment for each of the three currents. Our results, reported in Tables 12 and 13, are in general close to the values of [11], also included in the tables. For the air-like case of Table 12, we obtain electron densities $n_{e}$ which are very close to those of [11], as shown in the $n_{e}$ GOR and $n_{e}$ GM columns of Table 12. Corresponding $T_{e}$ calculated by GM are also given in Table 12. Our results for the relative population of the three lower $\mathrm{N}_{2}$ vibrational states in air-like mixture are also shown in Table 12.

Moreover, we made calculations for a $\mathrm{N}_{2} / \mathrm{O}_{2}$ mixture containing $2 \%$ of $\mathrm{O}_{2}$, to compare with the corresponding experimental and theoretical results of [11]. Table 13 illustrates this comparison. Even if in our calculations we used much less vibrationally excited $\mathrm{N}_{2}$ states than those included in [11], results show a quite good agreement. This indicates that the number of the vibrationally excited levels included in our GM is sufficient, at least for the air-like mixture and for the $\mathrm{N}_{2} / \mathrm{O}_{2}$ mixture with $2 \%$ of $\mathrm{O}_{2}$. In [11] the gas temperature has been calculated and measured. A diminishing of the gas temperature when the $\mathrm{O}_{2}$ percentage increases was observed. Throughout our calculations of the $\mathrm{N}_{2} / \mathrm{O}_{2}$ mixtures of Sections 8.1 and 8.2 such a temperature change is not taken into consideration.

\section{Conclusions}

A GM was developed and applied to the study of various cases of $\mathrm{N}_{2} \mathrm{O}$ discharges as ICP plasma reactors, hollow cathodes, and glow discharges. The important cases of the "core" region of HPT and of hall effect thruster (HET) propulsion devices fed with $\mathrm{N}_{2}, \mathrm{O}_{2}$, and their mixtures can also be 
studied by this model after validation. The model can also be extended to study in general discharges in $\mathrm{N}_{2}$ and $\mathrm{O}_{2}$ plasmas, including their mixtures, particularly this corresponding to air. Densities of species and electron temperature variations are presented and discussed for a wide range of pressure, absorbed power, and flow rates. Main results of our $\mathrm{N}_{2} \mathrm{O}$ discharge study were discussed and compared with existing experimental and theoretical results. We found that the main species of $\mathrm{N}_{2} \mathrm{O}$ are the $\mathrm{N}_{2}$ and the $\mathrm{O}_{2}$ for most of the cases, with the $\mathrm{N}_{2} \mathrm{O}$ amount being less important for low pressures and for increasing absorbed power. We have shown the importance of the $\mathrm{N}$ and $\mathrm{O}$ species at low pressures, which are notably of interest in electric propulsion. Indeed, for pressures from 1 mTorr to about 3 mTorr, the $\mathrm{N}$ and $\mathrm{O}$ species are as important as the $\mathrm{N}_{2}$ and $\mathrm{O}_{2}$ species. This tendency was omitted in previous $\mathrm{N}_{2} \mathrm{O}$ work, where the $\mathrm{N}_{2}$ and $\mathrm{O}_{2}$ dissociations were often absent. The densities of the main positive ions $\left(\mathrm{N}_{2} \mathrm{O}^{+}, \mathrm{N}_{2}{ }^{+}, \mathrm{O}_{2}{ }^{+}, \mathrm{N}^{+}\right.$, and $\left.\mathrm{O}^{+}\right)$were calculated, presented, and discussed. Also, the variation of the plasma electronegativity was calculated and discussed and plasma sheaths were modified accordingly. Because of the demonstrated importance of the $\mathrm{N}_{2}$ and $\mathrm{O}_{2}$ presence, the model was also applied in $\mathrm{N}_{2} / \mathrm{O}_{2}$ mixtures plasmas with two feeding percentages, namely, $2: 1\left[\mathrm{~N}_{2}\right]:\left[\mathrm{O}_{2}\right]$ and $4: 1\left[\mathrm{~N}_{2}\right]:\left[\mathrm{O}_{2}\right]$ (airlike). Results important for various applications are presented and commented.

Characterization of $\mathrm{N}_{2} / \mathrm{O}_{2}$ mixtures discharges including air was made. We found that for large ranges of pressure and absorbed power, discharges in $\mathrm{N}_{2} \mathrm{O}$ have properties rather close to those of $\mathrm{N}_{2} / \mathrm{O}_{2}$ mixtures.

A sensitivity study for the PR results was effectuated showing that for the parameters used, covering a large domain, the obtained results are satisfactory and vary smoothly in agreement with existing theoretical and experimental data.

It becomes evident from the present study that more $\mathrm{N}_{2} \mathrm{O}$ and air discharge experiments are needed to refine the characterization of plasmas in various domains of applications and to further validate our GM results in a larger domain of parameters.

\section{Acknowledgment}

The authors are indebted to the unknown referee for his valuable recommendations.

\section{References}

[1] M. A. Lieberman and A. J. Lichtenberg, Principles of Plasma Discharges and Materials Processing, John Wiley \& Sons, Hoboken, NJ, USA, 2nd edition, 2005.

[2] Ch. Berenguer and K. Katsonis, "Plasma reactors and plasma thrusters modeling by Ar complete global models," International Journal of Aerospace Engineering, vol. 2012, Article ID 740869, 18 pages, 2012.

[3] A. T. Hjartarson, E. G. Thorsteinsson, and J. T. Gudmundsson, "Low pressure hydrogen discharges diluted with argon explored using a global model," Plasma Sources Science and Technology, vol. 19, no. 6, Article ID 065008, 2010.
[4] K. Katsonis and Ch. Berenguer, "A complete global model for He Torch experiments and atmospheric entry study," in Proceedings of the ESA 5th International Workshop Radiation of High Temperature Gases in Atmospheric Entry, Barcelona, Spain, October 2012.

[5] Ch. Berenguer and K. Katsonis, "Modeling and diagnostics of $\mathrm{H} / \mathrm{He}$ mixture high temperature space plasmas," in Proceedings of the ESA 5th International Workshop Radiation of High Temperature Gases in Atmospheric Entry, Barcelona, Spain, October 2012.

[6] D. Vacher, S. Menecier, M. Dudeck, Ch. Berenguer, and K. Katsonis, "Optical diagnostics of an helium plasma formed with an inductively coupled plasma torch," in Proceedings of the ESA 5th International Workshop Radiation of High Temperature Gases in Atmospheric Entry, Barcelona, Spain, October 2012.

[7] D. A. Shutov, S.-Y. Kang, K.-H. Baek, K.-S. Suh, and K.-H. Kwon, "Inductively-coupled nitrous-oxide plasma etching of parylene-C films," Journal of the Korean Physical Society, vol. 55, no. 5, pp. 1836-1840, 2009.

[8] F. B. Yousif and A. B. Mondragon, "An investigation into electron temperature, number density, and optical emission spectroscopy of the DC hollow-cathode plasma discharge in $\mathrm{N}_{2} \mathrm{O}$," IEEE Transactions on Plasma Science, vol. 40, no. 6, pp. 1715-1723, 2012.

[9] C. O. Laux, T. G. Spence, C. H. Kruger, and R. N. Zare, "Optical diagnostics of atmospheric pressure air plasmas," Plasma Sources Science and Technology, vol. 12, no. 2, pp. 125138, 2003.

[10] T. de los Arcos, C. Domingo, V. J. Herrero, M. M. Sanz, A. Schulz, and I. Tanarro, "Diagnostics and kinetic modeling of a hollow cathode $\mathrm{N}_{2} \mathrm{O}$ discharge," Journal of Physical Chemistry A, vol. 102, no. 31, pp. 6282-6291, 1998.

[11] B. F. Gordiets, C. M. Ferreira, V. L. Guerra et al., "Kinetic model of a low-pressure $\mathrm{N}_{2}-\mathrm{O}_{2}$ flowing glow discharge," IEEE Transactions on Plasma Science, vol. 23, no. 4, pp. 750-768, 1995.

[12] E. G. Thorsteinsson and J. T. Gudmundsson, "A global (volume averaged) model of a nitrogen discharge: I. Steady state," Plasma Sources Science and Technology, vol. 18, no. 4, Article ID 045001, 2009.

[13] K. Katsonis, S. Pellerin, and K. Dzierzega, "Collisional-radiative type modelling and application in plasma diagnostics," High Temperature Material Processes, vol. 7, no. 4, pp. 559-568, 2003.

[14] J. T. Gudmundsson, I. G. Kouznetsov, K. K. Patel, and M. A. Lieberman, "Electronegativity of low-pressure high-density oxygen discharges," Journal of Physics D, vol. 34, no. 7, pp. 11001109, 2001.

[15] J. T. Gudmundsson and E. G. Thorsteinsson, "Oxygen discharges diluted with argon: dissociation processes," Plasma Sources Science and Technology, vol. 16, no. 2, pp. 399-412, 2007.

[16] Ch. Berenguer and K. Katsonis, "Global modeling of $\mathrm{N}_{2}$ plasmas," Tech. Rep. DEDALOS 2012-08, 2012.

[17] N. Kang, F. Gaboriau, S.-G. Oh, and A. Ricard, "Modeling and experimental study of molecular nitrogen dissociation in an Ar- $\mathrm{N}_{2}$ ICP discharge," Plasma Sources Science and Technology, vol. 20, no. 4, Article ID 045015, 2011.

[18] Ch. Berenguer and K. Katsonis, "Global modeling of $\mathrm{O}_{2}$ plasmas," Tech. Rep. DEDALOS 2012-12, 2012.

[19] C. S. Corr, S. Gomez, and W. G. Graham, "Discharge kinetics of inductively coupled oxygen plasmas: experiment and model," Plasma Sources Science and Technology, vol. 21, no. 5, Article ID 055024, 2012. 
[20] E. G. Thorsteinsson and J. T. Gudmundsson, "A global (volume averaged) model of a chlorine discharge," Plasma Sources Science and Technology, vol. 19, no. 1, Article ID 015001, 2010.

[21] C. Lee and M. A. Lieberman, "Global model of Ar, $\mathrm{O}_{2}, \mathrm{Cl}_{2}$, and $\mathrm{Ar} / \mathrm{O}_{2}$ high-density plasma discharges," Journal of Vacuum Science and Technology A, vol. 13, no. 2, pp. 368-380, 1995.

[22] A. V. Phelps, "Cross sections and swarm coefficients for nitrogen ions and neutrals in $\mathrm{N}_{2}$ and argon ions and neutrals in Ar for energies from $0.1 \mathrm{eV}$ to $10 \mathrm{keV}$,' Journal of Physical and Chemical Reference Data, vol. 20, no. 3, p. 557, 1991.

[23] L. Date, K. Radouane, B. Despax, M. Yousfi, H. Caquineau, and A. Hennad, "Analysis of the $\mathrm{N}_{2} \mathrm{O}$ dissociation in a RF discharge reactor," Journal of Physics D, vol. 32, no. 13, pp. 1478-1488, 1999.

[24] P. C. Cosby, "Electron-impact dissociation of nitrogen," The Journal of Chemical Physics, vol. 98, no. 12, pp. 9544-9559, 1993.

[25] Y.-K. Kim, W. Hwang, N. M. Weinberger, M. A. Ali, and M. E. Rudd, "Electron-impact ionization cross sections of atmospheric molecules," Journal of Chemical Physics, vol. 106, no. 3, pp. 1026-1033, 1997.

[26] S. Dupljanin, J. de Urquijo, O. Šašić et al., "Transport coefficients and cross sections for electrons in $\mathrm{N}_{2} \mathrm{O}$ and $\mathrm{N}_{2} \mathrm{O} / \mathrm{N}_{2}$ mixtures," Plasma Sources Science and Technology, vol. 19, no. 2, Article ID 025005, 2010.

[27] D. Rapp and P. Englander-Golden, "Total cross sections for lonization and attachment in gases by electron impact. I. Positive ionization," The Journal of Chemical Physics, vol. 43, no. 5, pp. 1464-1479, 1965.

[28] I. Iga, M. V. V. S. Rao, and S. K. Srivastava, "Absolute electron impact ionization cross sections for $\mathrm{N}_{2} \mathrm{O}$ and $\mathrm{NO}$ from threshold up to 1000 eV,' Journal of Geophysical Research E, vol. 101, no. 4, pp. 9261-9266, 1996.

[29] L. G. Christophorou and J. K. Olthoff, "Electron interactions with excited atoms and molecules," Advances in Atomic, Molecular and Optical Physics, vol. 44, pp. 155-293, 2001.

[30] L. Campbell, M. J. Brunger, A. M. Nolan et al., "Integral cross sections for electron impact excitation of electronic states of $\mathrm{N}_{2}$," Journal of Physics B, vol. 34, no. 7, pp. 1185-1199, 2001.

[31] A. V. Phelps and L. C. Pitchford, "Anisotropic scattering of electrons by $\mathrm{N}_{2}$ and its effect on electron transport," Physical Review A, vol. 31, no. 5, pp. 2932-2949, 1985.

[32] Y.-K. Kim and J.-P. Desclaux, "Ionization of carbon, nitrogen, and oxygen by electron impact," Physical Review A, vol. 66, no. 1, Article ID 012708, 12 pages, 2002.

[33] Y. Itikawa, "Cross sections for electron collisions with nitrogen molecules," Journal of Physical and Chemical Reference Data, vol. 35, no. 1, pp. 31-53, 2006.

[34] M. Allan, "Excitation of vibrational levels up to $\nu=17$ in $\mathrm{N}_{2}$ by electron impact in the $0-5 \mathrm{eV}$ region," Journal of Physics $B$, vol. 18, no. 22, pp. 4511-4517, 1985.

[35] J. B. Hasted, Physics of Atomic Collisions, Butterworth, London, UK, 2nd edition, 1972.

[36] R. H. Neynaber, L. L. Marino, E. W. Rothe, and S. M. Trujillo, "Low-energy electron scattering from atomic nitrogen," Physical Review, vol. 129, no. 5, pp. 2069-2071, 1963.

[37] C. Tian and C. R. Vidal, "Electron impact ionization of $\mathrm{N}_{2}$ and $\mathrm{O}_{2}$ : contributions from different dissociation channels of multiply ionized molecules," Journal of Physics B, vol. 31, no. 24, pp. 5369-5381, 1998.

[38] T. A. Cleland and D. W. Hess, "Diagnostics and modeling of $\mathrm{N}_{2} \mathrm{O}$ RF glow discharges," Journal of the Electrochemical Society, vol. 136, no. 10, pp. 3103-3111, 1989.
[39] P. Gamallo, M. González, and R. Sayós, "Ab initio derived analytical fits of the two lowest triplet potential energy surfaces and theoretical rate constants for the $\mathrm{N}\left({ }^{4} \mathrm{~S}\right)+\mathrm{NO}\left(\mathrm{X}^{2} \mathrm{II}\right)$ system," Journal of Chemical Physics, vol. 119, no. 5, pp. 2545-2556, 2003.

[40] I. A. Kossyi, A. Y. Kostinsky, A. A. Matveyev, and V. P. Silakov, "Kinetic scheme of the non-equilibrium discharge in nitrogenoxygen mixtures," Plasma Sources Science and Technology, vol. 1, no. 3, pp. 207-220, 1992.

[41] D. D. Monahan and M. M. Turner, "Global models of electronegative discharges: critical evaluation and practical recommendations," Plasma Sources Science and Technology, vol. 17, no. 4, Article ID 045003, 2008.

[42] L. G. Christophorou and J. K. Olthoff, Fundamental Electron Interactions With Plasma Processing Gases, Kluwer Academic/Plenum Publishers, New York, NY, USA, 2004.

[43] K. Katsonis, Etude statistique et cinétique des plasmas d'Argon en dehors de l'equilibre thermodynamique local [Doctorat d'Etat], Université Paris-sud, Fontenay-aux-Roses, France, 1976, EURCEA-FC-820.

[44] E. L. Chaney and L. G. Christophorou, "Electron attachment to $\mathrm{N}_{2} \mathrm{O}$," The Journal of Chemical Physics, vol. 51, no. 3, pp. 883-892, 1969.

[45] G. Younis, B. Despax, M. Yousfi, and H. Caquineau, "Power dissipation analysis in $\mathrm{N}_{2} \mathrm{O}$ RF discharges using Monte Carlo modelling," Journal of Physics D, vol. 40, no. 7, pp. 2045-2054, 2007.

[46] R. Atkinson, D. L. Baulch, R. A. Cox et al., "Evaluated kinetic and photochemical data for atmospheric chemistry: supplement VIII, halogen species a IUPAC subcommittee on gas kinetic data evaluation for atmospheric chemistry," Journal of Physical and Chemical Reference Data, vol. 21, no. 6, p. 1125, 1992.

[47] J. T. Gudmundsson and M. A. Lieberman, "Recombination rate coefficients in oxygen discharges," Tech. Rep. RH-16-2004, Science Institute, University of Iceland, 2004.

[48] P. B. Armentrout, S. M. Tarr, A. Dori, and R. S. Freund, "Electron impact ionization cross section of metastable $\mathrm{N}_{2}\left(A \sum_{u}^{+}\right)$," The Journal of Chemical Physics, vol. 75, no. 6, pp. 2786-2794, 1981.

[49] H. C. Straub, P. Renault, B. G. Lindsay, K. A. Smith, and R. F. Stebbings, "Absolute partial cross sections for electron-impact ionization of $\mathrm{H}_{2}, \mathrm{~N}_{2}$, and $\mathrm{O}_{2}$ from threshold to $1000 \mathrm{eV}$," Physical Review A, vol. 54, no. 3, pp. 2146-2153, 1996.

[50] M. J. Brunger, S. J. Buckman, and M. T. Elford, Photon and Electron Interactions with Atoms, Molecules and Ions, vol. 17 of Numerical Data and Functional Relationships in Science and Technology, Landolt-Börnstein, Spinger, New York, NY, USA, 2003, Edited by: Y. Itikawa.

[51] T. F. O'Malley, "Calculation of dissociative attachment in hot $\mathrm{O}_{2}$," Physical Review, vol. 155, no. 1, pp. 59-63, 1967.

[52] W. R. Henderson, W. L. Fite, and R. T. Brackmann, "Dissociative attachment of electrons to hot oxygen," Physical Review, vol. 183, no. 1, pp. 157-166, 1969.

[53] J. T. Gudmundsson, A. M. Marakhtanov, K. K. Patel, V. P. Gopinath, and M. A. Lieberman, "On the plasma parameters of a planar inductive oxygen discharge," Journal of Physics D, vol. 33, no. 11, pp. 1323-1331, 2000.

[54] D. A. Hayton and B. Peart, "Merged beam measurements of the mutual neutralization of $\mathrm{O}^{+} / \mathrm{O}^{-}$and $\mathrm{N}^{+} / \mathrm{O}^{-}$ions," Journal of Physics B, vol. 26, p. 2879, 1993.

[55] R. Padgett and B. Peart, "Merged-beam measurements of the mutual neutralization of $\mathrm{O}_{2}^{+} / \mathrm{O}^{-}$and $\mathrm{NO}^{+} / \mathrm{O}^{-}$ions," Journal of Physics B, vol. 31, no. 24, pp. L995-L1000, 1998. 
[56] A. G. Engelhardt, A. V. Phelps, and C. G. Risk, "Determination of momentum transfer and inelastic collision cross sections for electrons in nitrogen using transport coefficients," Physical Review, vol. 135, no. 6, pp. A1566-A1574, 1964.

[57] S. Kim, M. A. Lieberman, A. J. Lichtenberg, and J. T. Gudmundsson, "Improved volume-averaged model for steady and pulsed-power electronegative discharges," Journal of Vacuum Science and Technology A, vol. 24, no. 6, pp. 2025-2040, 2006.

[58] J. T. Gudmundsson, "Notes on the electron excitation rate coefficients for Argon and Oxygen discharge," Tech. Rep. RH21-2002, Reykjavik, Iceland, 2002.

[59] Ch. Berenguer, K. Katsonis, and C. Boisse-Laporte, "Study of PR plasmas obtained by gas mixtures feeding," Tech. Rep. DEDALOS 2013-02, 2013.

[60] Ch. Berenguer, K. Katsonis, and D. Pavarin, "The resonant lines VUV transitions in rare gas plasma thrusters," in Proceedings of the 32nd International Electric Propulsion Conference (IEPC '11), Wiesbaden, Germany, September 2011.

[61] C. P. Malone, P. V. Johnson, J. W. McConkey, J. M. Ajello, and I. Kanik, "Dissociative excitation of $\mathrm{N}_{2} \mathrm{O}$ by electron impact," Journal of Physics B, vol. 41, no. 9, Article ID 095201, 2008.

[62] K. Katsonis, Ch. Berenguer, D. Pavarin et al., "Optical diagnostics of a low temperature argon thruster," in Proceedings of the 32nd International Electric Propulsion Conference (IEPC '11), Wiesbaden, Germany, September 2011.

[63] Ch. Berenguer, K. Katsonis, D. Vacher et al., "Spectroscopic study of a neon fed ICP torch," in Proceedings of the 10th European Conference on Atoms Molecules and Photons (ECAMP X '10), Salamanca, Spain, July 2010.

[64] D. Pavarin, F. Ferri, M. Manente et al., "Thruster development set-up for the helicon plasma hydrazine combined micro research project," in Proceedings of the 32nd International Electric Propulsion Conference (IEPC '11), Wiesbaden, Germany, September 2011.

[65] C. Charles and R. W. Boswell, "Measurement and modelling of a radiofrequency micro-thruster," Plasma Sources Science and Technology, vol. 21, no. 2, Article ID 022002, 2012. 

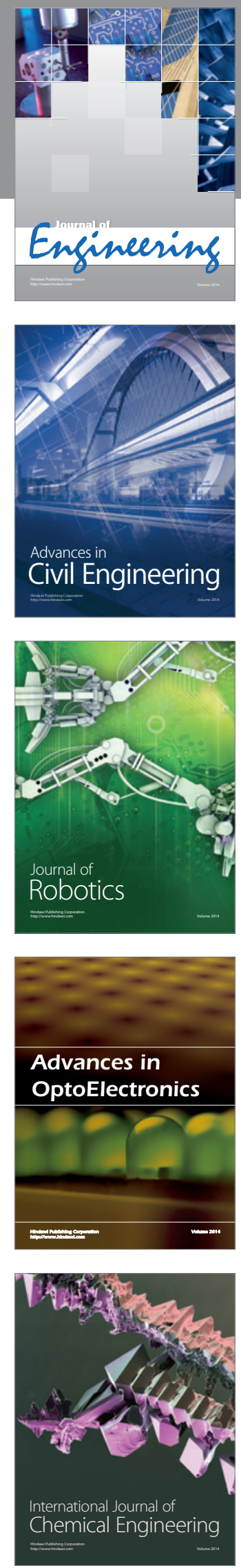

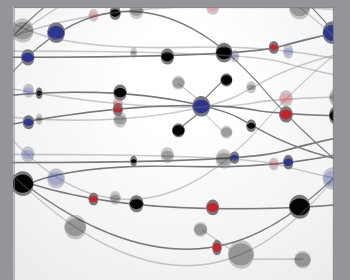

The Scientific World Journal
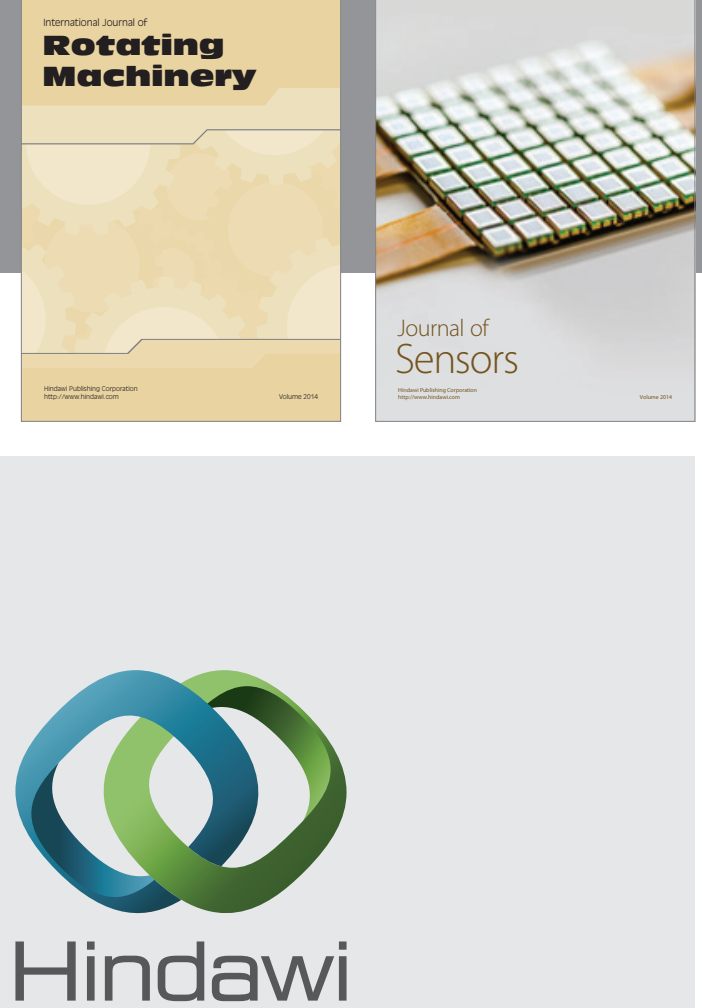

Submit your manuscripts at http://www.hindawi.com
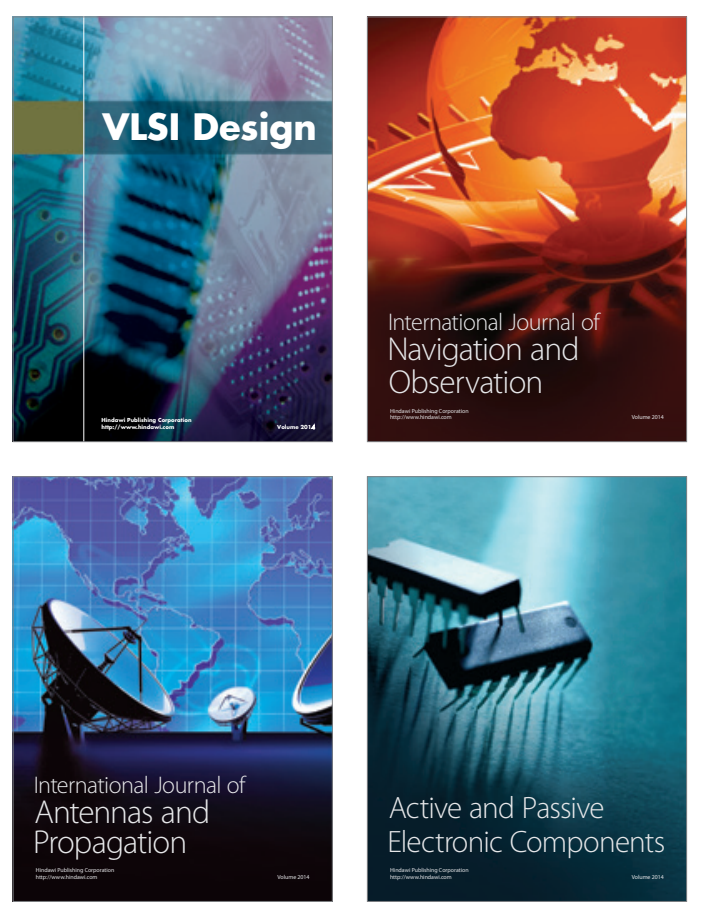
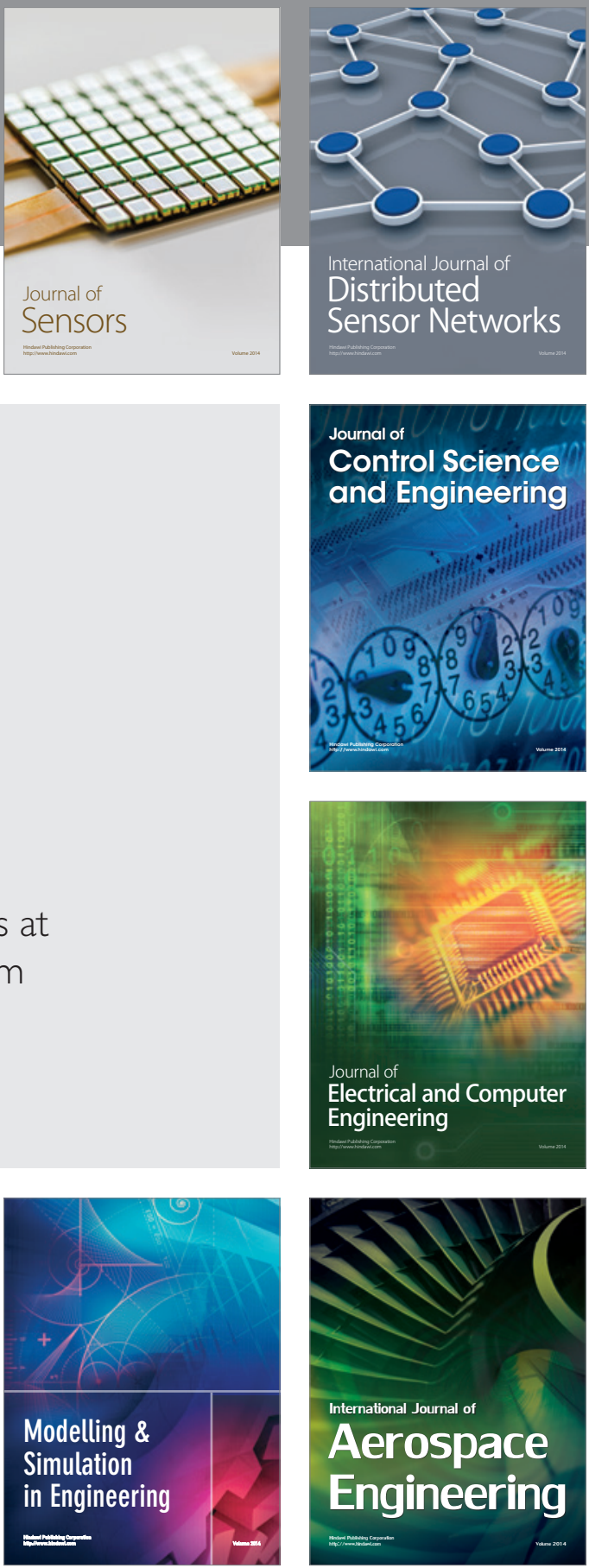

Journal of

Control Science

and Engineering
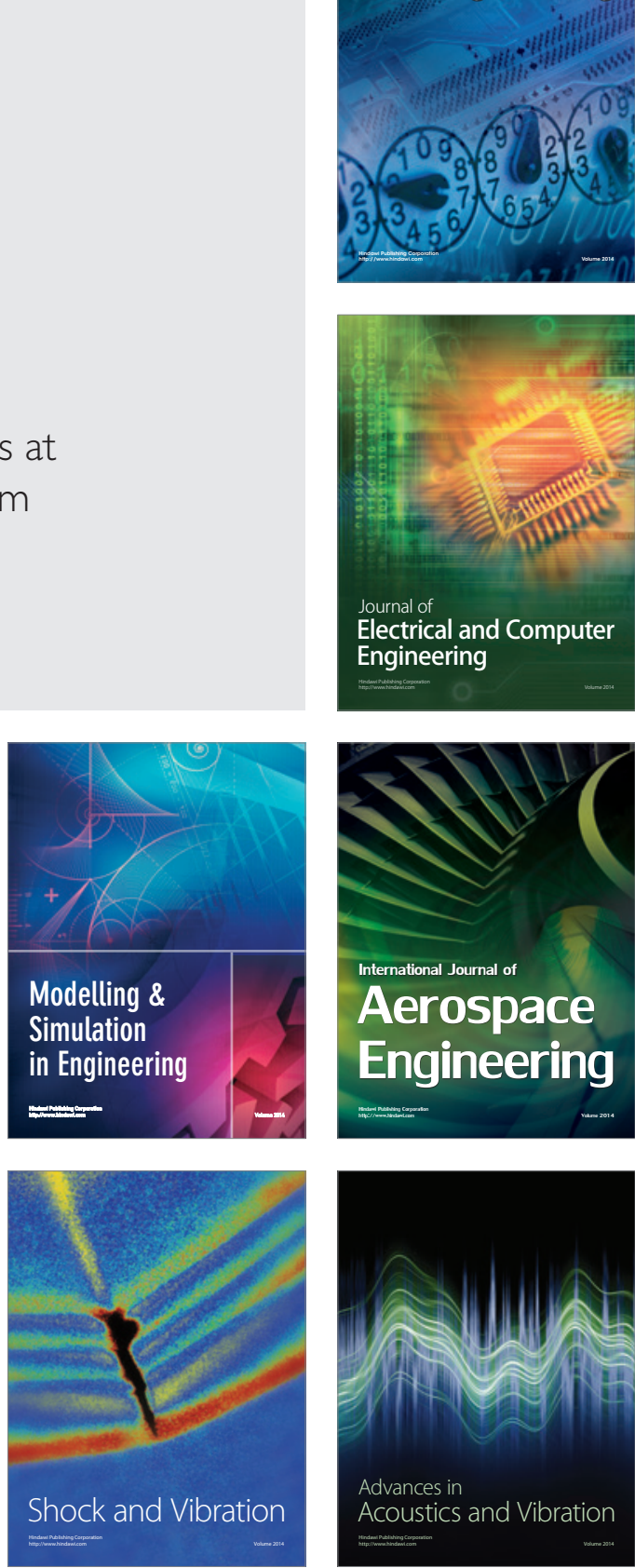